\title{
ON THE MECHANICAL AGEING
}

\section{OF LUBRICATING GREASES}

\section{YUXIN ZHOU}
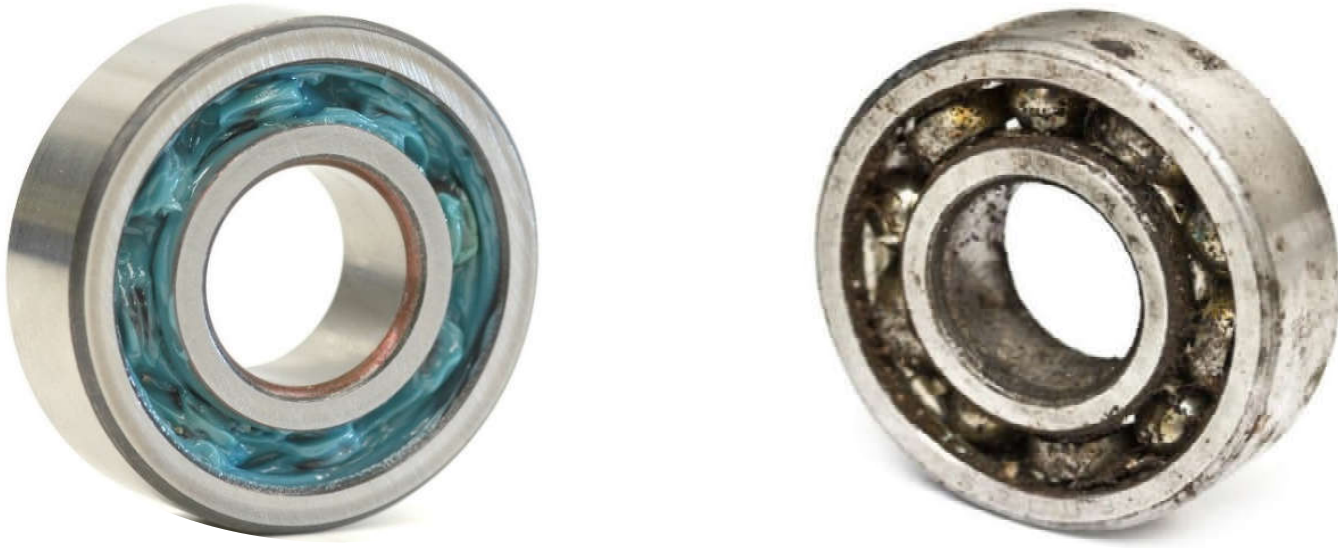


\section{ON THE MECHANICAL AGEING OF LUBRICATING GREASES}

YUXIN ZHOU

FACULTY OF ENGINEERING TECHNOLOGY

UNIVERSITY OF TWENTE 



\title{
ON THE MECHANICAL AGEING OF LUBRICATING GREASES
}

\author{
DISSERTATION
}

\author{
to obtain \\ the degree of doctor at the University of Twente, \\ on the authority of the rector magnificus, \\ prof.dr. T.T.M. Palstra, \\ on account of the decision of the graduation committee, \\ to be publicly defended \\ on Wednesday the $12^{\text {th }}$ September 2018 at 16:45 p.m.
}

by

\author{
Yuxin Zhou \\ born on the $23^{\text {rd }}$ October 1990 \\ in SongYuan, China
}


This dissertation has been approved by:

Supervisor:

Prof.dr.ir. P.M. Lugt

University of Twente

Co-supervisor:

Dr.ir. R. Bosman

University of Twente

This project was supported by SKF Research and Technology Development in Nieuwegein, The Netherlands. The support is gratefully acknowledged. 


\section{Graduation Committee}

Chairman:

Prof.dr. G.P.M.R. Dewulf

University of Twente

Supervisor:

Prof.dr.ir. P.M. Lugt

University of Twente

Co-supervisor:

Dr.ir. R. Bosman

University of Twente

Committee Members:

Prof.dr.-Ing. E. Kuhn

Hamburg University of Applied Sciences

Prof.dr. F.G. Mugele

University of Twente

Prof.dr. J.H.O. Seabra

University of Porto

Prof.dr.ir. C.H. Venner

University of Twente 
ISBN: 978-90-365-4614-0

DOI: $10.3990 / 1.978903654614$

(C) 2018 Yuxin Zhou, Enschede, The Netherlands. All rights reserved. No parts of this thesis may be reproduced, stored in a retrieval system or transmitted in any form or by any means without permission of the author. Alle rechten voorbehouden. Niets uit deze uitgave mag worden vermenigvuldigd, in enige vorm of op enige wijze, zonder voorafgaande schriftelijke toestemming van de auteur.

Cover design: Yuxin Zhou

The cover is divided by golden ratio.

The top is the mysterious cosmos and the background colour is ultra violet, the Pantone color of the year 2018 and the favourite colour of my girlfriend Bingqian.

The bottom shows the topic of this thesis: the study between fresh grease and aged grease. This research was performed in University of Twente and was sponsored by SKF. 


\section{Summary}

This thesis focuses on the mechanical degradation of lubricating greases, including the change of thickener micro-structure and rheological properties as well as the influence of the mechanical degradation of grease on the bearing lubricant film thickness.

Grease is a multi-phase material, where the base oil is trapped within the thickener network by a combination of Van der Waals and capillary forces. Inside a bearing, grease will act as a reservoir releasing lubricant into the contact area. During bearing operation, mechanical degradation of the grease is observed, reflected by the change of grease consistency, grease bleed, apparent viscosity, etc. This will lead to a loss of lubricant, severe starvation and ultimately the failure of the bearing.

The thesis starts with the ageing mechanism for lubricating greases with a fibre-like thickener structure (including lithium-based, lithium-complex-based and polyurea-based greases). Under shear, grease softening is found. The change of the rheological properties of the grease shows a two-phase ageing behaviour. The degradation is initially fast but subsequently slows down. This degradation is closely related to the change of the thickener micro-structure. In addition to shear, high temperatures will accelerate the ageing process following an Arrhenius behaviour. Based on these observations, an Ageing Master Curve is constructed using an energy concept. This model is later validated using a grease worker and applied to the grease ageing process inside a rolling bearing.

As a comparison to the fibre-like thickener structure greases, the ageing of calcium sulphonate complex grease is investigated. Different from the greases mentioned above, calcium sulphonate complex grease has a particle-like thickener structure that is difficult to break under shear, hence no shear softening is observed. As a result, the Ageing Master Curve is not applicable for this type of grease.

The ultimate goal of grease lubrication is to provide the bearing contacts with a separating film. This is why the influence of grease mechanical ageing on the film thickness is studied as well. The grease film thickness deviates from the calculated elastohydrodynamic film thickness (assuming lubrication by the base oil under fully flooded conditions). The grease film thickness appears to be influenced by churning, channelling, change of grease bleed 
and rheological properties caused by shear and/or temperature. In addition, the thickener fragments generated by mechanical degradation also contribute to the film thickness.

The results from the work described in this thesis give an important contribution to the development of rolling bearing grease life models. These models can then be used for the calculation of maintenance intervals.

This thesis is divided into two parts. The first part (Part I) is a short description of the work. The second part (Part II) consists of the papers in which the details are described. 


\section{Samenvatting}

Dit proefschrift beschrijft de mechanische degradatie van smeervetten, inclusief de verandering van de micro-structuur, de reologische eigenschappen en de invloed van deze degradatie op de smeerfilmdikte in wentellagers.

Smeervet is een meerfase materiaal waarbij olie opgesloten zit in een netwerk. Dit netwerk wordt gevormd door een dikmaker, als gevolg van Van der Waals en capillaire krachten. In een wentellager vormt het smeervet een reservoir waaruit olie wordt losgelaten om de contacten te smeren. Wanneer het lager draait, zal het smeervet degraderen hetgeen zich uit in een verandering van onder andere consistentie, bloeding en viscositeit. Dit leidt tot een verlies van smeermiddel, schrale smering en uiteindelijk tot het falen van het lager.

Dit proefschrift start met het verouderingsmechanisme voor smeervetten met een vezelachtige verdikkerstructuur (inclusief smeervetten gebaseerd op lithium, lithiumcomplex en polyurea). Als deze vetten worden verouderd door middel van afschuiving, worden ze zachter. De verandering van de reologische eigenschappen wordt gekarakteriseerd door twee fasen. De veroudering gebeurt in eerste instantie snel, maar wordt later langzamer. De degradatie is gerelateerd aan de verandering van de structuur van de dikmaker. Het verouderingsproces wordt verder versneld door een verhoging in temperatuur hetgeen kan worden beschreven met een Arrhenius-vergelijking. Uit de experimenten, waarbij het smeervet veroudert bij verschillende afschuif-gradiënten en temperaturen, is uiteindelijk een "Master Curve" afgeleid, waarbij gebruik is gemaakt van een energieconcept. Dit model is verder gevalideerd met een "grease worker" en toegepast op het verouderingsproces van smeervet in een kogellager.

Naast de vetten met een vezelachtige dikmakerstructuur is de veroudering van calcium sulfonaat complex smeervet onderzocht. Dit type smeervet heeft een microstructuur gebaseerd op deeltjes die veel moeilijker breken onder afschuiving dan de op vezels gebaseerde smeervetten. Daardoor laten de experimenten met dit smeervet geen verzachting zien na afschuiving en is de verouderings-"Master Curve" dus niet toepasbaar op dit type smeervet. 
Het uiteindelijke doel van smering is om de wentellager-contacten van een dunne smeerfilm te voorzien die de rollende elementen scheidt van de ringen. Daarom is tenslotte de invloed van mechanische veroudering op de filmopbouw in een kogellager onderzocht. De gevonden smeerfilmdiktes wijken duidelijk af van de berekende waardes waarbij, zoals gebruikelijk, wordt aangenomen dat er voldoende smeermiddel aanwezig is en dat voor de viscositeit die van de basisolie kan worden genomen. De smeerfilmdikte blijkt afhankelijk te zijn van "channeling" (de eigenschap dat het vet door de bewegende ballen in een kogellager wordt weggedrukt en daarna niet terugstroomt) en van de verandering van olieafscheiding en vloeispanning door afschuiving en/of temperatuur. Daarnaast is er een bijdrage in de smeerfilmdikte doordat gefragmenteerde dikmakerdeeltjes het contact in worden gesleurd. Hiermee levert dit proefschrift een belangrijke bijdrage aan de ontwikkeling van modellen die de levensduur van wentellagers kunnen voorspellen. Deze modellen kunnen vervolgens gebruikt worden bij de berekening van onderhoudsintervallen.

Dit proefschrift bestaat uit twee delen. Het eerste deel is een korte beschrijving van het werk en het tweede deel bestaat uit de artikelen waarin de details zijn beschreven. 


\section{Acknowledgement}

I would like to express my enormous gratitude to my supervisors Professor Piet Lugt and Doctor Rob Bosman for their valuable guidance, motivation and patience throughout my entire $\mathrm{PhD}$ project. Their support and encouragement helped me acquire this doctoral degree and sets a sound foundation for my future career.

Special thanks to Erik de Vries, Walter Lette, Dries Swaaij for their technical support in the laboratory. I am grateful to Professor Dik Schipper and Professor Emile van der Heide for their constructive advice during my project. I am also very thankful to Belinda SchaapBruinink and Debbie Zimmerman for their kind help. The valuable technical and financial support from SKF Research and Technology Development, Nieuwegein, the Netherlands, is greatly appreciated.

I extend my appreciation to my committee members: Professor Erik Kuhn, Professor Jorge Seabra, Professor Kees Venner, Professor Frieder Mugele and Professor Geert Dewulf, for their effort and time.

I would also like to extend my thanks to my colleagues from whom I learned a lot: Gangqiang Zhang, Wenwen Zhao, Sheng Zhang, Yibo Su, Wenqi Dang, Xiangqiong Zeng, Jincan Yan, Can Wang, Hui Cen, Liangyong Chu, Qierui Zhang, Febin Cyriac, Michel Klaassen, Aydar Akchurin, Marina Morales-Hurtado, Shaojie Liu, Melkamu Mekicha, Thomas Zijlstra, Xavier Borras, Niya Eval, Nadia Vleugels, Dmitry Sergachev, Muhammad Khafidh, Mohammad Bazrafshan, Shivam Alakhramsing, Nurul Hilwa Binti Mohd Zini, Nurhidayah Binti Ismail... Many thanks to all of you!

Furthermore, I thank my friends with whom I enjoyed a lovely four years' living in the Netherlands: Kui Zhang, Xibo Xiong, Zhi Hong, Wenbo Wang, Zhengchao Guo, Jia Liang, Liufei Yang, Lian Tao, Yao Fu, Yitong Zhou, Zhiliang, Qiao, Rujiao Du, Yuetian Zou, Xingwu Sun, Jun Wang, Youwen Fan, Mengdi Yang, Qirong Yao, Lin Xia, Yaxing Li,

Peihua Liu, Kenan Niu, Jiaobiao Zhang, Peter Bogaert, Daniel Linschoten, Ilaria Geremia... Thanks to your company, I have beautiful memories of my time here. 
Last but not least, I would like to thank my mom and dad for their unconditional support throughout my entire life. Deep appreciation to meine liebe Bingqian Sun, who helped me get through to the end of my $\mathrm{PhD}$ study.

Many thanks to all of you!

Yuxin Zhou

2018

Enschede, the Netherlands 


\section{Contents}

\section{Part I}

Nomenclature

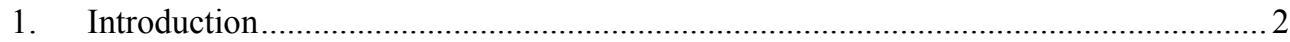

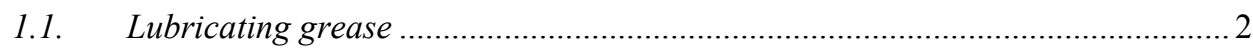

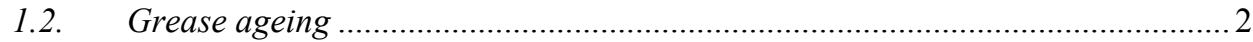

1.3. Film thickness of a grease-lubricated bearing ............................................. 4

2. Ageing Master Curve of greases with a fibre-like thickener structure......................... 5

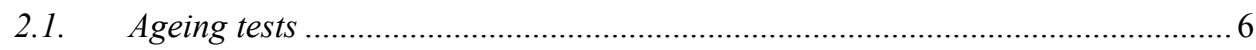

2.2. Sample evaluation ...................................................................................... 7

2.3. Grease Ageing Master Curve .......................................................................... 9

2.4. Ageing Master Curve validation and application .......................................... 12

3. Ageing of grease with a particle-like thickener structure .......................................... 14

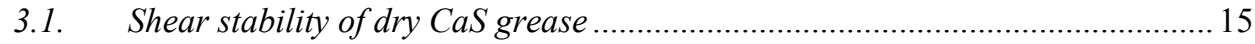

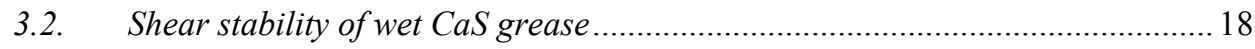

4. Grease film thickness measurement and the impact of ageing................................ 22

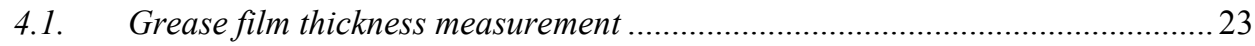

4.2. Film thickness profile for greases with a fibre-like structure........................... 24

4.3. Film thickness profile for greases with a particle structure .............................2 29

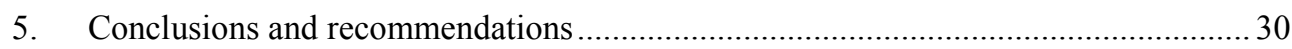

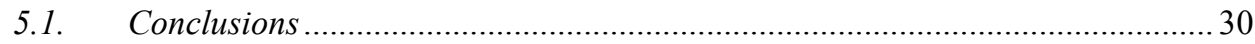

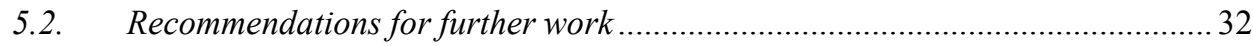

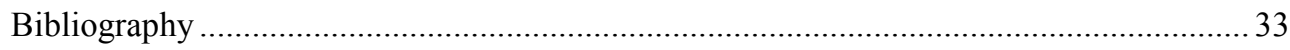




\section{Part II}

Paper A. Zhou Y, Bosman R, Lugt PM. A Model for shear degradation of lithium soap grease at ambient temperature. Tribology Transactions 2016 12/21:1-10.

Paper B. Zhou Y, Bosman R, Lugt PM. A master curve for the shear degradation of lubricating greases with a fibrous structure. Accepted for publication. Tribology Transactions 2018.

Paper C. Zhou Y, Bosman R, Lugt PM. An experimental study on film thickness in a rolling bearing for fresh and aged lubricating greases. Submitted to Tribology Transaction 2018.

Paper D. Zhou Y, Bosman R, Lugt PM. On the shear stability of dry and water contaminated calcium sulphate complex lubricating greases. Submitted to Tribology International 2018. 

Part I 


\section{Nomenclature}

\begin{tabular}{|c|l|}
\hline$C_{e}$ & Correcting factor for the bearing friction energy (-) \\
\hline$C_{T}$ & Arrhenius correction factor $(-)$ \\
\hline$E$ & Input work density during the Couette ageing procedure $\left(\mathrm{J} / \mathrm{mm}^{3}\right)$ \\
\hline$E_{b}$ & Bearing friction energy density $\left(\mathrm{J} / \mathrm{mm}^{3}\right)$ \\
\hline$E_{m}$ & Corrected energy density during the Couette ageing procedure $\left(\mathrm{J} / \mathrm{mm}^{3}\right)$ \\
\hline$h$ & Grease film thickness at the stable stage $(\mathrm{m})$ \\
\hline$h_{\text {cal }}$ & Bled oil film thickness for the calibration $(\mathrm{m})$ \\
\hline$h_{\text {grease }}$ & Measured grease film thickness $(\mathrm{m})$ \\
\hline$h_{\text {oil }}$ & Calculated oil film thickness $(\mathrm{m})$ \\
\hline$K$ & Fitting constant (-) \\
\hline$M$ & Ageing drag torque $(\mathrm{Nm})$ \\
\hline$n$ & Fitting constant $(-)$ \\
\hline$N$ & Rotational speed $(\mathrm{rpm})$ \\
\hline$t$ & Grease ageing time $(\mathrm{s})$ \\
\hline$T$ & Applied temperature during ageing $\left({ }^{\circ} \mathrm{C}\right)$ \\
\hline$T_{\text {bearing }}$ & Measured bearing temperature $\left({ }^{\circ} \mathrm{C}\right)$ \\
\hline$T_{0}$ & Reference temperature $\left({ }^{\circ} \mathrm{C}\right)$ \\
\hline$V_{a}$ & Grease volume inside the Couette Ageing Machine $\left(\mathrm{mm}{ }^{3}\right)$ \\
\hline$V_{\text {cap }}$ & Lubcheck output voltage $(\mathrm{V})$ \\
\hline$Y$ & Rheological properties of the grease during ageing $(-)$ \\
\hline$Y_{i}$ & Initial rheological value for fresh grease $(-)$ \\
\hline$Y_{\infty}$ & Second stage rheological value after infinitely long ageing $(-)$ \\
\hline$\alpha$ & Pressure-viscosity coefficient $\left(\mathrm{Pa}^{-1}\right)$ \\
\hline$v_{b}$ & Oil viscosity $(\mathrm{cSt})$ \\
\hline$\eta_{0}$ & Zero shear rate viscosity $(\mathrm{Pa} \cdot \mathrm{s})$ \\
\hline$\tau_{y}$ & Yield stress obtained from the oscillatory strain sweep test $(\mathrm{Pa})$ \\
\hline & \\
\hline & \\
\hline &
\end{tabular}




\section{Introduction}

\subsection{Lubricating grease}

Grease is a multi-phase material consisting of $70-90 \%$ base oil (mineral or synthetic), 3-30\% thickener (e.g. metal soap, polyurea or clay) and additives (1). Similar as a sponge holding water, the thickener consists of a soft, open network, which holds the base oil/additives by a combination of Van der Waals and capillary forces (1). Typical grease micro-structures are formed by a dispersion of particles with various shapes in oil, as presented in Figure 1. In general, the oil will separate from the grease, called 'grease bleed', an effect that is enhanced by pressure, shear and temperature. This bled oil will lubricate the contact, although in many cases also the thickener will contribute to this.

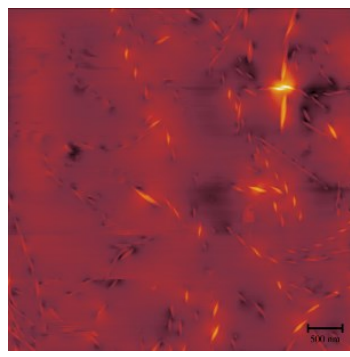

(a)

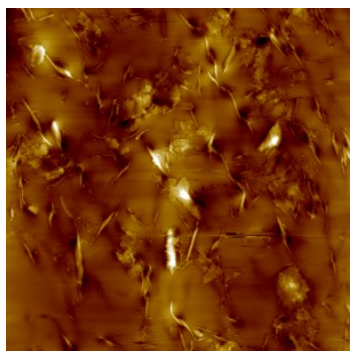

(b)

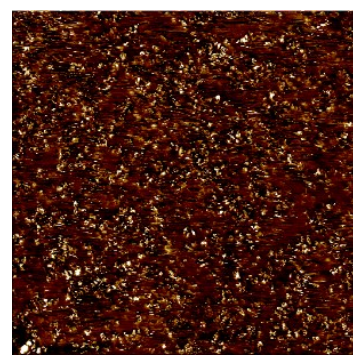

(c)

Figure 1 AFM topography image for (a) Lithium-based grease; (b) Polyurea-based grease; (c) Calcium sulphonate-based grease; image size: $5 \times 5 \mu \mathrm{m}$.

Compared to oil lubrication, the advantages of grease lubrication include ease of use, good sealing capability against contaminants, and low friction (with a suitable filling amount) (2). Grease is a semi-solid material, giving it a high consistency in the absence of shear, which prevents leakage and generates a lubricant reservoir inside the bearing (1).

\subsection{Grease ageing}

Grease undergoes degradation in a rolling bearing due to shear, vibration and possibly high temperatures. This may lead to oxidation or mechanical degradation. The aged grease may no longer provide a sufficiently thick film to separate the contacting surfaces, leading to surface damage and reduction of bearing life $(2,3)$. The actual life span of a bearing is thus often considered to be determined by the performance of the lubricating grease $(1,4)$. 
Failures can be prevented by re-lubrication well before the 'end of the grease life'. This requires a predictive model regarding grease life, which is currently mostly empirical (based on grease life tests). However, extrapolating outside the test domain requires a good understanding of the physics and chemistry of grease ageing, for which physical models would be preferred. The work presented in this thesis contributes to this.

Generally, grease degradation can be classified in two categories $(1,5)$ : mechanical degradation, including the destruction of the thickener network, oil separation (loss of base oil) $(1,6)$ and chemical degradation, caused mainly by oxidation (7). As shown in Figure 2, mechanical degradation is predominant at high-speed and low-temperature conditions, whilst chemical degradation prevails at high-temperature conditions (5). In practice, these two ageing processes often occur simultaneously and interact with each other (1). This thesis focuses on the first aspect: grease mechanical degradation under shear.

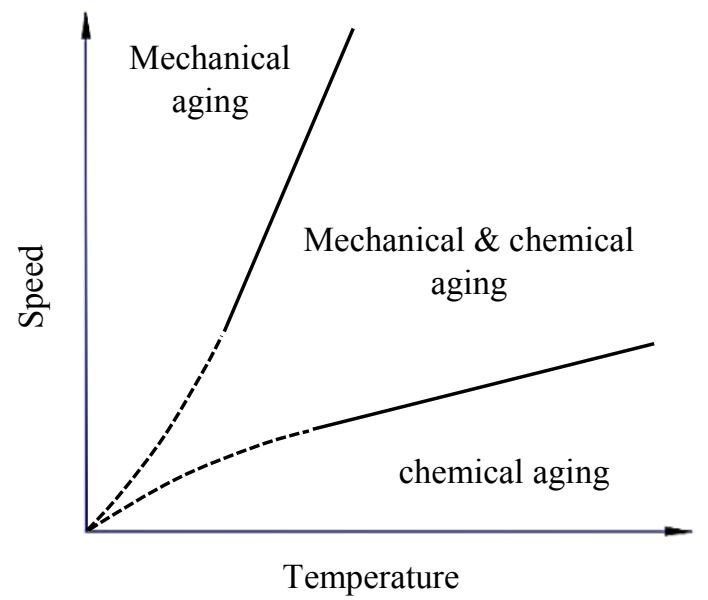

Figure 2 Grease ageing mechanism reproduced from Ito et al.(5)

The literature shows that under shear, greases may soften $(8-12)$, thicken $(10,13-15)$ or may not change in consistency (16). This behaviour can be quantified by measuring the change of the rheological properties, which is closely related to a possible change in the thickener micro-structure $(10,17-20)$. 


\subsection{Film thickness of a grease-lubricated bearing}

Earlier, many numerical and experimental studies have been performed on the development of grease film thickness models based on the classic Elasto-Hydrodynamic Lubrication (EHL) theory $(1,21)$, taking various aspects into account such as a grease 'apparent viscosity' (22-25) non-Newtonian rheological behaviour (25-28), starvation (29, 30), thickener particle geometry and concentration (31-33), replenishment induced by ball spin (34), bearing stop-start motion (35), transient loading (36), cage effects (3), etc.

Many of the experimental grease film thickness studies were performed using a ball-on-disc or disc-on-disc apparatus and limited work has been performed on the grease film thickness in a real bearing. Although single contact measurements are very valuable and widely applied for oil lubrication, it will not properly simulate the conditions in a rolling bearing, such as higher speeds, a large number of over-rollings, centrifugal forces, vibrations, cage scraping, contamination, oil loss, etc. (2,37). Moreover, grease shear degradation within a bearing is considered to play a significant role in the long term quality/thickness of the grease film (38-40), which is difficult to simulate in the single contact tests. To achieve a better understanding of the grease degradation mechanism and its impact on the film thickness, it is important to study this directly in a rolling bearing.

In this thesis a model for mechanical degradation will be described in the form of an 'Ageing Master Curve'. The Ageing Master Curve can be used to predict the change of the grease rheological properties versus the imposed energy. It will be shown that the mechanical degradation rate is also a function of temperature and that not all grease types show a mechanical degradation. Next, the impact of shear degradation on bearing performance will be shown by means of film thickness measurements in a deep groove ball bearing. It will be shown how the film thickness changes over time and how shear degradation will affect this.

This study was done using seven types of commercial greases with various thickener types, covering the most widely used types in rolling bearings, i.e., greases based on lithium, lithium complex, polyurea and calcium sulphonate complex respectively (2). Calcium sulphonate complex-based greases are often recommended in the presence of water (41). 
Therefore, for this grease type the impact of water on shear degradation will be addressed as well. The details of the seven greases are presented in Table 1.

Table 1 Composition of the studied greases

\begin{tabular}{|c|c|c|c|c|c|}
\hline Grease & NLGI & Base oil & $\begin{array}{c}\text { Base oil } \\
\text { viscosity at } \\
40^{\circ} \mathrm{C} / \\
100^{\circ} \mathrm{C}(\mathrm{cSt})\end{array}$ & Thickener & $\begin{array}{c}\text { Thickener } \\
\text { geometry }\end{array}$ \\
\hline $\mathrm{Li} / \mathrm{M}$ & 3 & Mineral oil & $100 / 10$ & Lithium & Fibre \\
\hline $\mathrm{Li} / \mathrm{SS}$ & 2 & Semi-synthetic & $42 / 7$ & Lithium & Fibre \\
\hline $\mathrm{LiX} / \mathrm{PAO}$ & $2-3$ & PAO & $191 / 42$ & $\begin{array}{c}\text { Lithium } \\
\text { complex }\end{array}$ & Fibre \\
\hline $\mathrm{PU} / \mathrm{E}$ & $2-3$ & Ester & $70 / 9$ & Polyuria & $\begin{array}{c}\text { Fibre and } \\
\text { platelet }\end{array}$ \\
\hline $\mathrm{CaS} / \mathrm{M}$ & 2 & Mineral oil & $420 / 26$ & $\begin{array}{c}\text { Calcium } \\
\text { sulphonate } \\
\text { complex }\end{array}$ & Particle \\
\hline $\mathrm{CaS} / \mathrm{MS}$ & $1-2$ & $\begin{array}{c}\text { Synthetic/Mineral } \\
\text { oil }\end{array}$ & $80 / 9$ & $\begin{array}{c}\text { Calcium } \\
\text { sulphonate } \\
\text { complex }\end{array}$ & Particle \\
\hline $\mathrm{CaS} / \mathrm{PAO}$ & $1-2$ & PAO & $320 / 30$ & $\begin{array}{c}\text { Calcium } \\
\text { sulphonate } \\
\text { complex }\end{array}$ & Particle \\
\hline
\end{tabular}

The ageing mechanism for grease with a fibre-like structure (lithium, lithium complex and polyurea greases) and grease with a particle structure (calcium sulphonate complex greases) is clearly different and will therefore be described in separate chapters (chapter 2 and chapter 3). Chapter 3 will also include the shear stability of water contaminated calcium sulphonate grease. In chapter 4, the effect of grease ageing on the film thickness for a deep groove ball bearing will be presented. The thesis will end with conclusions and recommendations for future work in this area. Everything described in this thesis has been published earlier or has been submitted for publication. The papers can be found in the appendix.

\section{Ageing Master Curve of greases with a fibre-like thickener structure}

In practice, greases with a fibre-like thickener structure show softening under shear. This may result in leakage or continuous churning and associated high running temperatures. Both cases will negatively affect bearing lubrication (1). Several empirical models have 
been developed to describe grease degradation or predict the grease life $(10,11,42-44)$. These models are limited to specific test rigs, however, and a universal model which is generally applicable does not exist. Rezasoltani and Khonsari (8, 12) described shear degradation using the entropy concept and Kuhn $(45,46)$ used the frictional energy, both of which are interesting approaches. Paper B shows that mechanical ageing can indeed be described using an energy concept but that the thermal aspect is not well addressed by using entropy.

In this chapter, the ageing of four types of lubricating greases with a fibre-like structure will be studied: $\mathrm{Li} / \mathrm{M}, \mathrm{Li} / \mathrm{SS}, \mathrm{LiX} / \mathrm{PAO}$ and PU/E. Ageing will be described in terms of change in micro-structure and rheological properties.

\subsection{Ageing tests}

Currently, there are many ways to age greases. Aged grease can be obtained from field tests directly $(9,13)$. Alternatively, grease can be degraded in bearings running under laboratory conditions $(14,40,47-50)$ or using standard grease ageing rigs such as a grease worker (ASTM D217 $(8,11,14))$ or a roll stability tester (ASTM D1831 $(10,17,20))$. However, in these tests the grease ageing conditions are not straightforward, which makes it difficult to establish a clear relationship between grease ageing and the imposed 'mechanical load'.

To perform grease ageing under more controlled conditions, a 'Couette Ageing Machine' has been designed and manufactured, which resembles a large cylindrical rheometer (5153), where the grease can be sheared between a stationary housing case and a rotating bob within a thermal bath. The rig is shown in Figure 3 and Figure 4. The advantage of this setup is that a uniform (apparent) shear rate can be generated and that the temperature can be controlled.

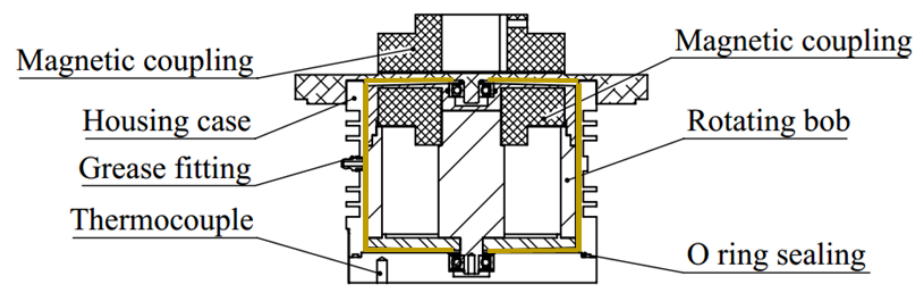

Figure 3 Schematic drawing of the ageing head (the grease is shown in yellow) 


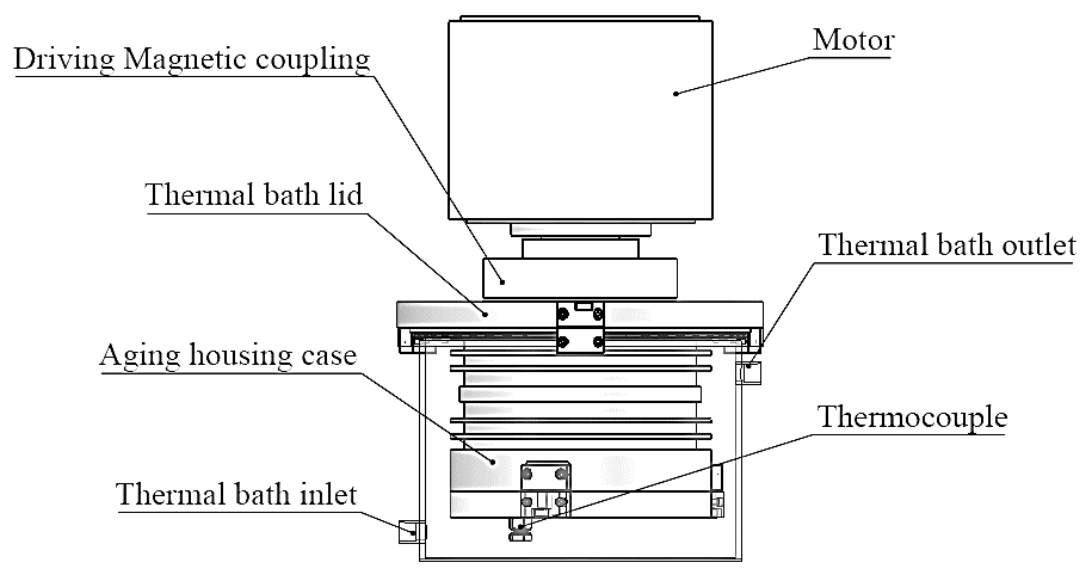

Figure 4 Schematic drawing of the Couette Ageing Machine

In addition to shear, grease softening has been observed at elevated temperatures even in the absence of oxidation (54-56). Therefore, in addition to the Couette Ageing Machine tests, pure thermal ageing tests were performed where fresh greases were inserted in a sealed glass container and heated in an oven varying the temperature and time.

Detailed information about the Couette Ageing Machine and the ageing conditions can be found in Paper B.

\subsection{Sample evaluation}

Rheological measurements were performed for the grease samples using an MCR 501 Anton-Paar rheometer with plate-plate configuration. As shown in Figure 5-a, the grease zero-shear viscosity $\eta_{0}$ was obtained from the Flow Curve test using the Cross model fit (57). The grease yield stress $\tau_{y}$ was calculated from the Oscillatory Strain Sweep (OSS) test using the method described by Cyriac et al. (54), see Figure 5 (b). 


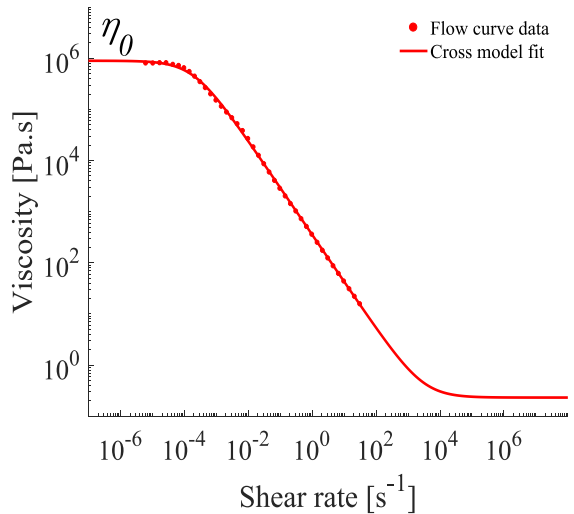

(a)

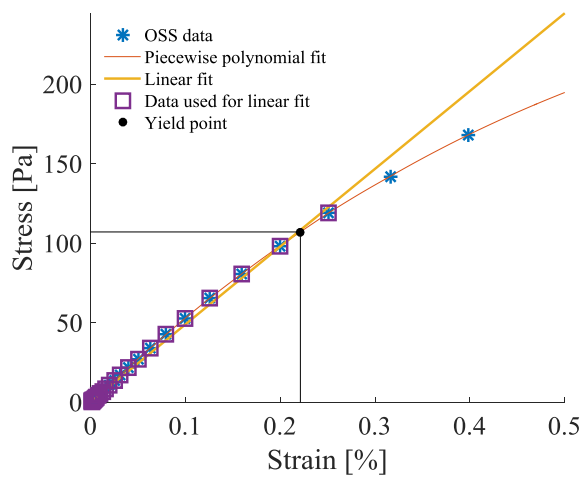

(b)

Figure 5 Rheological test output: (a) zero-shear-viscosity from a Flow Curve test; (b) yield stress from an Oscillatory Strain Sweep test

The grease micro-structure study was performed using Atomic Force Microscopy (AFM) (58-61) in tapping mode. The advantage of AFM over the traditional electronic microscopy (SEM or TEM $(62,63)$ ) is that the grease can be studied without removing the oil. The absence of oxidation during ageing was confirmed by Fourier Transform Infrared (FTIR) Spectroscopy, see Paper A. 


\subsection{Grease Ageing Master Curve}

The ageing time and temperature dependency of the $\mathrm{Li} / \mathrm{M}$ and $\mathrm{LiX} / \mathrm{PAO}$ rheological properties for different working conditions are presented in Figure 6. Clearly, softening as a function of shear rate, temperature and time occurs. Similar behaviour was found for $\mathrm{Li} / \mathrm{SS}$ and PU/E.

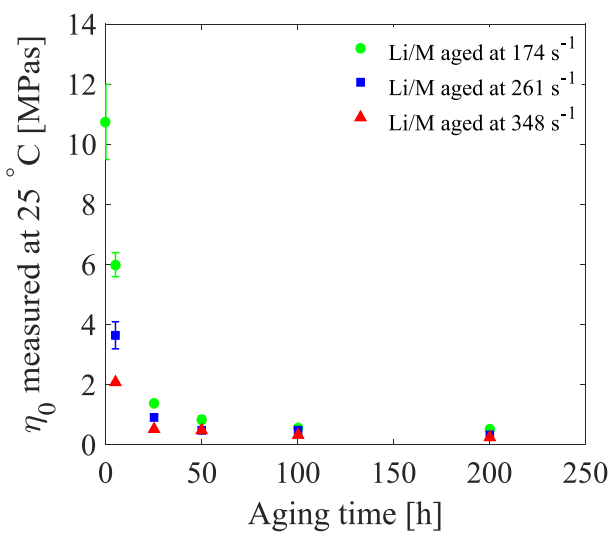

(a)

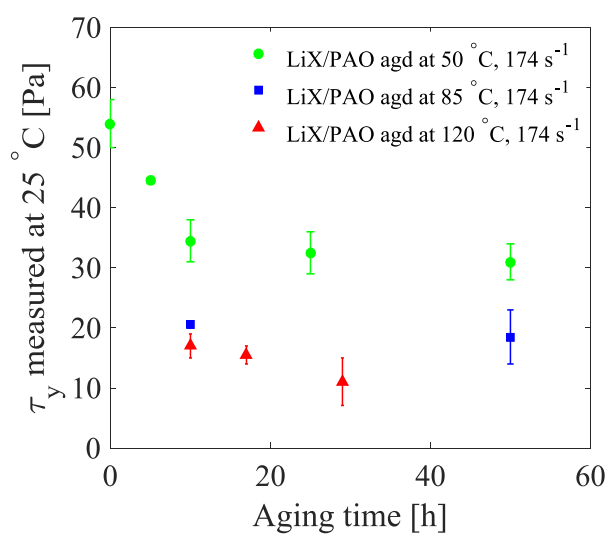

(b)

Figure 6 Change of grease rheological property for (a) $\eta_{0}$ of $\mathrm{Li} / \mathrm{M}$ at various ageing shear rates; (b) $\tau_{y}$ of $\mathrm{LiX} / \mathrm{PAO}$ at various ageing temperatures

To develop a general model for grease ageing that would be applicable for any shear rate and time, the grease ageing tests were evaluated from an energy point of view, where the input ageing energy density $E\left(J / \mathrm{m}^{3}\right)$ was calculated from the applied work and ageing time $t(s)$ per unit of grease volume (8):

$$
E=\frac{\int \frac{M \cdot N \cdot 2 \pi}{60} d t}{V_{a}}
$$

where the torque $M(\mathrm{Nm})$ and the rotational speed $N(\mathrm{rpm})$ were calculated from the motor output and where $V_{a}$ is the grease filling volume inside the Couette Ageing machine $\left(\mathrm{mm}^{3}\right)$.

The pure thermal ageing tests showed that the greases show softening following Arrhenius behaviour, which is similar to the relation that is used to describe the influence of temperature on grease life $(1,64)$. To add the thermal ageing effect, a temperature dependent 'Arrhenius Correction Factor' $C_{T}$ at a reference temperature $T_{0}$ was introduced: 
for the tested lithium and lithium complex greases, i.e., Li/M, Li/SS and $\mathrm{LiX} / \mathrm{PAO}, C_{T}=$ $2^{\frac{T-T_{0}}{15}}$

for the tested polyurea greases, i.e., PU/E, $C_{T}=2^{\frac{T-T_{0}}{10}}$. Detailed information on the thermal ageing results and the 'Arrhenius Correction Factor' $C_{T}$ can be found in Paper B.

In the current study, the room temperature $25^{\circ} \mathrm{C}$ is selected as the reference value, so $T_{0}=$ $25^{\circ} \mathrm{C}$. By multiplying the input work density $E$ with the Arrhenius Correction Factor $C_{T}$, giving a 'Corrected Energy Density' $E_{m}$, the ageing curves shown in Figure 6 collapse into a single curve, see Figure 7.

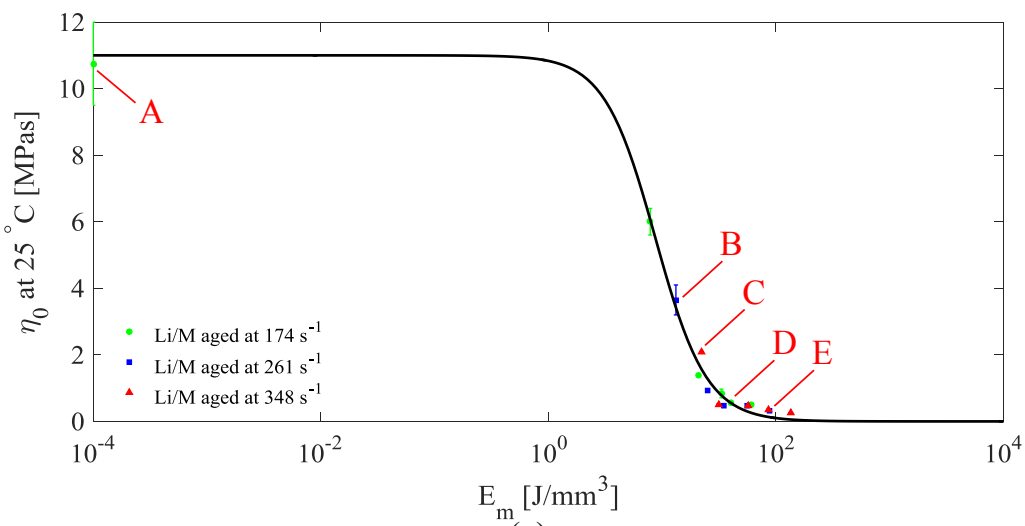

(a)

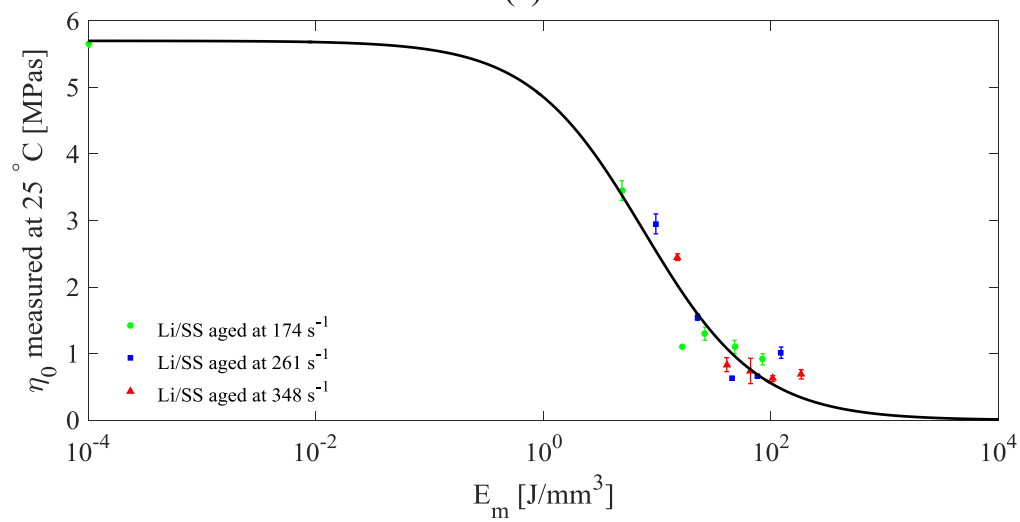

(b) 


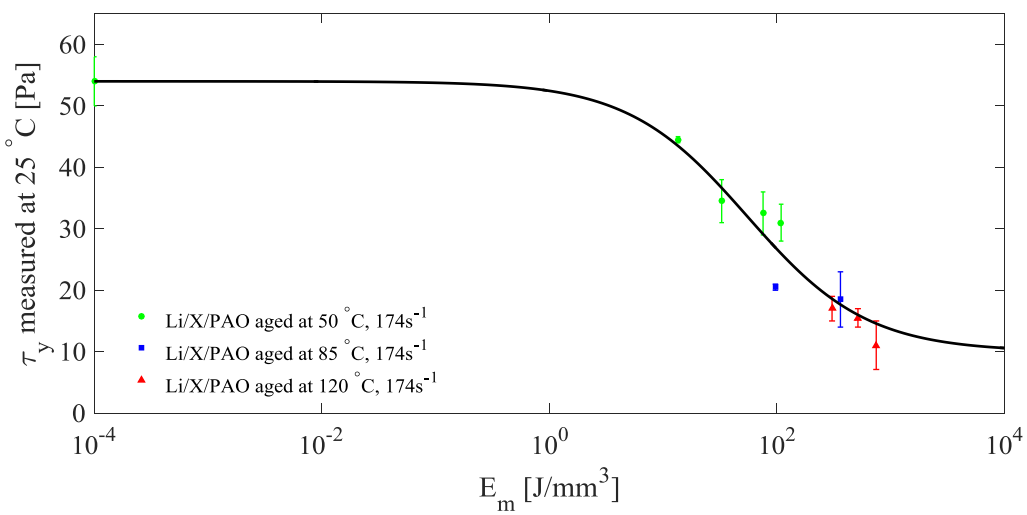

(c)

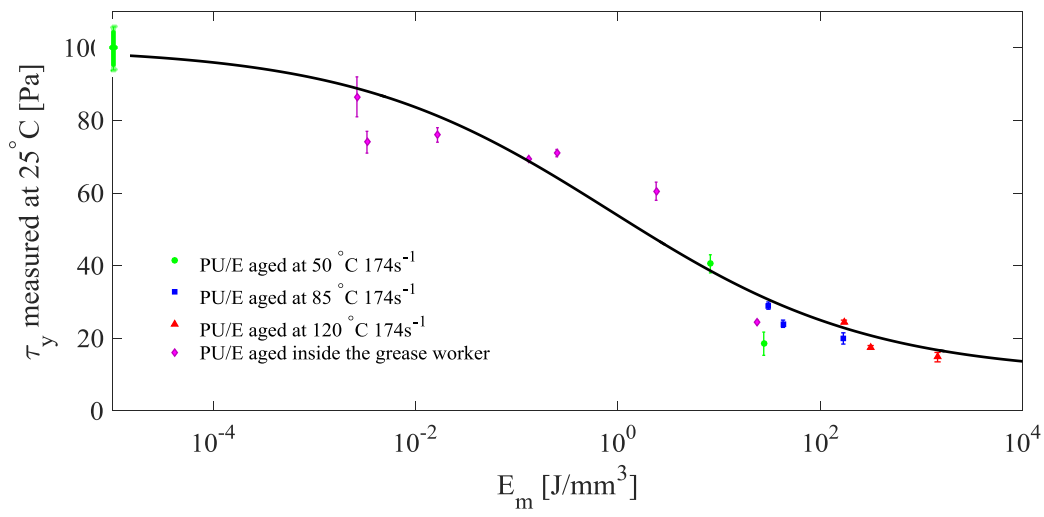

(d)

Figure 7 Change of grease rheological properties vs $E_{m}$ for $\mathrm{Li} / \mathrm{M}(\mathrm{a}), \mathrm{Li} / \mathrm{SS}(\mathrm{b}), \mathrm{LiX} / \mathrm{PAO}(\mathrm{c})$, $\mathrm{PU} / \mathrm{E}(\mathrm{d})$ (the $\mathrm{Li} / \mathrm{M}$ samples selected for AFM evaluation are labelled as A, B, C, D and E)

All four greases show a two-phase ageing behaviour, which can be correlated to the change of thickener micro-structure. As shown in Figure 8, during the first phase (Figure 8 A-D) grease ageing is dominated by network breakage, fibre re-orientation and scission, resulting in a progressive decrease of the rheological properties of the grease. As the size of the thickener fibres decreases over time, there will be a reduced probability for scission of these fragmented fibres, resulting in asymptotic behaviour (Figure $8 \mathrm{D}-\mathrm{E}$ ). 


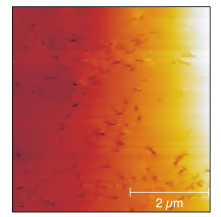

(A)

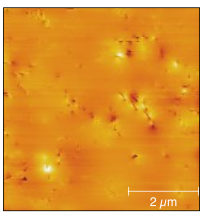

(B)

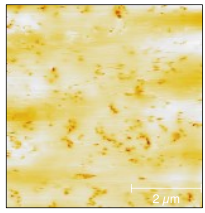

(C)

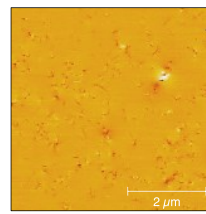

(D)

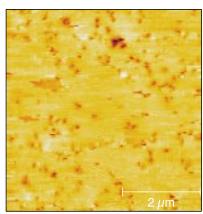

(E)

Figure 8 AFM phase image of the fresh and aged Li/M samples selected from Figure 7-(a) The 'Ageing Master Curve' describing the change of the rheological properties as a function of the Corrected Energy Density $E_{m}$ now reads:

$$
Y=\frac{Y_{i}-Y_{\infty}}{1+K \cdot E_{m}{ }^{n}}+Y_{\infty},
$$

where $Y$ represents a rheological property $\left(\eta_{0}\right.$ or $\left.\tau_{y}\right)$, with the index $i$ denoting the initial rheological value for fresh grease and $\infty$ the ultimate value; $K$ and $n$ are fitting constants. This curve applies to all four greases, see Figure 7 and Paper B.

\subsection{Ageing Master Curve validation and application}

The grease Ageing Master Curve was validated using a housemade grease worker shown in Figure 9, where fresh PU/E was aged for a given number of strokes at the reference temperature $T_{0}$. The input work density was calculated from the product of the drag force collected from the load cell and the piston displacement. The grease worker ageing results show good agreement with the Ageing Master Curve obtained from the Couette Ageing Machine, see Figure 7(d). 


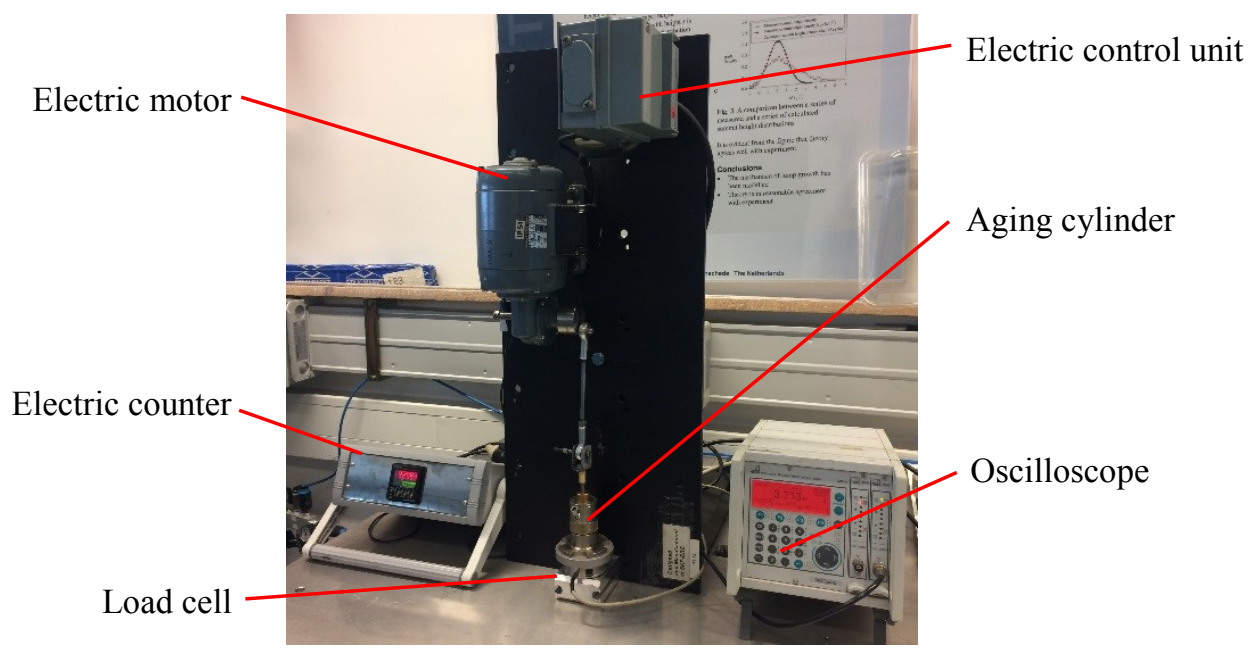

Figure 9 House made grease worker

To study grease ageing inside a real rolling bearing and to investigate the applicability of the Ageing Master Curve to rolling bearings, fresh PU/E was run inside a deep groove ball bearing using an $\mathrm{R} 0 \mathrm{~F}+$ test rig, which was designed to determine grease life under controlled temperature, speed and loading conditions (65). Similar to what was measured when aged in the Couette Ageing Machine, aged PU/E shows a decreasing yield stress during the running process.

As shown in Figure 10, where the yield stress is plotted versus bearing frictional energy density $E_{b}$, (calculated from the SKF catalogue (66)), PU/E aged inside the R0F+ test bearings shows similar ageing behaviour to that given by the Ageing Master Curve in Figure 7-d but with a large discrepancy in energy. This is probably caused by the fact that inside a bearing, only a fraction of grease will be aged $(47,48)$, while the evaluated volume, i.e., the aged sample, was collected as a mixture of grease from various parts of the bearing. This is clearly different from ageing inside the Couette Ageing Machine, where the collected sample for measuring the rheology has undergone uniform shear. To compensate for the fact that only a small fraction of grease is aged inside the bearing, the bearing frictional energy density $E_{b}$ was multiplied by a correcting factor $C_{e}$, which resulted in good agreement between the Ageing Master Curve and the bearing test results, see Figure 10 . 


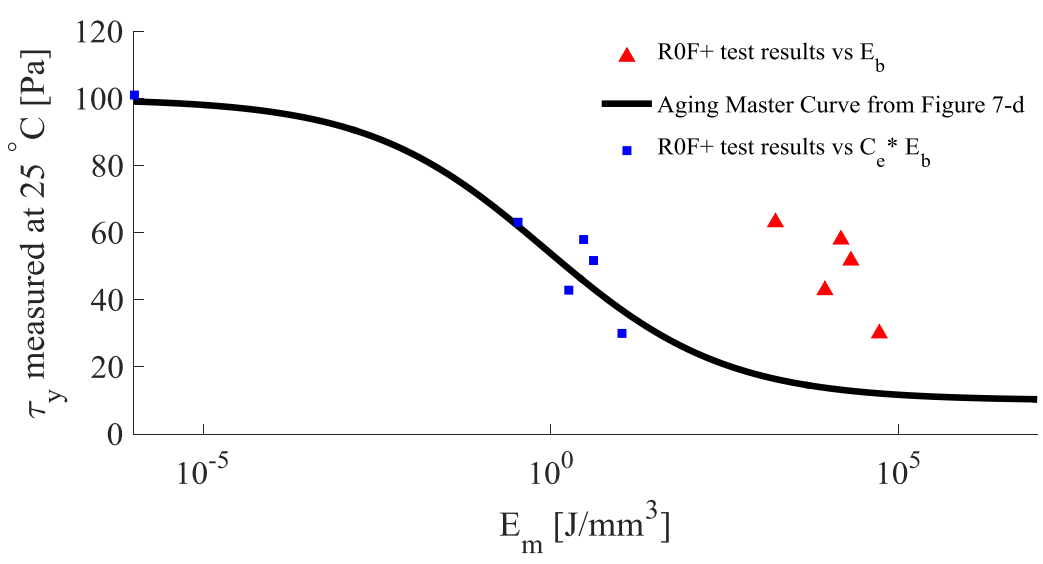

Figure $10 \mathrm{PU} / \mathrm{E} \mathrm{R} 0 \mathrm{~F}+$ test results

This Ageing Master Curve can therefore be used as a potential building block for grease life estimation when a threshold value of the grease property is defined based on the grease type and bearing running conditions. Details about the Ageing Master Curve can be found in Papers A and B.

\section{Ageing of grease with a particle-like thickener structure}

Calcium sulphonate complex greases (here denoted as 'CaS greases') show little influence of water ingress on their performance and are therefore often selected for bearings running in humid environments. The thickener has inherent anti-wear, extreme pressure and friction-reducing properties (67-74), which makes this grease suitable for high load conditions. The high dropping point makes it possible to operate at high temperatures.

Other than lithium-based and polyurea-based grease, CaS grease has a particle-like thickener micro-structure. As shown in Figure 11, CaS thickener particles have an approximately spherical geometry $(31,75)$, consisting of a wafer-like calcite core $(100$ $400 \mathrm{~nm}$ in diameter) surrounded by calcium sulphonate (about $2 \mathrm{~nm}$ in length) $(70,73,76$, 77). Conventional overbased calcium sulphonate greases have poor pumpability and lowtemperature performance due to the high thickener content (78). To improve this, 12hydroxystearic acid was introduced as a complexing agent, forming the CaS grease (77). 

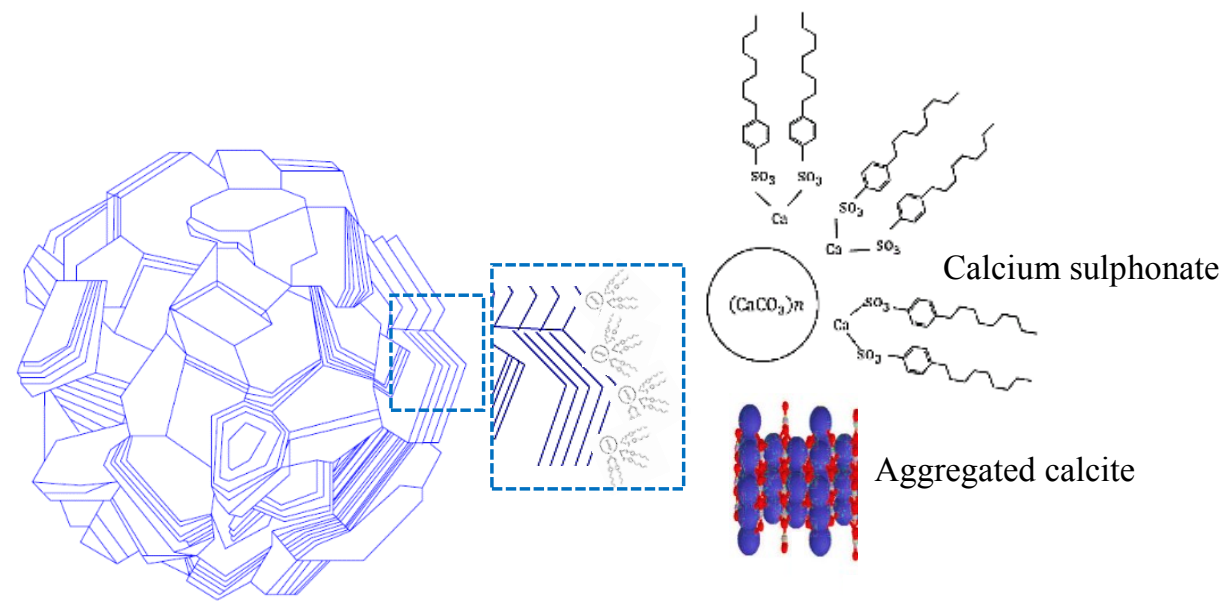

Figure 11 Micro-structure of a CaS thickener particle $(73,77)$

Compared to grease that has a fibre-like thickener structure, CaS grease is considered to have a better shear stability, which is ascribed to this particle-like thickener structure (76, 81). As mentioned above, $\mathrm{CaS}$ grease is a preferred grease for bearings running in a humid environment because of its excellent water-absorbing capability $(79,80)$. When mixed with water, large inverse micelles are generated with water as the core and $\mathrm{CaS}$ thickener particles as a shell (80). With increasing water concentration, the size of these water/CaS micelles increases, which may result in an instable structure (81). Under shear, free water may be released, which is harmful to the bearing. In this chapter, the shear stability of both dry $\mathrm{CaS}$ grease (grease as received) and wet $\mathrm{CaS}$ grease (grease mixed with water) will be presented in terms of grease micro-structure and rheological properties. The tested greases are $\mathrm{CaS} / \mathrm{M}$ and $\mathrm{CaS} / \mathrm{MS}$ (see Table 1).

\subsection{Shear stability of dry CaS grease}

To study if the 'Ageing Master Curve' from Chapter 2 can also be used to describe CaS grease ageing behaviour, fresh $\mathrm{CaS}$ grease was aged inside the Couette Ageing Machine (Figure 3) and evaluated using the rheometer, AFM and FTIR.

The Couette ageing test results for CaS greases are shown in Figure 12. The yield stress for the aged samples was measured at $25^{\circ} \mathrm{C}$ and is plotted as a function of the input work density $E$. The CaS greases clearly show a different ageing behaviour from the lithium- 
based and polyurea-based greases from Chapter 2. There is no significant yield stress change when the $\mathrm{CaS}$ grease is sheared at $50^{\circ} \mathrm{C}$ for long periods. For $\mathrm{CaS} / \mathrm{M}$, shearing at an elevated temperature $\left(85^{\circ} \mathrm{C}, 120^{\circ} \mathrm{C}\right)$ results in thickening, whereas the CaS/MS softens slightly with increasing input energy at $120^{\circ} \mathrm{C}$.

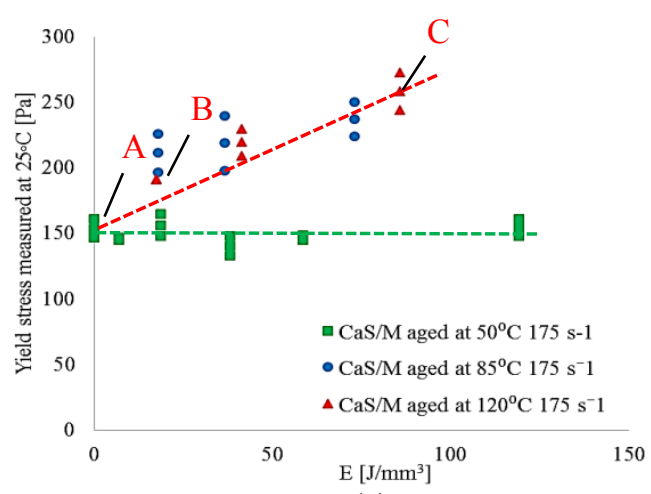

(a)

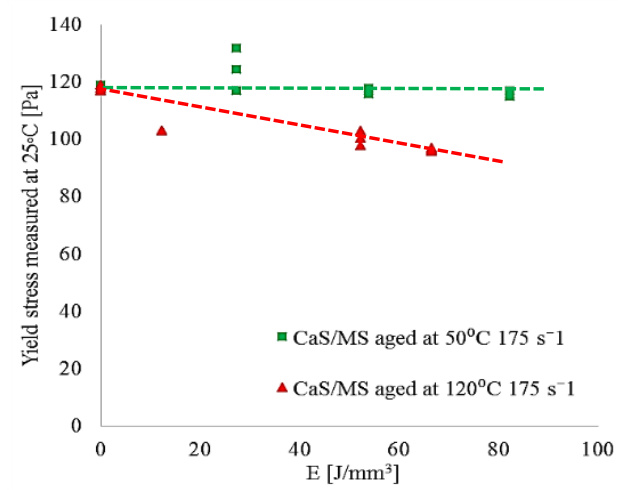

(b)

Figure 12 Couette ageing test results for (a) CaS/M; (b) CaS/MS (the samples selected for AFM evaluation are labelled as A, B and C)

After heating in the oven at an elevated temperature for 100 hours, CaS grease shows no change in yield stress or in micro-structure. Therefore, it is impossible to merge the ageing results shown in Figure 12 into a single curve by making use of the Arrhenius correction factor $C_{T}$. For these greases, the 'Ageing Master Curve' concept presented in Chapter 2 is not applicable.

To explain the thickening behaviour shown in Figure 12-a, the first hypothesis is that the thickening is caused by the clustering of thickener particles under shear at high temperatures. However, this could not be observed from the AFM measurements, see Figure 13. 

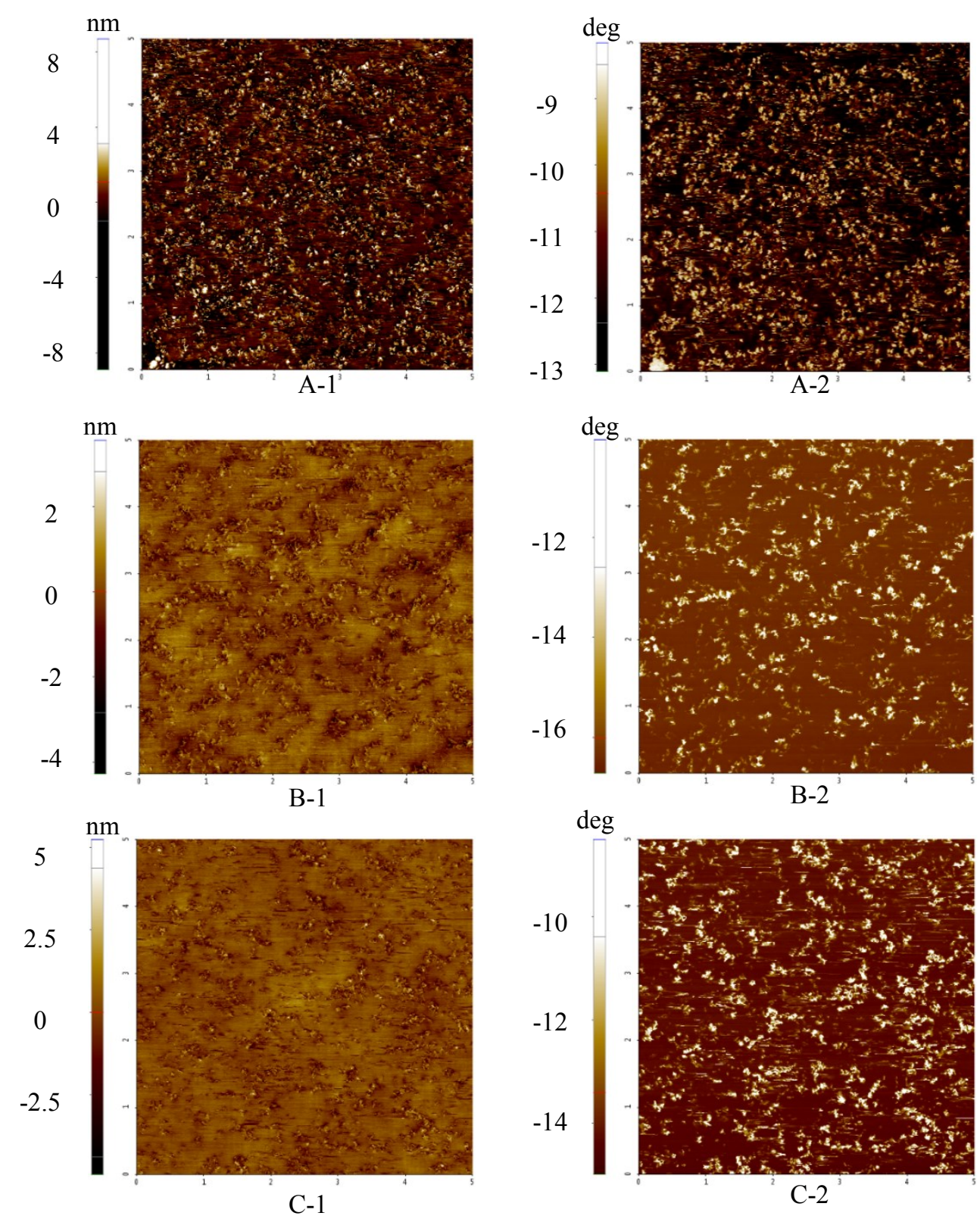

Figure 13 AFM results of the fresh and aged CaS/M samples selected from Figure 12-a: the left column gives the height images giving the surface topography; the right column gives the phase image indicating the material variation, image size: $5 \times 5 \mu \mathrm{m}$ 
Another possible explanation could be that the elevated ageing temperature in the Couette Ageing Machine $\left(85^{\circ} \mathrm{C}\right.$ and $\left.120^{\circ} \mathrm{C}\right)$ would result in a phase transformation of calcium carbonate leading to a change of the thickener crystalline structure (82). However, according to the FTIR results shown in Figure 14, the concentration of calcite and vaterite remains unchanged when $\mathrm{CaS}$ is aged at different temperatures $\left(713\right.$ and $874 \mathrm{~cm}^{-1}$ corresponds to the calcite; 745,859 and $1070 \mathrm{~cm}^{-1}$ corresponds to the vaterite). Until now, the thickening behaviour for $\mathrm{CaS} / \mathrm{M}$ as shown in Figure 12(a) cannot be explained.

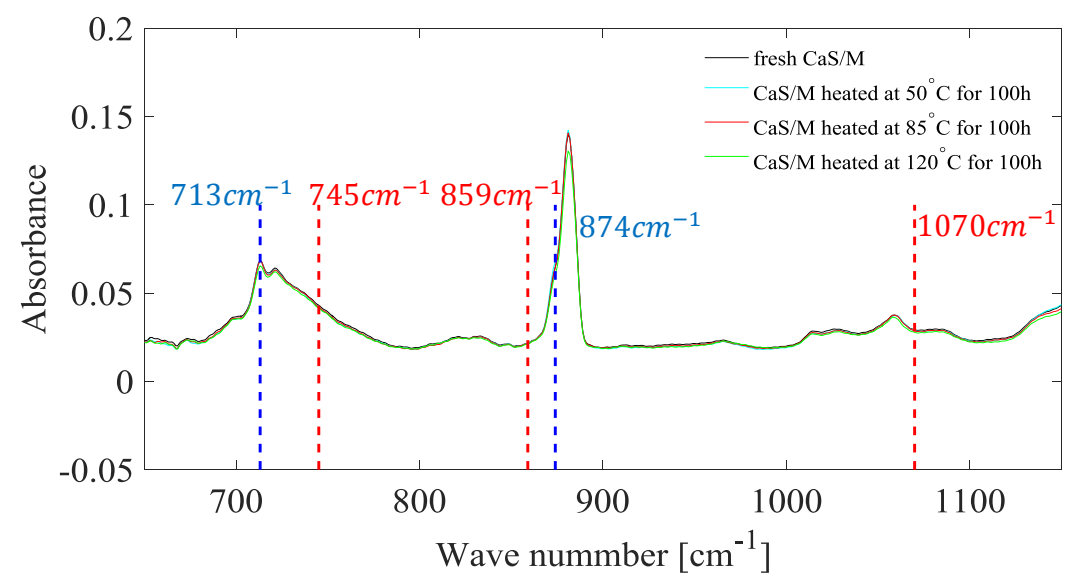

Figure 14 FTIR spectra of the fresh and thermal aged CaS/M

\subsection{Shear stability of wet CaS grease}

To investigate the influence of water ingress on the shear stability of $\mathrm{CaS}$ grease, water/grease mixtures were prepared in the grease worker (Figure 9), applying 500 strokes at ambient temperature $\left(25^{\circ} \mathrm{C}\right)$ and then further aged for 100,000 and 400,000 more strokes. Two levels of water were used. The first level was 15\%: this is also used in the "water stability test' ASTM D7342, where the percentage is defined as the ratio of the mass of water to the total mixture multiplied by $100 \%$. The second level was $50 \%$ because this is the saturation level (81). With so much water mixed in, CaS grease will generate large water/CaS inverse micelles, resulting in an unstable grease structure. As a reference, dry $\mathrm{CaS}$ grease was also aged for the same number of strokes in the grease worker. 
In Figure 15, the yield stress of the dry and wet $\mathrm{CaS}$ grease is plotted as a function of the input work density $E$ generated inside the grease worker. As can be expected, dry $\mathrm{CaS}$ grease remains stable. However, wet $\mathrm{CaS}$ grease shows a different ageing behaviour for different water content levels.

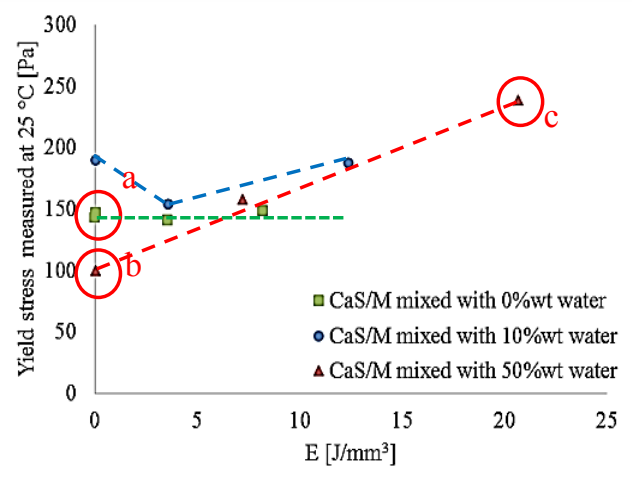

(a)

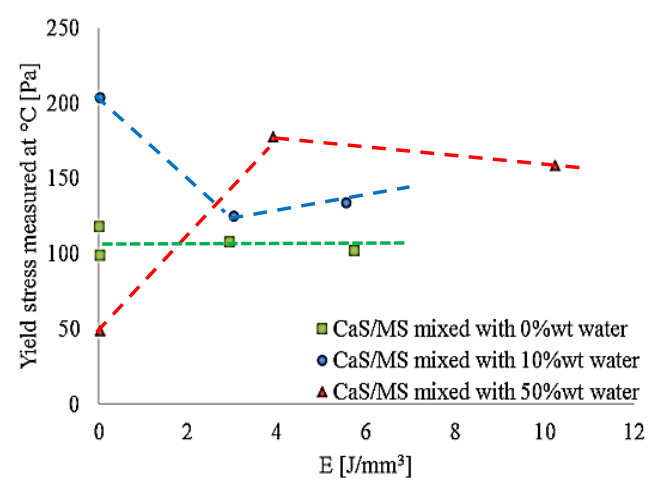

(b)

Figure 15 Grease worker test results for (a) CaS/M; (b) CaS/MS (the samples selected for AFM evaluation are labelled $a s \mathrm{a}, \mathrm{b}$ and $\mathrm{c}$ )

For the CaS grease with $10 \%$ wt water, after 500 strokes mixing $(E \approx 0)$ the yield stress increases with increasing $E$. This is attributed to the generation of a water/CaS thickener micellar structure. As shown in Figure 16, when mixing with water the hydrophilic calcite aggregations will adhere to the water molecules and form a shell. The water is trapped in this shell (81). At the beginning, these micelles function as 'apparent thickeners', which increase the effective thickener fraction, resulting in higher yield stress in comparison with the dry grease. However, the water/CaS micelles are less stable than the pure $\mathrm{CaS}$ thickener particles. When subjected to more shear in the grease worker, they are broken and the water influence is thus restricted. This will then lead to a reduction of the yield stress. With prolonged shear $\left(E>5.5 \mathrm{~J} / \mathrm{mm}^{3}\right)$, smaller but more homogeneous water/CaS micelles are generated again. Compared to the original $\mathrm{CaS}$ thickener particles, these micelles have a larger size and higher capability to trap the base oil (75), resulting in a higher yield stress. 


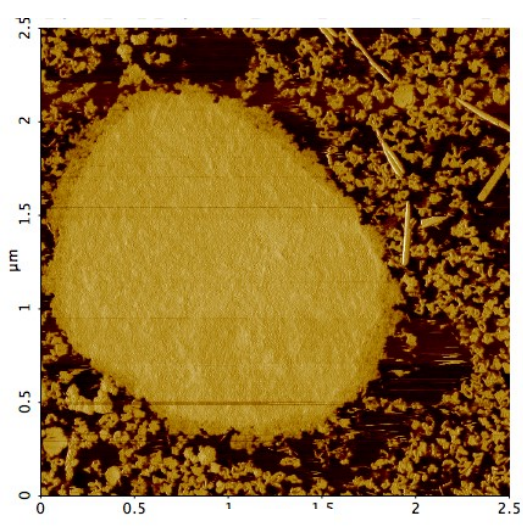

(a)

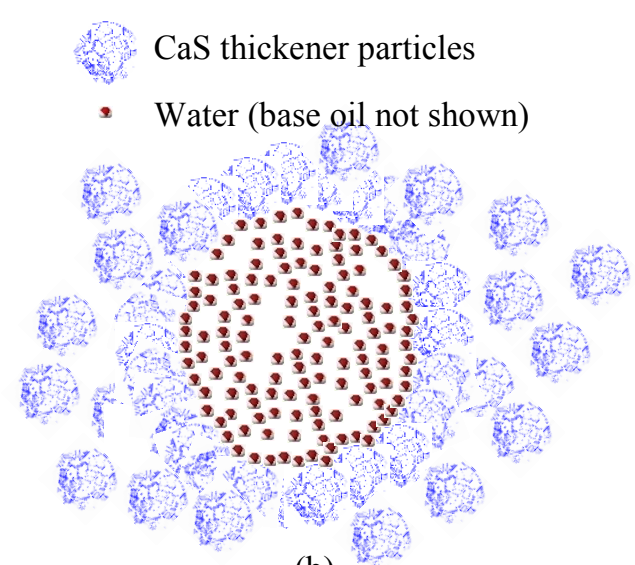

(b)

Figure 16 AFM phase image (a) and the schematic drawing (b) of the water/CaS micelle

When the CaS grease is mixed with $50 \%$ wt water the initial 500 strokes mixture makes the grease softer. At this stage, the $\mathrm{CaS}$ grease is saturated with water. According to (81), $\mathrm{CaS}$ grease mixed with higher water content will generate not only more micelles but also larger micelles. Although these micelles have a hard CaS thickener shell, they are formed mainly by water. Under shear, they are easy to deform and break. The larger they are, the less stable. During the rheological measurement with a plate-plate configuration, the shear field is not uniform within the sample. These large weak micelles will break at the high shear zone, resulting in shear banding/localization and smaller yield stress value are obtained (83). Under increasing amount of shear in the grease worker, the large fragile micelles are progressively broken into smaller but more stable micelles. The stronger micellar structure thus results in the recovery of the yield stress. These structural changes of the wet CaS/MS are also observed in the AFM.

After a sufficient amount of accumulated shear, the added water is completely emulsified into the grease, forming a stable micellar structure. Compared to the $10 \% \mathrm{wt}$ water/grease mixture, $50 \%$ wt water/grease mixture has more water/CaS micelles per unit volume and therefore has a higher 'apparent thickener' volume fraction. For a relation between particle volume fraction and yield stress in a colloidal gel, the reader is referred to (84). 


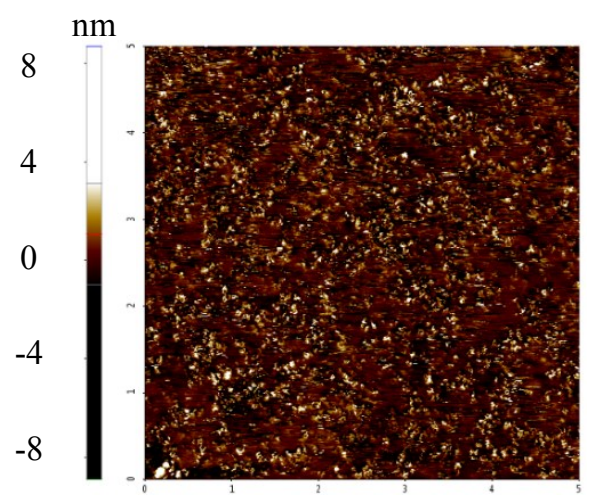

a-1
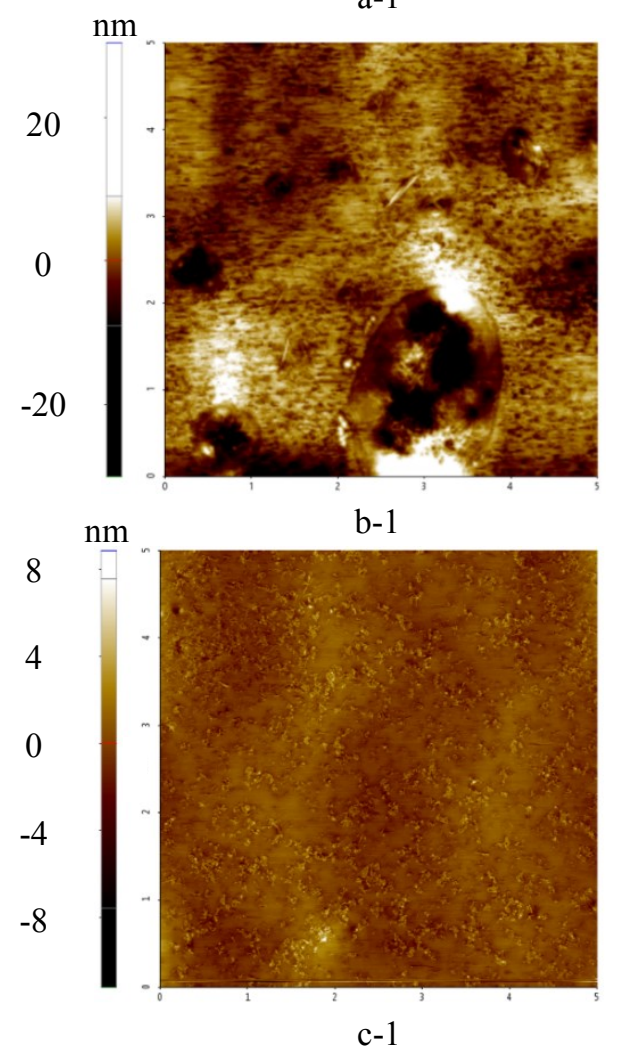
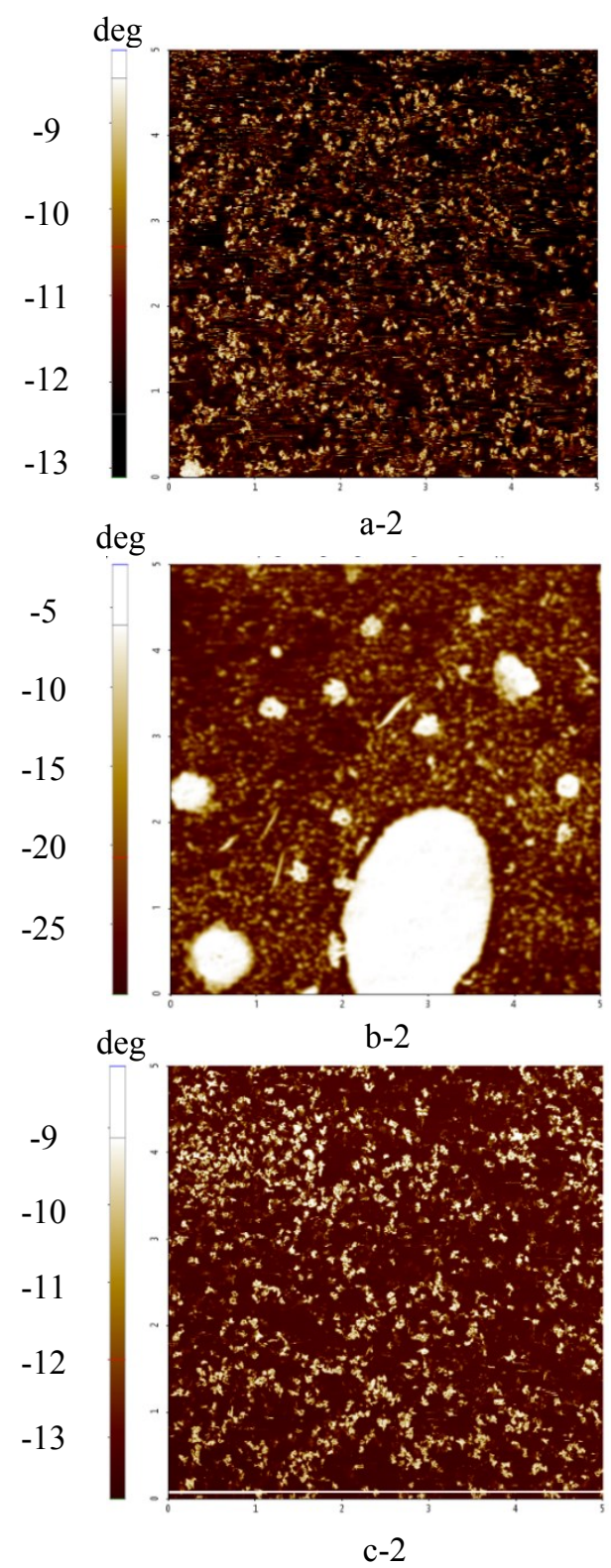

Figure 17 AFM results of the fresh and aged CaS/M samples selected from Figure 15(a): the left column is the height images giving the surface topography; the right column is the phase image indicating the material variation, image size: $5 \times 5 \mu \mathrm{m}$ 
To summarize, CaS greases show a different ageing behaviour from the greases with a fibre-like thickener structure. The particle-like thickener structure gives this type of grease good shear stability. With water ingress, $\mathrm{CaS}$ grease shows a dynamic ageing behaviour due to the change of micro-structure. However, the added water is encapsulated in a rigid water/CaS thickener micellar structure, which protects the lubricated bearing from free water. More details on the CaS grease ageing behaviour can be found in Paper D.

\section{Grease film thickness measurement and the impact of ageing}

The thickness of the lubricant film between the rolling elements and raceway is considered as a key parameter in determining bearing life $(85,86)$. An insufficient film thickness will result in solid-solid contact, leading to wear and damage of the contacting surfaces. Lubricating greases have been widely studied using single contact configurations and bearing tests, where dynamic grease film thickness behaviour was observed $(22,23,32,87$, 88 ), caused by dynamics in the complex feed and loss mechanism $(4,37,89)$ and by a change of grease properties caused by a changing micro-structure (3, 40), bleeding capability (38), oxidation $(7,90)$, rheological properties $(38,91)$, etc. Other than the extensive and ground-breaking work described in the papers mentioned above, limited studies have been performed on measuring the actual film thickness inside greaselubricated full bearings.

In this chapter film thickness measurement during 100 hours of running time of an axially loaded ball bearing, lubricated by different greases, will be presented. Grease bleed (the main factor for lubricant feed to the contacts) and yield stress (measure of grease mobility) are considered to be the most important properties determining the film thickness. These two parameters are listed in Table 2 for the fresh greases studied (yield stress obtained from the OSS tests (54) and grease bleed measured using the SKF Grease Test Kit (92)). Also provided is the base oil viscosity $v_{b}$ and the pressure-viscosity coefficient $\alpha$ (obtained following Van Leeuwen's method (31) (93)). The oil properties will be used in the fully flooded EHL film thickness calculation presented later. 
Table 2 Grease and oil properties

\begin{tabular}{|c|c|c|c|c|}
\hline Grease sample & $\begin{array}{c}\text { Grease bleed } \\
\left(\mathrm{mm}^{2}\right)\end{array}$ & $\begin{array}{c}\tau_{y} \\
(\mathrm{~Pa})\end{array}$ & $\begin{array}{c}v_{b} \text { at } 40^{\circ} \mathrm{C} / \\
100^{\circ} \mathrm{C}(\mathrm{cSt})\end{array}$ & $\begin{array}{c}\alpha \\
\left(10^{-9} \mathrm{~Pa}^{-1}\right)\end{array}$ \\
\hline Fresh Li/M & 899 & 57 & $100 / 10$ & 27 \\
\hline Fresh Li/SS & 1357 & 35 & $42 / 7$ & 24 \\
\hline Fresh LiX/PAO & 479 & 54 & $191 / 42$ & 17 \\
\hline Fresh PU/E & 615 & 101 & $70 / 9$ & 24 \\
\hline Fresh CaS/PAO & 269 & 106 & $320 / 30$ & 17 \\
\hline Fresh CaS/M & 115 & 154 & $420 / 26$ & 27 \\
\hline
\end{tabular}

\subsection{Grease film thickness measurement}

The grease film thickness measurements were performed using a house made bearing test rig (Figure 18). The tested bearing is a shielded deep groove ball bearing $6209-2 \mathrm{Z} / \mathrm{C} 3$, which was axially loaded by an air spring and driven by a motor (not shown) via a magnetic coupling. $30 \%$ of the bearing's free volume was filled with grease from both sides. The self-induced temperature was recorded by the thermocouple attached to the bearing outer ring. Detailed information about the test rig and the running conditions can be found in Paper C and (94).

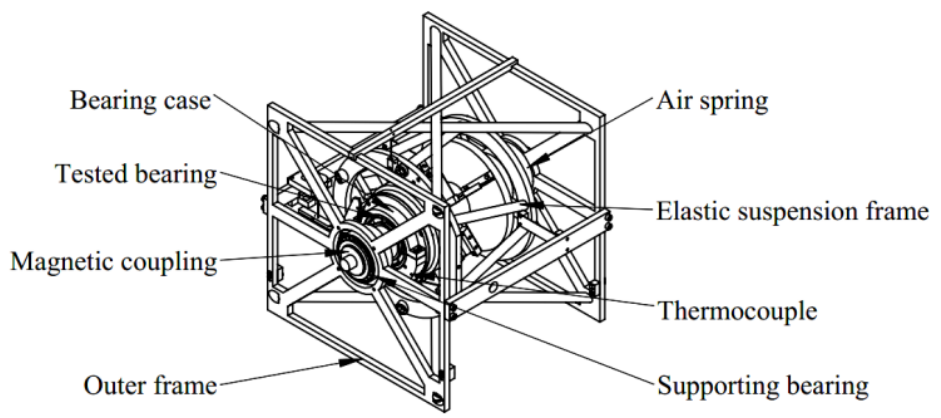

Figure 18 Bearing test rig

The bearing film thickness was determined using Lubcheck Mk3. This method measures the electrical capacitance of the bearing $(95,96)$. Instead of calculating the film thickness directly from the bearing capacitance $(97,98)$, the film thickness was calibrated using the oil bled from the various greases. Figure 19 shows the measured capacitance versus $h_{\text {cal }}$, the film thickness calculated according to the Hamrock and Dowson equation (21). This calibration can be used for the grease lubricated bearing. It is assumed that the lubricant 
inside the contact consists mainly of bled oil and that the grease and its bled oil have similar dielectric properties under shear (10\% difference according to (23)).

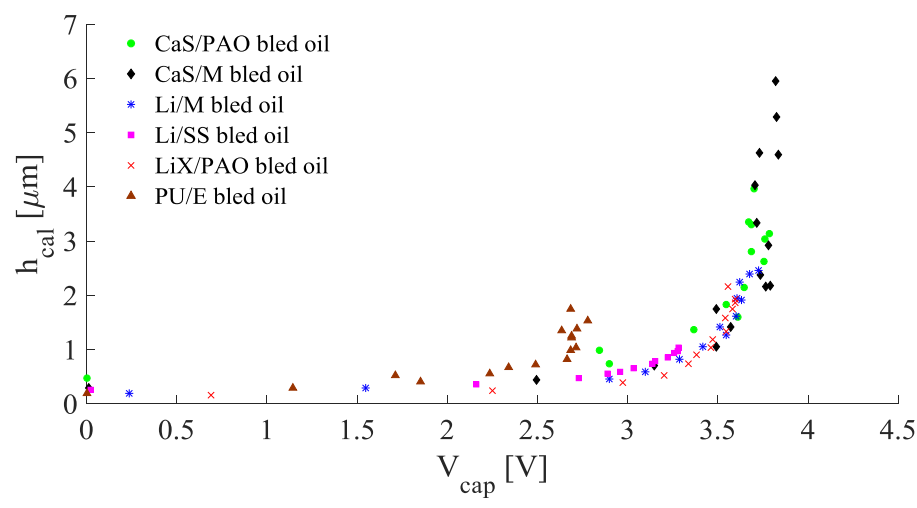

Figure 19 Bled oil calibration results

Inside a running bearing, grease will experience severe shear due to macroscopic flow during the churning phase (1). Shear in thin layers will occur throughout the running time of the bearing $(3,22)$. The grease shear stability will affect the lubricant feed to the contacts (90) and therefore the film build-up. Consequently, the film thickness profile during the 100 hours of continuous running is expected to be different for ageing-sensitive greases $(\mathrm{Li} / \mathrm{M}$, $\mathrm{Li} / \mathrm{SS}, \mathrm{LiX} / \mathrm{PAO}$ and PU/E) and for mechanical stable greases (CaS/PAO and CaS/M). The measured grease film thickness will be compared with the calculated fully-flooded film thickness using the bled oil viscosity at the measured bearing temperature.

\subsection{Film thickness profile for greases with a fibre-like structure}

In Figure 20, the measured grease film thickness $h_{\text {grease }}$, calculated EHL bled oil film thickness $h_{\text {oil }}$ and measured bearing temperature $T_{\text {bearing }}$ for $\mathrm{Li} / \mathrm{M}, \mathrm{Li} / \mathrm{SS}, \mathrm{LiX} / \mathrm{PAO}$ and PU/E are plotted against the running time on log scale. For all four greases the film thickness is clearly not constant. In all tests, there was initially (during and immediately after about 5 10 seconds start-up) sufficient bulk grease in the contact inlets, resulting in fully flooded condition (22), where $h_{\text {grease }}$ is approximately equal to $h_{\text {oil }}$. Due to grease channelling and rising temperature, $h_{\text {grease }}$ drops rapidly. This is then followed by a film 
recovery, where grease bleed and replenishment reduce the level of starvation. Li/SS was found to have the highest bleeding rate and the film thickness for this grease recovers progressively until $h_{\text {oil }}$ is reached. LiX/PAO and $\mathrm{Li} / \mathrm{M}$ have a similar bleeding rate and show a similar degree of recovery. However, at the end of the 100 hours of running time LiX/PAO was experiencing severe film thickness fluctuations, which is attributed to (micro-)churning, where a fraction of the grease from the reservoirs may incidentally fall back into the contact area due to creep flow, vibrations, centrifugal force and/or cage scraping $(23,35,39,89)$. PU/E has a relatively low bleeding rate but nevertheless shows impressive recovery. This is ascribed to its considerable shear softening, as will be discussed in more detail below. 


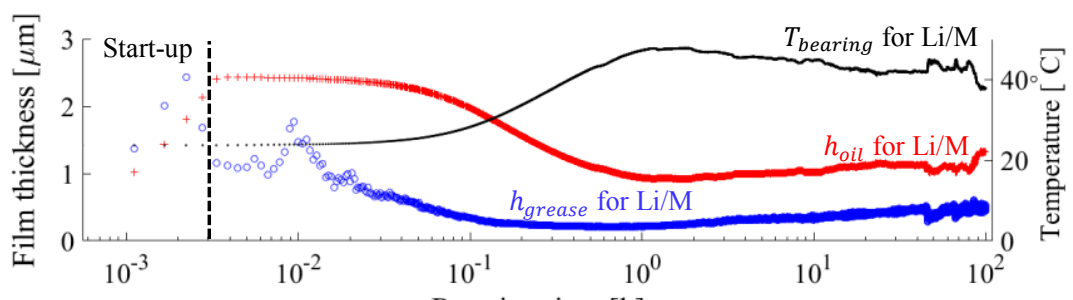

Running time [h]

(a)

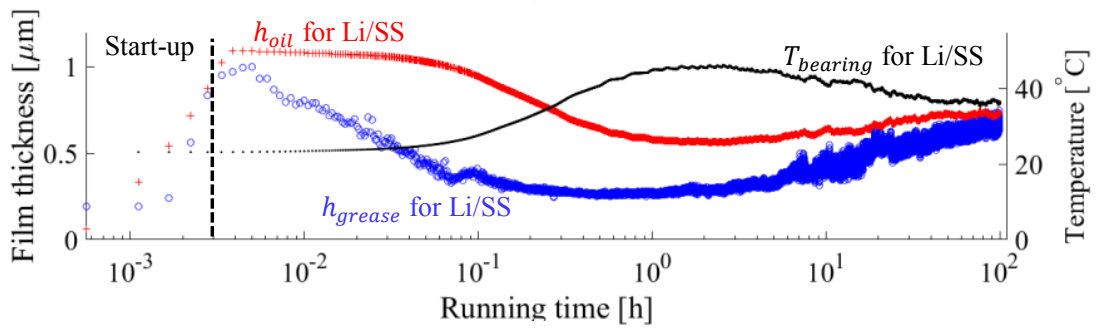

(b)

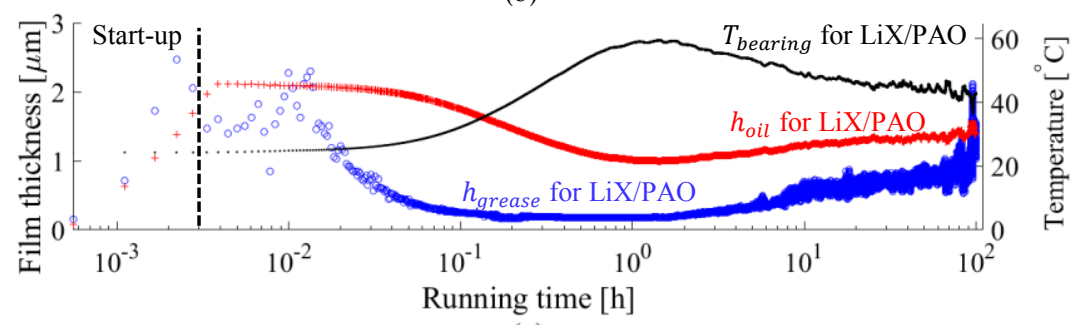

(c)

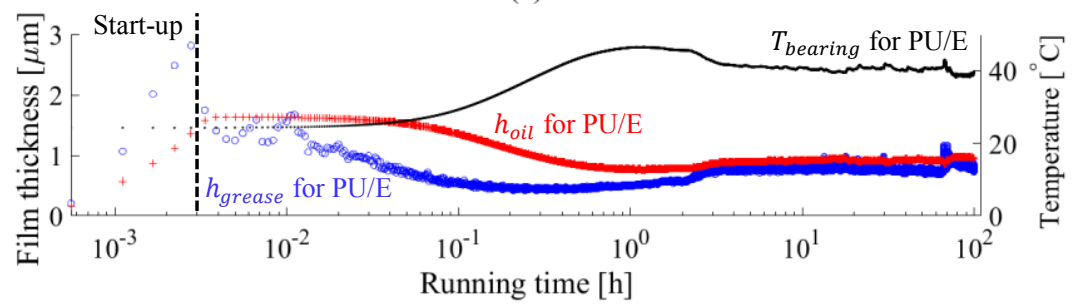

(d)

Figure 20 Film thickness profile of (a) Li/M; (b) Li/SS; (c) LiX/PAO; (d) PU/E

To study the impact of mechanical ageing on this recovery behaviour, the film thickness was measured using aged PU/E samples collected from the Couette ageing tests, covering the full spectrum of shear degradation, reflecting a decreasing yield stress and increasing grease bleed as shown in Figure 21. 


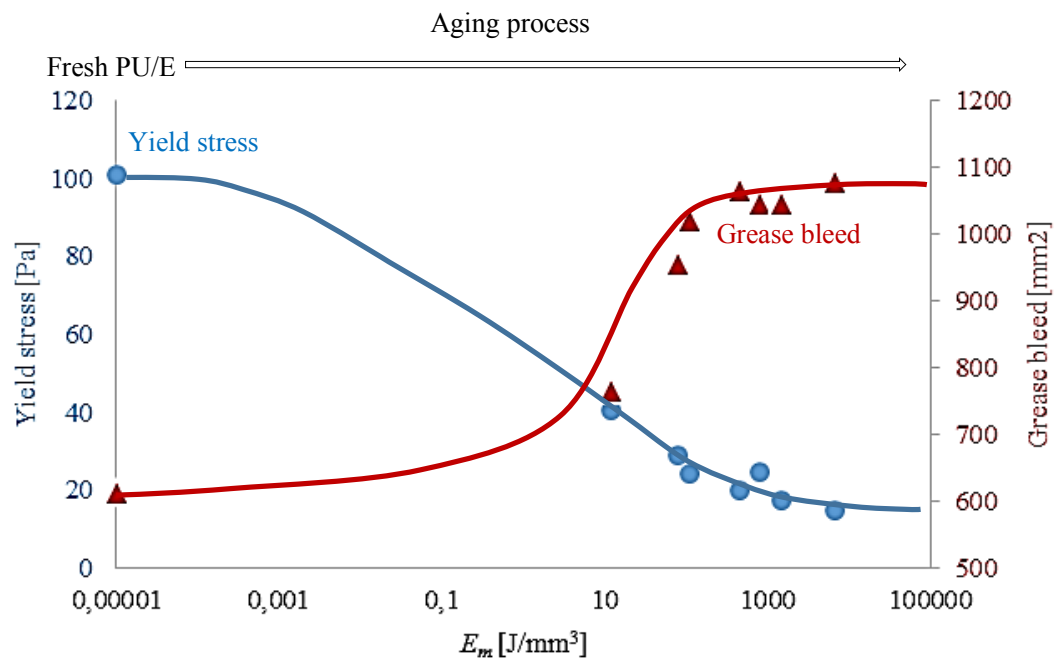

Figure 21 Ageing curves for PU/E grease. The points on these curves represent the yield stress and grease bleed of the samples used in the film thickness measurements

The bearing film thickness test results using the fresh and aged PU/E are shown in Figure 22, where the average film thickness in the stable stage $h$ (after 5 hours running) is plotted versus the corresponding grease bleed (Figure 22-a) and yield stress (Figure 22-b). The average bled oil film thickness at the stable stage is also added as a reference line. Clearly, the results show that the grease film thickness increases during the ageing process and counteracts starvation $\left(h>h_{\text {oil }}\right)$. Shear degradation contributes in three ways to this film thickness increase: degradation leads to higher grease bleed, more grease migration (lower yield stress) and a decrease in thickener particle size which, dispersed in the bled oil, increases the film thickness (31). 


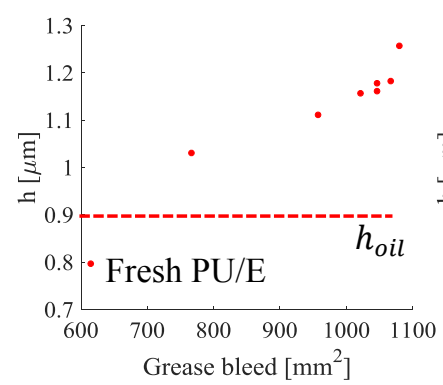

(a)

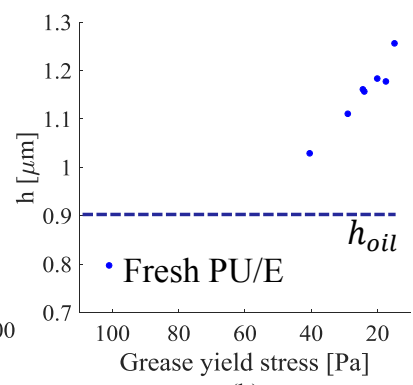

(b)

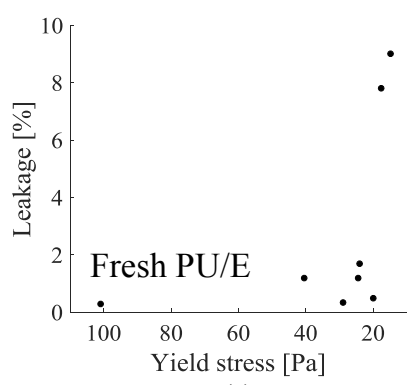

(c)

Figure 22 Bearing test results for fresh/aged PU/E: (a) $h$ vs grease bleed; (b) $h$ vs yield stress; (c) bearing leakage vs yield stress

The current results suggest that the grease film thickness will increase during ageing and exceed the fully flooded bled oil film thickness. This behaviour is not observed in practice $(1$, 37). Considering the relatively low temperatures in these tests, oxidation, polymerization and evaporation will not take place, even after very long running times. It is more likely that the film thickness would ultimately decrease due to leakage. As shown in Figure 22(c), softening (decreasing yield stress) leads to leakage (probably the result of more grease flow inside the bearing). This will result in the loss of lubricant and ultimately a reduction of film thickness.

The contribution of the various mechanisms behind the film formation and decay in bearings lubricated by greases with a fibre-like thickener structure are shown schematically in Figure 23. For a freshly greased bearing, after starting up, the grease itself will function as the lubricant, resulting in fully flooded conditions where the films may be even thicker than those formed by the bled oil. Next, the film thickness decreases rapidly due to increase in temperature caused by churning and subsequent grease channelling. During this phase the reservoirs are formed and start bleeding oil, which is promoted by shear degradation and higher temperature. In addition, shear softening will promote replenishment and the breakage (scission) of the thickener fibres forming small particles will increase the contribution of the thickener to the film thickness. Grease channelling will cause starvation. However, grease bleed, together with shear degradation, will result in a film thickness recovery again which will lead to a relatively stable film thickness, during which a lubricant feed-and-loss balance exists. However, grease softening and increasing bleeding rate will result in leakage which will lead to a loss of lubricant and again starvation. 


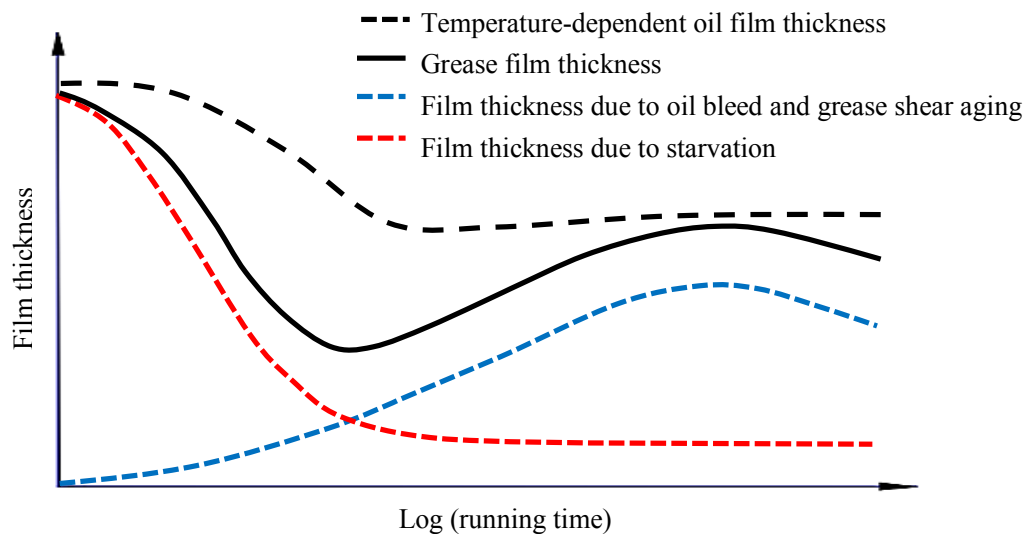

Figure 23 Hypothetical film thickness profile inside a running bearing lubricated by grease with a fibre-like structure

\subsection{Film thickness profile for greases with a particle structure}

Figure 24 shows $h_{\text {grease }}$ and $h_{\text {oil }}$ for $100 \mathrm{~h}$ running test lubricated by CaS/PAO and CaS/M. In contrast to lithium-based and urea-based greases, the calcium sulphonate complex greases show severe starvation throughout the tests and no predominant film thickness recovery is observed. This is ascribed to the combination of low grease bleed (at this relatively low running temperature) and high shear stability (as was shown in Chapter 3). It was already reported by Cann and co-workers for single contacts $(22,90)$ that high grease shear stability would limit replenishment, leading to continuous starvation without recovery. In addition, the two $\mathrm{CaS}$ greases have relatively high base oil viscosity (Table 2). According to the Hamrock and Dowson equation, higher viscosity will result in higher EHL $h_{\text {oil }}$. However, for the lubrication inside a bearing, it has been found that grease with a high base oil viscosity will restrict the oil replenishment and aggravate starvation (85). Therefore, a high base oil viscosity also enlarges the gap between $h_{\text {oil }}$ and $h_{\text {grease }}$.

The fact that calcium sulphonate complex greases provide a lower film thickness does not mean that these greases are not suitable for bearing lubrication. According to the literature $(70,74)$, the calcite will form a protective layer on the contact surface, giving this type of grease excellent anti-wear and extreme pressure properties and thus providing good boundary lubricating condition. 


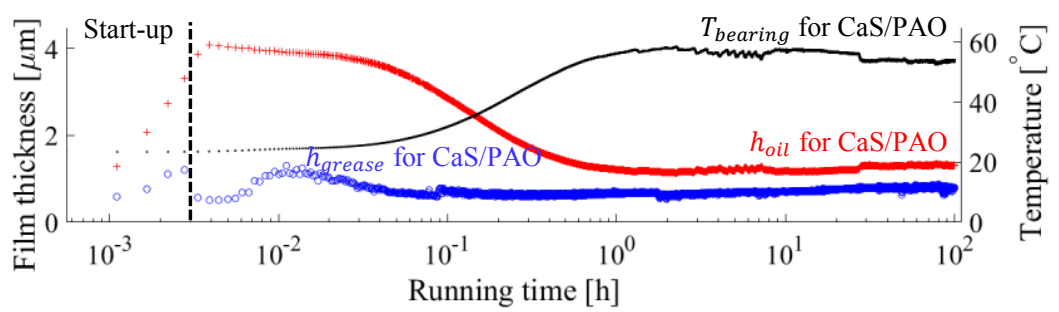

(a)

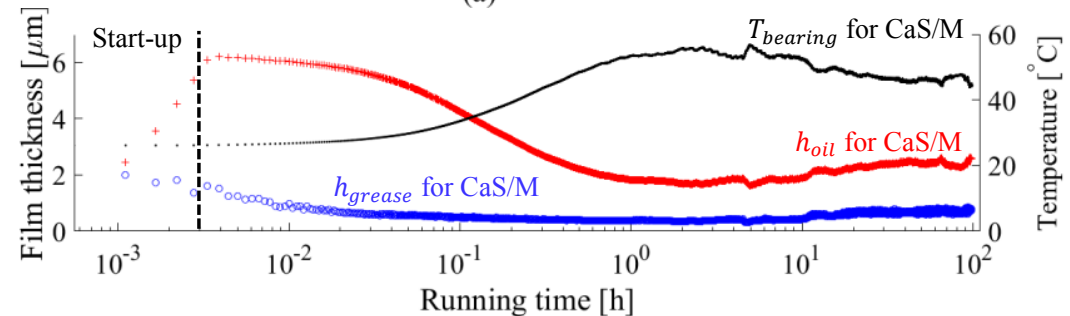

(b)

Figure 24 Film thickness profile of (a) $\mathrm{CaS} / \mathrm{PAO}$; (b) $\mathrm{CaS} / \mathrm{M}$

More information on the grease film thickness inside the bearing can be found in Paper C.

\section{Conclusions and recommendations}

\subsection{Conclusions}

This thesis focuses on the influence of shear, temperature and (for $\mathrm{CaS}$ ) water on the degradation of different greases and their lubricating performance. Fresh lubricating greases with different thickening agents and base oils were aged under controlled shear conditions using a rig with controlled shear and a grease worker. In addition, the grease film thickness in a deep groove ball bearing was measured and studied for different greases. The main results are summarized below.

For greases with a fibre-like thickener micro-structure, such as, lithium-thickened, lithium complex-thickened and polyurea-thickened grease, softening was observed. This is attributed to the change of the thickener micro-structure during the ageing procedure. The softening behaviour was studied from an energetic point of view. An 'Ageing Master Curve' was developed, where the change of the grease rheological properties is described as a function of input ageing energy, including shear rate and temperature. This 'Ageing Master Curve' was validated by ageing greases inside a scaled grease worker. Finally, this 'Ageing Master Curve' was applied to describe grease ageing inside rolling bearings using an R0F+ 
test rig. It was shown that this concept can potentially be used as a method for predicting the (remaining) grease life.

Unlike lithium, lithium complex and polyurea grease, calcium sulphonate complex grease has a particle-like thickener micro-structure. This type of grease shows good shear stability. According to the AFM results, the size and geometry of the thickener particles do not change during the ageing process. Also, a high temperature does not change the CaS grease yield stress. Therefore, the 'Ageing Master Curve' is not applicable.

Water ingress will stiffen calcium sulphonate complex grease and no free water is observed during the prolonged ageing. This is because of the formation of small and homogeneous water/thickener micelles under continuous shear, which increases the thickener particle volume fraction and increases the yield stress. This can explain why calcium sulphonate complex grease has an excellent water absorption capability.

To relate the ageing characteristics to grease performance, the grease film thickness was measured in an axial load deep groove ball bearing for greases with different microstructure and base oils during 100 hours using the electric capacitance method. The measurements showed that the grease film thickness is not constant in time. Right after starting up, a thick film will be constructed, because there is sufficient grease in the contact inlet and the bulk grease is building up the film directly. Next, the film thickness decays rapidly due to the rising temperature caused by churning and starvation due to grease channelling. In the meantime, the grease reservoir will start releasing oil to feed the contact area. For the shear sensitive greases, shear degradation plays an important role in the film thickness build-up process. Due to the breakage of the thickener network, the grease becomes softer and will bleed more oil, which enhances the lubricant feed to the contacts. Additionally, the generated small thickener fragments easily become trapped in the contact area further contributing to the thickness of the film. Therefore, a considerable film thickness recovery is observed. However, shear softening also results in more leakage. It is expected that during prolonged running (i.e. much longer than the current 100 hours), the grease film thickness will decrease again caused by the loss of grease and bled oil. By contrast, a calcium sulphonate complex grease has a relatively low oil bleed at the low running temperatures currently used. In addition, it is a shear stable grease, so shear does not change 
the grease properties. Therefore, for bearings lubricated by the calcium sulphonate complex greases, no film thickness recovery was found and starvation persists throughout the 100hour running test.

\subsection{Recommendations for further work}

It was shown that the 'Ageing Master Curve' for describing/predicting the mechanical ageing of grease with a fibre-like thickener structure (potentially) describes the mechanical ageing of grease in bearings. Although this is promising, more work is needed to support this concept. This includes more tests and an improvement of the relation between imposed energy $E$ and the bearing running conditions.

The results showed that calcium sulphonate complex grease has excellent water-absorbing capabilities even under pro-longed shear. This is a favourable property because it will prevent the formation of free water and therefore corrosion in a bearing. However, it was found earlier that this emulsified water will restrict grease bleed (99), which is an unfavourable property. Therefore, it is recommended to study the wet grease lubrication performance, for instance by measuring the film thickness of water-contaminated greases using the bearing test rig that was used in this thesis. Previously, this was performed for short periods of time (100 hours). Since the grease film thickness has been found not constant with time and closely related to the grease bleed and degradation, prolonged tests (e.g. 100 hours or more) are suggested.

As for the grease film thickness in a bearing, the current work shows that shear degradation will reduce starvation. However, a running time of 100 hours is only a fraction of the bearing service life. The current hypothesis is that the film thickness will drop again due to leakage and loss of lubricant. To verify this, it is recommended to run film thickness measurements for very long times. 


\section{Bibliography}

(1) Lugt PM. Grease lubrication in rolling bearings. The Atrium, Southern Gate, Chichester, West Sussex, PO19 8SQ, United Kingdom: John Wiley and Sons; 2013.

(2) Lugt PM. A review on grease lubrication in rolling bearings. Tribology Transaction 2009;52(4):470-480.

(3) Damiens B, Lubrecht A, Cann P. Influence of cage clearance on bearing lubrication. Tribology Transaction 2004;47(1):2-6.

(4) Cen H, Lugt PM, Morales-Espejel G. On the film thickness of grease- lubricated contacts at low speeds. Tribology Transaction 2014;57(4):668-678.

(5) Ito H, Tomaru M, Suzuki T. Physical and chemical aspects of grease deterioration in sealed ball bearings. Lubrication Engineering (STLE) 1988;44(10):872-879.

(6) Rezasoltani A, Khonsari M. On monitoring physical and chemical degradation and life estimation models for lubricating greases. Lubricants 2016;4(3):34.

(7) Cann P. Grease degradation in a bearing simulation device. Tribology International 2006;39(12):1698-1706.

(8) Rezasoltani A, Khonsari MM. On the correlation between mechanical degradation of lubricating grease and entropy. Tribology Letters 2014;56(2):197-204.

(9) Lundberg J, Höglund E. A new method for determining the mechanical stability of lubricating greases. Tribology International 2000;33(3):217-223.

(10) Moore RJ, Cravath AM. Mechanical breakdown of soap-base greases. Industrial \& Engineering Chemistry 1951;43(12):2892-2897.

(11) Plint M, Alliston-Greiner A. A new grease viscometer: a study of the influence of shear on the properties of greases. NLGI spokesman 1992;56(2):7-15.

(12) Rezasoltani A, Khonsari M. An engineering model to estimate consistency reduction of lubricating grease subjected to mechanical degradation under shear. Tribology International 2016;103:465-474.

(13) Salomonsson L, Stang G, Zhmud B. Oil/ thickener interactions and rheology of lubricating greases. Tribology Transaction 2007;50(3):302-309.

(14) Renshaw TA. Effects of shear on lithium greases and their soap phase. Industrial \& Engineering Chemistry 1955;47(4):834-838.

(15) Mas R, Magnin A. Rheological and physical studies of lubricating greases before and after use in bearings. Journal of Tribology 1996;118(3):681-686.

(16) Fish G, Ward W. Calcium Sulfonate Grease Formulation. 2012.

(17) Bondi A, Cravath AM, Moore RJ, Peterson WH. Basic factors determining the structure and rheology of lubricating grease. The Institute Spokesman 1950;13(12):12-18. 
(18) Sanchez MC, Franco J, Valencia C, Gallegos C, Urquiola F, Urchegui R. Atomic force microscopy and thermo-rheological characterization of lubricating greases. Tribology Letters 2011;41(2):463-470.

(19) Yoshiyuki S, Yusuke N, Yusuke I, Hiroki S, Yukitoshi F. Characterization of nano size thickener fiber in grease by SAXS. World Tribology Congress; 2013.

(20) Cen H, Lugt PM, Morales-Espejel G. Film thickness of mechanically worked lubricating grease at very low speeds. Tribology Transaction 2014;57(6):1066-1071.

(21) Hamrock BJ, Dowson D. Elastohydrodynamic lubrication of elliptical contacts for materials of low elastic modulus. I: fully flooded conjunction. ASME Journal of Lubrication Technology 1978;100(2):236-245.

(22) Mérieux J, Hurley S, Lubrecht A, Cann P. Shear-degradation of grease and base oil availability in starved EHL lubrication. Tribology Series 2000;38:581-588.

(23) Wilson A. The relative thickness of grease and oil films in rolling bearings. Proceedings of the Institution of Mechanical Engineers 1979;193(1):185-192.

(24) Muennich H, Gloeckner H. Elastohydrodynamic lubrication of grease-lubricated rolling bearings. ASLE Transactions 1980;23(1):45-52.

(25) Yang Z. A study of grease film thickness in elastohydrodynamic rolling point contacts. I. Mech. E. Conference Publication, 1987; ; (1):97.

(26) Jonkisz W, Krzemiński-Freda H. Pressure distribution and shape of an elastohydrodynamic grease film. Wear 1979;55(1):81-89.

(27) Kauzlarich JJ, Greenwood J. Elastohydrodynamic lubrication with Herschel-Bulkley model greases. ASLE Transactions 1972;15(4):269-277.

(28) Dong D, Qian X. A theory of elastohydrodynamic grease-lubricated line contact based on a refined rheological model. Tribology International 1988;21(5):261-267.

(29) Damiens B, Venner CH, Cann P, Lubrecht A. Starved lubrication of elliptical EHD contacts. Journal of tribology 2004;126(1):105-111.

(30) Van Zoelen M, Venner CH, Lugt PM. Prediction of film thickness decay in starved elasto-hydrodynamically lubricated contacts using a thin layer flow model. Proceedings of the Institution of Mechanical Engineers, Part J: Journal of Engineering Tribology 2009;223(3):541-552.

(31) Cyriac F, Lugt PM, Bosman R, Padberg C, Venner C. Effect of thickener particle geometry and concentration on the grease EHL film thickness at medium speeds. Tribology Letters 2016;61(2):1-13.

(32) Cann P. Starvation and reflow in a grease-lubricated elastohydrodynamic contact. Tribology Transaction 1996;39(3):698-704.

(33) Cann P, Spikes H. Film thickness measurements of lubricating greases under normally starved conditions. NLGI spokesman 1992;56(2):21-27. 
(34) Wen SZ, Ying TN. A theoretical and experimental study of EHL lubricated with grease. Journal of Tribology 1988;110(1):38-43.

(35) Cann P, Lubrecht A. An analysis of the mechanisms of grease lubrication in rolling element bearings. Lubrication Science 1999;11(3):227-245.

(36) Cann P, Lubrecht A. The effect of transient loading on contact replenishment with lubricating greases. Tribology Series: Elsevier; 2003. p. 745-750.

(37) Wikström V, Jacobson B. Loss of lubricant from oil-lubricated near-starved spherical roller bearings. Proceedings of the Institution of Mechanical Engineers, Part J: Journal of Engineering Tribology 1997;211(1):51-66.

(38) Cousseau T, Graça B, Campos A, Seabra J. Grease aging effects on film formation under fully-flooded and starved lubrication. Lubricants 2015;3(2):197-221.

(39) Cann P, Lubrecht A. Bearing performance limits with grease lubrication. World Tribology Congress III: American Society of Mechanical Engineers; 2005.

(40) Kaneta M, Ogata T, Takubo Y, Naka M. Effects of a thickener structure on grease elastohydrodynamic lubrication films. Proceedings of the Institution of Mechanical Engineers, Part J: Journal of Engineering Tribology. 2000;214:327-336.

(41) Cyriac F, Lugt PM, Bosman R. Impact of water on the rheology of lubricating greases. Tribology Transaction 2016;59(4):679-689.

(42) Spiegel K, Fricke J, Meis K. Die Fließeigenschaften von Schmierfetten in Abhängigkeit von Beanspruchung, Beanspruchungsdauer und Temperatur. International Colloquium Tribology, Esslingen, Germany 2000.

(43) Czamy R. Einfluss der Thixotropie auf die Rheologischen Eigenschaften der Schmierfette. Tribologie und Schmierungstechnik 1989;36(3):134-140.

(44) Booser E. Grease life forecast for ball-bearings. Lubrication Engineering 1974;30(11):536-541.

(45) Kuhn E. Energetical model for friction and degradation process of lubricating greases. World Tribology Congress, Wien; 2001.

(46) Kuhn E. Analysis of a grease-lubricated contact from an energy point of view. International Journal of Materials and Product Technology 2010;38(1):5-15.

(47) Cann P, Webster MN, Doner JP, Wikstrom V, Lugt PM. Grease degradation in R0F bearing tests. Tribology Transaction 2007;50(2):187-197.

(48) Cann P, Doner JP, Webster MN, Wikstrom V. Grease degradation in rolling element bearings. Tribology Transaction 2001;44(3):399-404.

(49) Hosoya S, Hayano M. Deterioration of lithium soap greases and functional life in ball bearings. NLGI spokesman 1989;53(6):246-251. 
(50) Dykas B, Krantz T, Berger G, Street KW, Morales W. Grease degradation in critical helicopter drivetrain bearings. Proceedings of the STLE/ASME International Joint Tribology Conference; 2010.

(51) Paszkowski M. Assessment of the effect of temperature, shear rate and thickener content on the thixotropy of lithium lubricating greases. Proceedings of the Institution of Mechanical Engineers, Part J: Journal of Engineering Tribology 2013;227(3):209-219.

(52) Czarny R. The influence of surface material and topography on the wall effect of grease. Lubrication Science 2002;14(2):255-274.

(53) Paszkowski M. Identification of the thixotropy of lithium greases. 16th International Colloquium Tribology; 2008.

(54) Cyriac F, Lugt PM, Bosman R. On a new method to determine the yield stress in lubricating grease. Tribology Transaction 2015;58(6):1021-1030.

(55) Couronne I, Vergne P. Rheological behavior of greases: part II-effect of thermal aging, correlation with physico-chemical changes. Tribology Transaction 2000;43(4):788794.

(56) Huang L, Guo D, Cann P, Wan GT, Wen S. Thermal oxidation mechanism of polyalphaolefin greases with lithium soap and diurea thickeners: effects of the thickener. Tribology Transaction 2016;59(5):801-809.

(57) Cross MM. Rheology of non- Newtonian fluids: A new flow equation for pseudoplastic systems. Journal of Colloid Science 1965;20(5):417-437.

(58) Hurley S, Cann P. Examination of grease structure by SEM and AFM techniques. NLGI Spokesman 2001;65(5):17-26.

(59) Paszkowski M, Olsztyńska-Janus S. Grease thixotropy: Evaluation of grease microstructure change due to shear and relaxation. Industrial Lubrication and Tribology 2014;66(2):223-237.

(60) Delgado MA, Franco JM, Valencia C, Kuhn E, Gallegos C. Transient shear flow of model lithium lubricating greases. Mechanics of Time-Dependent Materials 2009;13(1):6380 .

(61) Hokao M, Inami N, Watabe E, Yokouchi A, Sugimura J. A study of the structure formed by thickeners of greases using atomic force microscope. Tribology Online 2013;8(1):76-82.

(62) Shuff PJ, Clarke LJ. Structure of grease via electron microscopy and image analysis. Lubrication Science 1991;4(1):35-50.

(63) Hermansson, Mathias H. Structure and interactions in lubricating greases. 1998.

(64) Kawamura T, Minami M, Hirata M. Grease life prediction for sealed ball bearings. Tribology Transaction 2001;44(2):256-262. 
(65) Lugt PM, Kommer A, Lindgren H, Deinhofer L. The ROF methodology for grease life testing. NLGI Spokesman 2013;77(1):18-27.

(66) SKF group. SKF rolling bearings catalogue. 2016.

(67) Hsu SM, Gates RS. Boundary lubricating films: formation and lubrication mechanism. Tribology International 2005;38(3):305-312.

(68) Zheleznyi L, Bogaichuk A, Kobylyanskii E, Mishchuk O. Antiwear properties of hightemperature greases. Chemistry and Technology of Fuels and Oils 2007;43(6):488-494.

(69) Liu D, Zhang M, Zhao G, Wang X. Tribological behavior of amorphous and crystalline overbased calcium sulfonate as additives in lithium complex grease. Tribology Letters 2012;45(2):265-273.

(70) Giasson S, Espinat D, Palermo T. Study of microstructural transformation of overbased calcium sulphonates during friction. Lubrication Science 1993;5(2):91-111.

(71) Ward B. Understanding calcium sulfonate thickeners. 2006; Available at: http://www.machinerylubrication.com/Articles/Print/909. Accessed 11/6, 2014.

(72) Haiyan W. Manufacture and performance of Calcium sulfonate complex grease, in Chinese. Master Thesis, Shandong University. 2007.

(73) Authier D, Herman A. Calcium sulfonate carbonate greases: a solution to water resistance. Eurogrease (3), S 2013:19-35.

(74) Liu D, Zhao G, Wang X. Tribological performance of lubricating greases based on calcium carbonate polymorphs under the boundary lubrication condition. Tribology Letters 2012;47(2):183-194.

(75) Saatchi A, Shiller PJ, Eghtesadi SA, Liu T, Doll GL. A fundamental study of oil release mechanism in soap and non-soap thickened greases. Tribology International 2017;110:333-340.

(76) Muir RJ. High performance calcium sulfonate complex lubricating grease. NLGI spokesman 1988;52(4):140-146.

(77) Mackwood W. Calcium sulfonate complex greases. Tribology \& lubrication technology Oct. 2016:28-40.

(78) Kumar A, Humphreys S, Mallory B. Overbased calcium sulfonate greases for extreme environment. Greasetech India 2012;XIV(3):5-12.

(79) Cyriac F, Lugt PM, Bosman R, Venner CH. Impact of water on EHL film thickness of lubricating greases in rolling point contacts. Tribology letters 2016;61(3):23.

(80) Leckner, J. Water+Grease = fatal attraction? 25th ELGI Annual General Meeting Amsterdam, The Netherlands; 2013.

(81) Bosman R, Lugt PM. The microstructure of calcium sulfonate complex lubricating grease and its change in the presence of water. Tribology Transaction 2018:1-8. 
(82) Fish G. Calcium sulphonate greases. Performance and application overview. . Lubrisense white paper 2014;16.

(83) Divoux T, Fardin MA, Manneville S, Lerouge S. Shear banding of complex fluids. Annual Review of Fluid Mechanics 2016;48:81-103.

(84) Genovese DB. Shear rheology of hard- sphere, dispersed, and aggregated suspensions, and filler- matrix composites. Advances in Colloid and Interface Science 2012;171-172:116.

(85) Ohno N, Tanimoto K, Kuwano N, Hirano F. Effect of the base oil viscosity of lithium soap greases on life of thrust ball bearings. Japanese Journal of Tribology 1998;43(12):1545-1556.

(86) Zaretsky EV. STLE life factors for rolling bearings. STLE Special Publication 1992.

(87) Ward P, Leveille A, Frantz P. Measuring the EHD film thickness in a rotating ball bearing. 39th Aerospace Mechanisms Symposium; 2008.

(88) Hurley S. Starved lubrication of EHL contacts : relationship to bulk grease properties. NLGI Spokesman 2000;64(2):15.

(89) Lugt PM, Velickov S, Tripp JH. On the chaotic behavior of grease lubrication in rolling bearings. Tribology Transaction 2009;52(5):581-590.

(90) Cann P, Lubrecht A. Bearing performance limits with grease lubrication: the interaction of bearing design, operating conditions and grease properties. Journal of Physics D: Applied Physics 2007;40(18):5446.

(91) P. Baart. Grease lubrication mechanisms in bearing seals. Doctoral Thesis, Luleå Tekniska Universitet; 2011.

(92) Noordover A, David S, Fiddelaers F, Van Den Kommer A, Grease test kit and methods of testing grease. 2016.

(93) Van Leeuwen H. The determination of the pressure-viscosity coefficient of a lubricant through an accurate film thickness formula and accurate film thickness measurements. Proceedings of the Institution of Mechanical Engineers, Part J: Journal of Engineering Tribology 2009;223(8):1143-1163.

(94) E. J. H. Heijdens. Online measurement of the frictional moment in rolling element bearings. Master Thesis, Faculty of Engineering Technology, University of Twente; 2015.

(95) Heemskerk R, Vermeiren K, Dolfsma H. Measurement of lubrication condition in rolling element bearings. ASLE Transactions 1982;25(4):519-527.

(96) Storken J, Ippel H, Girardin-Humbert C. Lubcheck Mk3 user manual. SKF Engineering \& Research Centre BV, Nievwegein 1997.

(97) Franke E, Poll G. Service life and lubrication conditions of different grease types in high-speed rolling bearings. Tribology Series 1999;36:601-609. 
(98) Jablonka K, Glovnea R, Bongaerts J. Quantitative measurements of film thickness in a radially loaded deep-groove ball bearing. Tribology International 2018;119:239-249.

(99) Hudedagaddi CB, Raghav AG, Tortora AM, Veeregowda DH. Water molecules influence the lubricity of greases and fuel. Wear 2017;376:831-835.

(100) Cyriac F. On rheology, film-build-up and water in grease lubricated bearings. Doctoral Thesis, Faculty of Engineering Technology, University of Twente; 2016. 

Part II 
Paper A 


\section{A model for shear degradation of lithium soap grease at ambient temperature}

Yuxin Zhou ${ }^{1}$, Rob Bosman ${ }^{1}$ and Piet M. Lugt ${ }^{1,2}$

${ }^{1}$ University of Twente, Enschede, The Netherlands

${ }^{2}$ SKF Engineering \& Research Centre, Nieuwegein, The Netherlands

\section{List of symbols}

\begin{tabular}{|c|c|}
\hline$f$ & Frequency for the oscillatory test $(\mathrm{Hz})$ \\
\hline $\bar{F}$ & Average load per stroke inside the grease worker $(N)$ \\
\hline $\mathrm{G}^{\prime}$ & Storage modulus $(\mathrm{Pa})$ \\
\hline $\mathrm{G}^{\prime \prime}$ & Loss modulus $(\mathrm{Pa})$ \\
\hline$h$ & Gap height of the ageing machine $(m)$ \\
\hline K & Coefficient of degradation (-) \\
\hline$L$ & Average thickener fibre length $(\mu m)$ \\
\hline$L_{\text {piston }}$ & Piston displacement for one full stroke of the grease worker $(\mathrm{m})$ \\
\hline$m$ & Degradation exponent (-) \\
\hline$R^{2}$ & Goodness value of the fitting (-) \\
\hline$R_{a}$ & Surface roughness of the measuring plates (Centre Line Average, $\mu m$ ) \\
\hline$R_{i}$ & Radius of the rotating bob $(m)$ \\
\hline$R_{o}$ & Radius of the stable housing case $(m)$ \\
\hline$S_{g}$ & Generated entropy per unit volume during ageing $\left(\mathrm{J} / \mathrm{mm}^{3} \mathrm{~K}\right)$ \\
\hline$\dot{S_{g}}$ & Entropy generation rate per unit volume during ageing $\left(\mathrm{J} / \mathrm{mm}^{3} \mathrm{Ks}\right)$ \\
\hline$S_{g w}$ & Generated entropy per unit volume inside the grease worker $\left(\mathrm{J} / \mathrm{mm}^{3} \mathrm{~K}\right)$ \\
\hline$S_{p s}$ & Generated entropy per unit volume during pre-shear $\left(\mathrm{J} / \mathrm{mm}^{3} \mathrm{~K}\right)$ \\
\hline$T_{g w}$ & Ambient temperature of the grease worker $(K)$ \\
\hline$T_{p s}$ & Temperature during pre-shear $(K)$ \\
\hline$V_{a}$ & Grease volume inside the Couette ageing rig $\left(\mathrm{mm}^{3}\right)$ \\
\hline$V_{g w}$ & Grease volume inside the grease worker $\left(\mathrm{mm}^{3}\right)$ \\
\hline$W_{g w}$ & Work applied inside the grease worker $(J)$ \\
\hline$Y_{i}$ & Initial rheological value for fresh grease \\
\hline
\end{tabular}




\begin{tabular}{|c|l|}
\hline$Y_{\infty}$ & Second stage rheological value after infinitely long ageing \\
\hline$\dot{\gamma}_{a}$ & Ageing shear rate $\left(\mathrm{s}^{-1}\right)$ \\
\hline$\dot{\gamma}_{p s}$ & Shear rate for pre-shear $\left(\mathrm{s}^{-1}\right)$ \\
\hline$\Delta$ & Cone penetration depth $(0.1 \mathrm{~mm})$ \\
\hline$\eta_{0}$ & Zero shear rate viscosity $(\mathrm{Pa} \cdot \mathrm{s})$ \\
\hline$\eta_{b}$ & Base oil viscosity $(\mathrm{Pa} \cdot \mathrm{s})$ \\
\hline$\eta_{i}$ & Initial zero-shear-viscosity for fresh grease $(\mathrm{Pa} \cdot \mathrm{s})$ \\
\hline$\eta_{\infty}$ & Grease viscosity after infinitely long ageing $(\mathrm{Pa} \cdot \mathrm{s})$ \\
\hline$\eta_{\dot{\gamma}_{a}}$ & Grease viscosity at the ageing shear rate $\dot{\gamma}_{a}(\mathrm{~Pa} \cdot s)$ \\
\hline$\tau$ & Shear stress within the ageing gap $(\mathrm{Pa})$ \\
\hline$\tau_{c}$ & Cross-over stress $(\mathrm{Pa})$ \\
\hline$\tau_{p s}$ & Shear stress during pre-shear $(\mathrm{Pa})$ \\
\hline$\tau_{y-O S C}$ & Yield stress obtained from the oscillatory strain sweep test $(\mathrm{Pa})$ \\
\hline$\tau_{y-H B}$ & Yield stress obtained from the Herschel-Bulkley model $(\mathrm{Pa})$ \\
\hline$\varphi$ & Thickener volume fraction $(-)$ \\
\hline$\omega$ & Rotational speed of the ageing machine $(\mathrm{rad} / \mathrm{s})$ \\
\hline
\end{tabular}

\begin{abstract}
In this paper the shear degradation of lithium 12-hydroxy stearate grease will be measured using a housemade Couette ageing machine. In this device the shear rate is well defined. The ageing is related to the generated entropy density as described in Rezasoltani and Khonsari's work (1). The rheological properties of the aged samples were evaluated using a parallel-plate rheometer. The results showed that there are two ageing phases with different degradation rates: a progressive degradation phase at the early stage, followed by a rather slow deterioration afterwards. Based on this observation, an ageing equation was formulated to describe the ageing behaviour of lithium thickened grease. Atomic force microscopy results of the fresh and aged greases showed that the variation of the thickener micro-structure provides a good explanation of the lithium grease degradation mechanism: under shear, the original fibrous network is progressively destroyed and becomes fragmented, leading to the loss of consistency and change of the rheological properties.
\end{abstract}




\section{Keywords}

\section{Grease degradation; Rheology; Micro-structure}

\section{Introduction}

Grease is a widely applied lubricant mostly used in rolling bearings. It is a multi-phase system consisting of three parts: thickener (3-30\%), base oil (70-90\%) and additives (2). As a semi-solid material, grease has a high consistency, which prevents leakage and creates a 'reservoir' of lubricant inside the bearing. However, when subjected to the severe conditions within a rolling bearing, grease will undergo high shear possibly causing deterioration. The degradation of this grease is usually reflected by the loss of its original consistency (softening), possibly yielding leakage from the bearing and hence, starvation. It may also lead to continuous churning and high temperature. Both cases result in a reduced life of the bearing (2). It is therefore valuable to investigate the mechanism of grease degradation and to develop predictive models for this.

Generally, the degradation of grease is classified as chemical or mechanical ageing. This paper focuses on the mechanical ageing of lithium 12-hydroxystearate thickened grease. This type of grease takes the major share of the worldwide industrial grease market and is widely applied in rolling bearings due to its wide temperature applicability, relatively good mechanical stability, water resistant properties and low cost (2).

The most straightforward way to study grease ageing is to obtain data from field tests directly, where the grease is worked in a real bearing (3). Such field practice requires a long time-scale study. For example, in the work of Lundberg and Höglund (4), aged samples were collected from the wheel bearings of railway waggons after years of service. Another drawback of this method is the fact that it is practically impossible to estimate the exact ageing conditions, i.e., the shear stress/rate, temperature and time, to which the sample was subjected during operation.

Currently, there are two standards for measuring grease degradation. One is the mechanical stability test where normal load and shear are applied, this is considered particularly meaningful in the situation where the bearing is subjected to vibrations and where the grease is continuously thrown back into the tracks. A typical mechanical stability test rig is 
the roll stability test (ASTM D 1831), where grease is sheared between a heavy roller (with a lead core) and a hollow rotating cylinder at an elevated temperature (generally $80{ }^{\circ} \mathrm{C}$ ). It was found that this test can be used to simulate the practical working conditions in automobile wheel bearings $(5,6)$, and rolling bearings in railway waggons $(7,8)$. The other test is the shear stability test, where only shear is applied. This is considered important for bearing running under relatively stable working conditions. When subjected to continuous shear, it is observed that the shear degradation of the grease results in the release of oil and thus provides the lubricant replenishment $(9,10)$. In the 'grease worker' (ASTM D 217), which consists of a closed cylinder and a piston plate with a number of holes, the grease is sheared through the holes during a well-defined number of strokes (usually 10000 or 100 000 strokes).

The drawback of the two ASTM ageing methods mentioned above is that the applied shear condition is not well defined, which makes it difficult to use these methods for the development of predictive ageing models. To measure ageing as a function of shear and time, a modified Couette rheometer was used in the shear measurements of grease by Paszkowski (11). Rezasoltani and Khonsari (1) made use of a parallel plate rheometer for the long-term shear tests of lithium thickened grease. Ageing in a rheometer provides a controlled ageing process, where the rheology can directly be measured as a function of time. However, the disadvantage of parallel plate configuration is that the shear field within the gap is not uniform, resulting in an inhomogeneous ageing condition. In addition, in the current rheological study, leakage was observed in the parallel plate geometry due to the centrifugal forces, and in the open Couette configuration due to the Weissenberg effect (12). Hence, at some point in time during ageing, the measurement will become inaccurate. Therefore, more robust test rigs are required.

Rezasoltani and Khonsari (1) discovered a linear relationship between the energy input and the grease properties during grease ageing tests using a parallel plate rheometer. They mentioned that this 'linear correlation remains valid regardless of the applied shear rate or the grease temperature'. This was verified using a journal bearing mounted between two rolling bearings to provide a uniform film along the circumference of the journal bearing (hence the journal bearing was not loaded) and a modified grease worker. The experimental data of the journal bearing test rig showed a slight deviation from the linear relation 
obtained from the rheological measurements at the end of their experiments, which was ascribed to grease separation from the journal and a slippage effect during the tests.

The aim of the current study is twofold: the first objective is to follow-up on the work of Rezasoltani and Khonsari (1). The influence of grease mechanical degradation on its shear stability will be evaluated at similar ageing condition using lithium thickened grease samples but with an increased ageing period, hence increasing the total amount of generated entropy. The second goal is to study the underlying mechanism responsible for the ageing of lithium grease.

To achieve the first task, fresh greases will be sheared in a house made Couette ageing machine at specific shear rates for a set period of time. After that the grease is sampled and its rheological properties measured. Even though lubricating grease can be considered chemically stable at low temperatures (13), Fourier Transform Infrared Spectroscopy (FTIR) measurements will be performed for the fresh and aged samples to confirm this. The physical processes occurring during the mechanical degradation will be studied by measuring the change in the micro-structure of the aged samples using Atomic Force Microscopy (AFM).

\section{Material and Method}

Two commercial lithium thickened greases $\mathrm{Li} / \mathrm{M}$ and $\mathrm{Li} / \mathrm{SS}$ were used. Some information on the composition is presented in Table 1 (14).

Table 1 Composition and properties of the greases studied

\begin{tabular}{|c|c|c|c|c|c|c|}
\hline Grease & NLGI & Thickener & $\begin{array}{c}\text { Volume } \\
\text { fraction of } \\
\text { the thickener } \\
\varphi\end{array}$ & $\begin{array}{c}\text { Shape \& } \\
\text { Average size } \\
\text { of thickener }\end{array}$ & Base oil & $\begin{array}{c}\text { Base oil } \\
\text { viscosity at } \\
25^{\circ} \mathrm{C} \eta_{b}\end{array}$ \\
\hline $\mathrm{Li} / \mathrm{M}$ & 3 & $\begin{array}{c}\text { Lithium 12- } \\
\text { hydroxy } \\
\text { stearate }\end{array}$ & $14 \%$ & $\begin{array}{c}\text { Twisted fibre } \\
L \approx 2 \mu m\end{array}$ & $\begin{array}{c}\text { Mineral } \\
\text { oil }\end{array}$ & $0.23 \mathrm{~Pa} \cdot s$ \\
\hline $\mathrm{Li} / \mathrm{SS}$ & 2 & $\begin{array}{c}\text { Lithium 12- } \\
\text { hydroxy } \\
\text { stearate }\end{array}$ & $16 \%$ & $\begin{array}{c}\text { Twisted fibre } \\
L \approx 2 \mu m\end{array}$ & $\begin{array}{c}\text { Semi- } \\
\text { synthetic }\end{array}$ & $0.07 \mathrm{~Pa} \cdot s$ \\
\hline
\end{tabular}




\section{Ageing Tests}

\section{Test Rig}

In the current study, the grease has been aged by means of applying specific shear rates for a set period, similar to what is done in a grease worker. However, other than in the grease worker, the shear rate is now well defined. Normal load (or hydrostatic pressure) will not be applied for now (so only the shear stability of the grease will be studied). Also, the grease should be aged in a closed system, where leakage is avoided. Another requirement for the new test rig is that a sufficient amount of aged grease can be collected for subsequent rheological tests.

The new test rig (called here 'Couette Ageing Test Rig') is shown in Figure 1. The basic concept is analogous to a cylindrical viscometer: the grease is to be sheared between a stationary housing case and a rotating bob, which is driven by a motor and a belt transmission. The shear rate exerted over the grease can thus be calculated based on the input rotational speed and the geometry of the ageing head. The temperature during the ageing procedure is captured by the thermo-couple at the end of the ageing head. To prevent grease leakage due to the Weissenberg effect, a lip seal is mounted on top of the ageing gap. The rig was designed for a volume of $V_{a}=5.0 \times 10^{4} \mathrm{~mm}^{3}$ for each ageing test (where $R_{i}=40 \mathrm{~mm}, R_{o}=42 \mathrm{~mm}, h=100 \mathrm{~mm}$, leaving a $2 \mathrm{~mm}$ gap between the rotating bob and the housing case). 


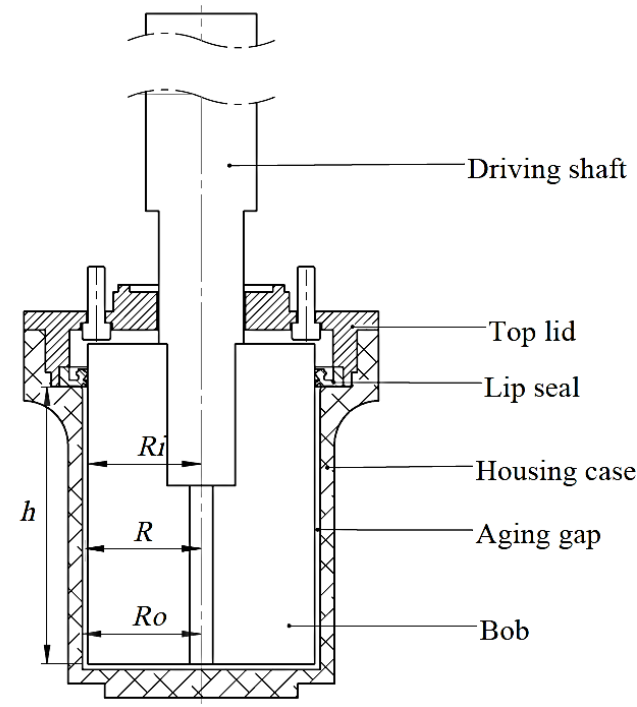

Figure 1 Couette ageing test rig

\section{Ageing Condition}

The ageing rotational speeds are selected such that the imposed shear rates are similar to those applied on the ageing tests performed by Rezasoltani and Khonsari (1). The input rotational speeds, the corresponding shear rates and the ageing periods are listed in Table 2.

Table 2 Ageing condition for $\mathrm{Li} / \mathrm{M}$ and $\mathrm{Li} / \mathrm{SS}$

\begin{tabular}{|c|c|c|c|c|c|c|}
\hline Rotational speed (rpm) & Shear rate $\dot{\gamma}_{a}\left(s^{-1}\right)$ & \multicolumn{5}{|c|}{ Ageing time $(\mathrm{h})$} \\
\hline 83 & 174 & 5 & 25 & 50 & 100 & 200 \\
\hline 125 & 261 & 5 & 25 & 50 & 100 & 200 \\
\hline 166 & 348 & 5 & 25 & 50 & 100 & 200 \\
\hline
\end{tabular}

\section{Sampling}

The lip seal (see Figure 1) generates a moderate amount of frictional heat, leading to a temperature gradient in the vertical direction. Together with possible thickener-oil separation due to shear, the thickener of the aged grease might no longer be evenly distributed inside the ageing gap. The aged samples were therefore mixed for 500 strokes in a house made grease worker before the rheological measurements were performed. 


\section{Rheological Measurements}

Rheological measurements were performed for the fresh and aged grease samples using a MCR 501 Anton-Paar rheometer with parallel plate configuration. The viscosity was measured by steady state flow curve measurements. In addition, oscillatory strain sweep measurements were performed to measure the grease visco-elastic properties.

\section{Preparation}

There are three major concerns during the rheological measurements: wall slip, loading history and edge effects. To reduce the influence of wall slip, measuring plates with rough surfaces are recommended $(15,16)$. Therefore, the plates were roughened by sand-blasting (top plate: $R_{a}=1.5 \mu \mathrm{m}$; bottom plate: $R_{a}=2.3 \mu \mathrm{m}$ ). To minimize the initial deviation induced by the placing and loading procedure, the grease samples were first deposited on the bottom plate, and the top plate was descended at a controlled speed, until the measure position was reached, leaving a $1 \mathrm{~mm}$ measuring gap. Thereafter, pre-shear following a DIN standard (17) was applied (pre-shear at $\dot{\gamma}_{p_{s}}=100 \mathrm{~s}^{-1}$ for $60 \mathrm{~s}$ at $25^{\circ} \mathrm{C}$ ). Subsequently, the accumulated grease at the plate periphery was carefully removed with a spatula. The loading and pre-shear procedure are illustrated in Figure 2.

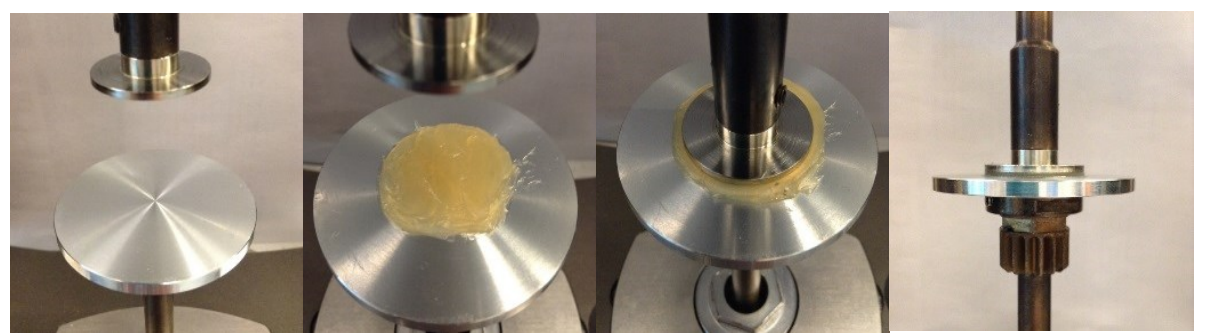

Plate geometry Deposit sample Load \& pre-shear sample Trim sample

Figure 2 Loading and pre-shear procedure

As a thixotropic material, regeneration of the thickener micro-structure occurs after shearing the grease $(16,18)$. Therefore, before data collection, sheared grease is left to rest for a sufficient 'relaxation time'. This duration will depend on the grease micro-structure, thickener concentration, pre-shear condition, etc. and can be determined by a Time Sweep Measurement. 
Here, the time dependency of the shear modulus was recorded while imposing an oscillatory shear well within the linear visco-elastic regime (the applied shear is sufficiently small to not disrupt the grease properties). The detailed procedure is as follows: after preshear, a two hours' oscillatory test was applied at a constant shear stress of $10 \mathrm{~Pa}$, oscillation frequency $f=1 \mathrm{~Hz}$ and temperature $25 \pm 1^{\circ} \mathrm{C}$. Both $\mathrm{Li} / \mathrm{M}$ and $\mathrm{Li} / \mathrm{SS}$ show a similar trend: the highest recovery of $G^{\prime}$ takes place at the first hour of relaxation and the value levels out afterwards, which is in agreement with the literature (18).

As a consequence, a relaxation time of 60 minutes was applied prior to the tests. The application of pre-shear and sufficient relaxation guarantees that the deviation for the following rheological results can be controlled within a $10 \%$ spread, which satisfies the requirements for grease rheological measurement specified in DIN 51810-2 (17).

\section{Flow Curve and Oscillatory Strain Sweep Measurement}

Once the sample was prepared following the procedure described above, the rheological tests were conducted. The flow curve measurement was performed at $25 \pm 1^{\circ} \mathrm{C}$, with the shear rate increasing from $10^{-8} s^{-1}$ up to $10^{2} s^{-1}$. The oscillatory strain sweep measurement was performed at $25 \pm 1^{\circ} \mathrm{C}$, at a frequency of $1 \mathrm{~Hz}$, with the shear strain sweeping from $10^{-3} \%$ to $10^{3} \%$. Each type of measurement was repeated at least twice. The repeatability of both flow curve and oscillatory strain sweep measurements was calculated based on the deviation from the average value of the duplicated test results, see Table 3 .

Table 3 Repeatability of the rheological measurements

\begin{tabular}{|c|c|c|}
\hline Deviation & Flow curve measurement & Oscillatory strain sweep \\
\hline $\mathrm{Li} / \mathrm{M}$ & $\pm 7.1 \%$ of the mean & $\pm 7.8 \%$ of the mean \\
\hline $\mathrm{Li} / \mathrm{SS}$ & $\pm 4.6 \%$ of the mean & $\pm 10 \%$ of the mean \\
\hline
\end{tabular}

\section{Data Process}

\section{Rheological Output}

Two representative results for both flow curve and oscillatory strain sweep measurements are presented in Figure 3. As shown in Figure 3-a, the flow curve measurement shows shear 
thinning of grease under continuously increasing shear. A zero-shear-viscosity $\eta_{0}=8.9 \times$ $10^{5} \mathrm{~Pa} \cdot s$ was obtained using the Cross model fit (19). In Figure 3-b, the storage modulus G', loss modulus G', and cross-over stress $\tau_{c}$ are obtained from the plot directly and the yield stress $\tau_{y-\text { OSC }}$ was calculated using the method described by Cyriac et al. (20).

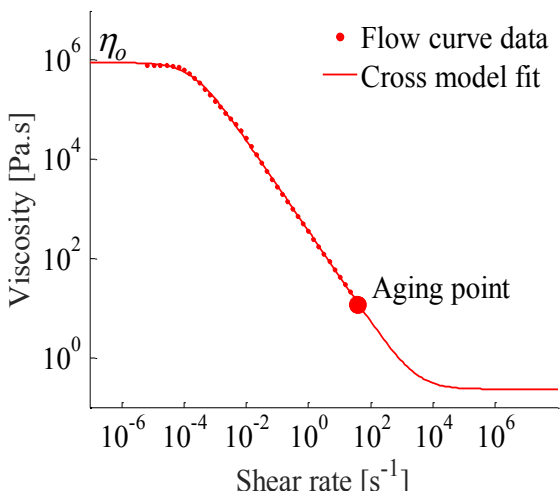

(a)

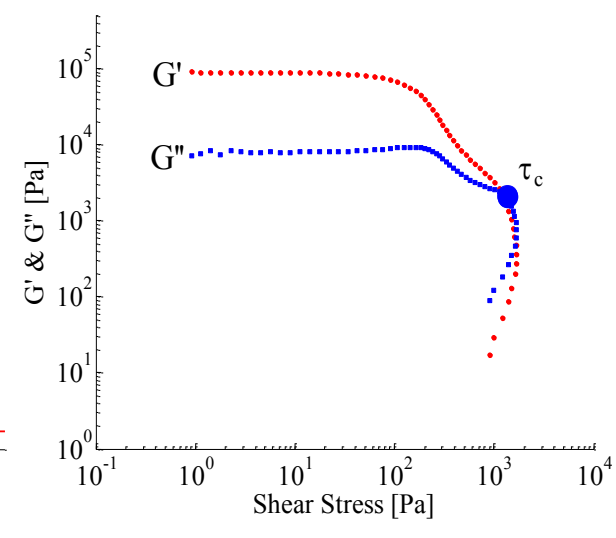

(b)

Figure 3 Typical rheological output obtained from an aged sample: (a) flow curve test; (b) oscillatory strain sweep test

\section{Entropy Generation Calculation}

The generated entropy per unit volume during ageing $\left(S_{g}\right)$ will be calculated based on the estimated frictional energy generated by the grease, recorded temperature during the ageing process, following the approach proposed by Rezasoltani and Khonsari (1).

If chemical reactions are neglected, the mechanical degradation of grease is such a slow process that 'the major portions of the system are in homogeneous states that change slowly enough with time' (21). In this case, the generated entropy is equal to the accumulated energy divided by the ageing temperature, which is produced through the absorption of heat (22).

The recorded temperature showed that during ageing, the variation of ageing temperature was smaller than $2^{\circ} \mathrm{C}$ and the change of the system's internal energy was negligible compared to the accumulated energy during ageing. Therefore, the accumulated energy is 
equal to the work exerted on the grease, i.e. the integration of the grease frictional torque and the rotational speed over the ageing time (21). The generated entropy per unit volume $S_{g}$ can thus be expressed as:

$$
S_{g}=\frac{\text { work } / V_{a}}{\text { Temperature }}=\frac{\int \text { Torque } \cdot \omega d t}{\text { Temperature } \times V_{a}}
$$

Here $\omega$ is the input rotational speed, $t$ is the ageing time, and $V_{a}$ is the grease volume inside the Couette ageing rig. In the current rig, the torque generated by the grease cannot be recorded directly and is calculated using the shear stress $\tau$ acting over the area $2 \pi R h$ at the distance $R$ from the central axis (23):

$$
\text { Torque }=2 \pi R h \tau \cdot R=2 \pi R^{2} h \tau=\left.2 \pi R^{2} h \dot{\gamma}_{a} \eta\right|_{\dot{\gamma}_{a}}
$$

Here $\dot{\gamma}_{a}$ is the applied shear rate presented in Table $2,\left.\eta\right|_{\dot{\gamma}_{a}}$ is the grease apparent viscosity at the ageing shear rate. The geometrical notations in equation ( 2 ) are shown in Figure 1. During the ageing process, the grease apparent viscosity is not constant. To obtain the viscosity at the ageing shear rate $\left(\left.\eta\right|_{\dot{\gamma}_{a}}\right)$, grease samples were collected after each ageing period. On these samples, flow curve measurements were performed, from which the $\left.\eta\right|_{\dot{\gamma}_{a}}$ was estimated from a Cross model fit. An example of this $\left.\eta\right|_{\dot{\gamma}_{a}}$ is displayed as 'Ageing point' in Figure 3-a.

In this way, the torque during the ageing process can be calculated periodically. As an illustration, Figure 4 shows an example of the torque distribution where Li/M was aged at $83 \mathrm{rpm}$ for 200 hours. The accumulated energy and the corresponding entropy generation density can be calculated by integrating the torque distribution over the ageing period using equation (1). 


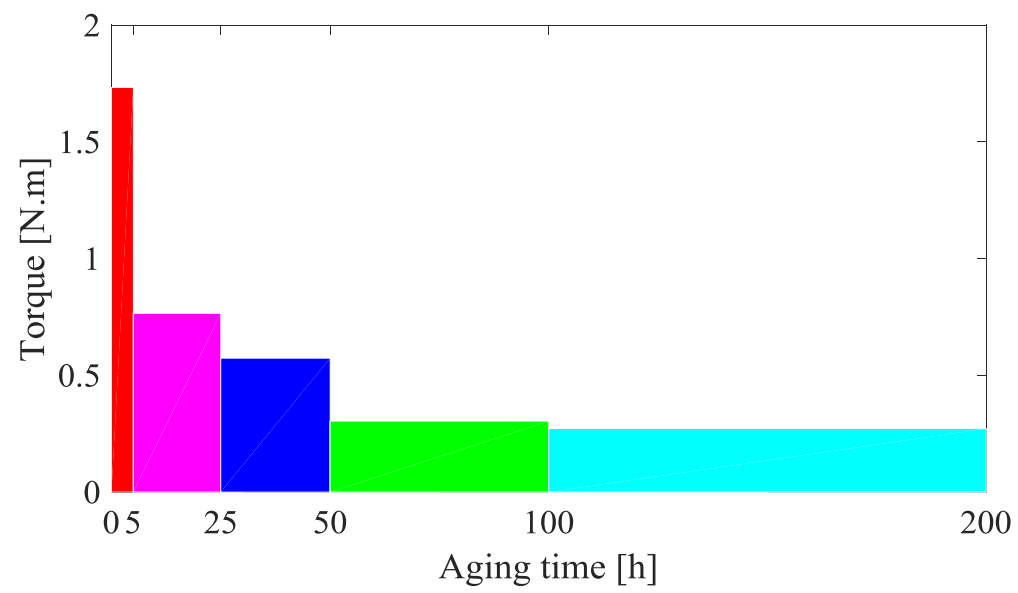

Figure 4 Calculated torque distribution for LiM aged at 83 rpm for 200 hours

The work and entropy induced by the 500 strokes mixture within the grease worker was calculated based on Rezasoltani and Khonsari's method (1): the entropy generated inside the grease worker is equal to the applied work $W_{g w}$ divided by the ambient temperature $T_{g w}$, where $W_{g w}$ is the product of the average load and the piston distance for one stroke, multiplied by the number of strokes (500).

The average load $\bar{F}$ for one stroke (both tension and compression) during the pre-shearing, recorded by a load cell mounted beneath the cylinder of the grease worker, was $\bar{F}=8.75 \mathrm{~N}$ for fresh $\mathrm{Li} / \mathrm{M}$ and $\bar{F}=6.20 \mathrm{~N}$ for fresh $\mathrm{Li} / \mathrm{SS}$. The piston displacement for one full stroke was measured as $L_{\text {piston }}=5.68 \times 10^{-2} \mathrm{~m}$. The volume of the grease sheared inside the cylinder was $V_{g w}=1.23 \times 10^{4} \mathrm{~mm}^{3}$ and the ambient temperature $T_{g w}=25^{\circ} \mathrm{C}=298 \mathrm{~K}$. The entropy generation per unit volume during the 500 strokes is thus calculated as:

$$
S_{g w}=\frac{W_{g w} / V_{g w}}{T_{g w}}=\frac{500 \bar{F} \cdot L_{\text {piston }}}{V_{g w} \cdot T_{g w}}
$$

For Li/M, $S_{g w}=6.8 \times 10^{-5} \mathrm{~J} / \mathrm{mm}^{3} \mathrm{~K}$; and for Li $/ \mathrm{SS}, S_{g w}=4.8 \times 10^{-5} \mathrm{~J} / \mathrm{mm}^{3} \mathrm{~K}$.

In addition, the pre-shear procedure before the rheological measurement also creates entropy. As specified in the 'Preparation' section, the grease sample will be pre-sheared at $\dot{\gamma}_{p s}=100 s^{-1}$ for $60 \mathrm{~s}$ at $25^{\circ} \mathrm{C}$. Based on the approach of Rezasoltani and Khonsari (1), 
the generated entropy density during the pre-shear procedure $S_{p s}$ within the rheometer can be expressed as:

$$
S_{p s}=\dot{\gamma}_{p s} \cdot \frac{\int \tau_{p s} d t}{T_{p s}}
$$

where $\dot{\gamma}_{p s}$ is the shear rate applied during pre-shear $\left(\dot{\gamma}_{p s}=100 s^{-1}\right), \tau_{p s}$ is the shear stress recorded during pre-shear, $t$ is time and $T_{p s}$ is the temperature during pre-shear (controlled at $\left.T_{p s}=25^{\circ} \mathrm{C}\right)$.

For fresh Li/M, $S_{p s}=1.0 \times 10^{-5} \mathrm{~J} / \mathrm{mm}^{3} \mathrm{~K}$; for fresh Li/SS, $S_{p s}=5.2 \times 10^{-5} \mathrm{~J} / \mathrm{mm}^{3} \mathrm{~K}$.

The generated entropy density during the sample preparation, i.e. $S_{g w}+S_{p s}$, is at least 100 times smaller than that generated during the ageing test and can therefore be neglected. For the following study, only the entropy density generated during the ageing tests $S_{g}$ will be taken into account.

\section{Ageing Mechanism Investigation}

The micro-structure of the grease thickener is studied using Atomic Force Microscopy (AFM) in dynamic tapping mode, which is widely applied on the soft biological samples (24) and greases $(25,26)$. The advantage of AFM over the conventional Scanning Electron Microscopy (SEM) and Transmission Electron Microscopy (TEM) is that the soap structure can be observed without the need to remove the oil $(27,28)$. In addition, the sample preparation is limited to smearing a small volume of grease on a flat glass plate.

\section{Results and Discussion}

\section{Verification of Chemical Reaction}

The FTIR spectra (limited wave number range of 4000-650 $\mathrm{cm}^{-1}$ ) of fresh and aged Li/M are presented in Figure 5. As an inhomogeneous material, grease thickener is not evenly distributed, resulting in the amplitude variation at zone $3500-3230 \mathrm{~cm}^{-1}$ (-OH bond); $1580 \mathrm{~cm}^{-1}\left(\mathrm{COO}^{-}\right.$asymmetric stretch) and $1459 \mathrm{~cm}^{-1}$ (-CH deformation), which indicates the difference of thickener concentration. However, no extra peaks are found between the fresh and aged samples' spectra, therefore, based on the detecting accuracy of 
the current FTIR device, chemical reactions are not observed during the ageing tests. A similar result was found for $\mathrm{Li} / \mathrm{SS}$. This was to be expected, since the maximum value of the recorded temperature during ageing was low for the lithium thickened greases $\left(52^{\circ} \mathrm{C}\right.$ for $\mathrm{Li} / \mathrm{M}$ and $48^{\circ} \mathrm{C}$ for $\mathrm{Li} / \mathrm{SS}$ ). Hence, the entropy calculation approach from Rezasoltani and Khonsari (1) can be applied (21).

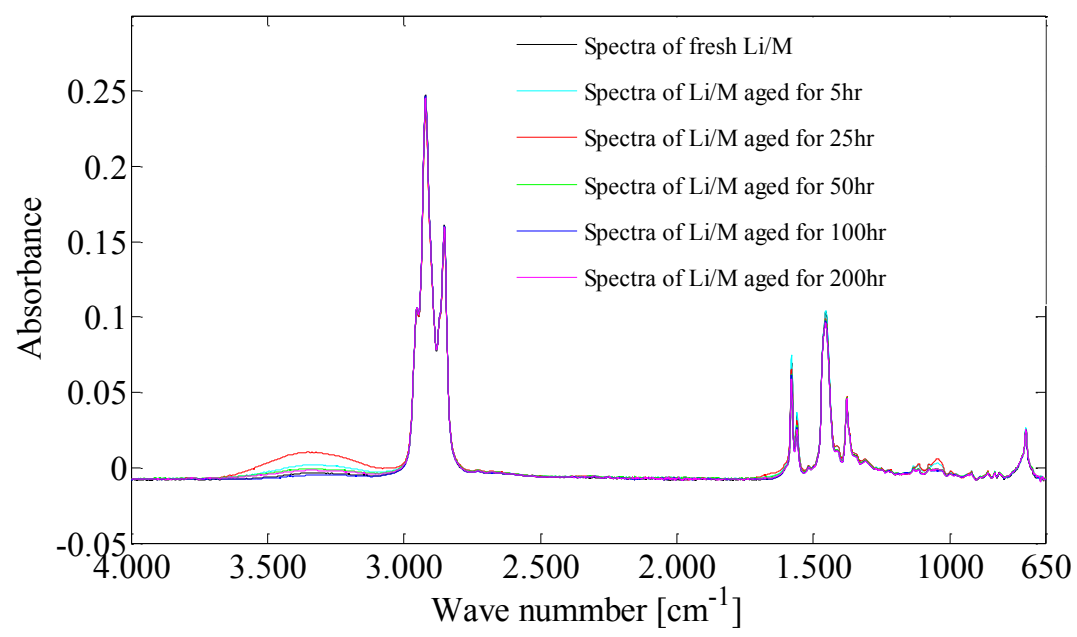

Figure 5 FTIR spectra of fresh and aged Li/M

\section{Thermodynamic Characterization of Grease Mechanical Degradation}

In this section, the results from ageing grease in the Couette ageing rig will be presented and compared to those found by Rezasoltani and Khonsari (1). As specified in the 'Methodology' section, we used the same shear rates and the same definition of entropy as Rezasoltani and Khonsari. However, they used the 'Net penetration value' as a response parameter, a measure for the consistency of a grease sample. To compare the current rheological values to Rezasoltani and Khonsari's results, a relationship between the penetration value and the yield stress was applied (29):

$$
\tau_{y-H B}=3 \times 10^{10} \cdot \Delta^{-3.17}
$$

where $\tau_{y-H B}$ is the yield stress obtained from the flow curve data based on HerschelBulkley model (29), and $\Delta$ is the cone penetration depth in $10^{-1} \mathrm{~mm}$. 
Rezasoltani and Khonsari did not use the standard ASTM method to measure the penetration depth. However, it is assumed that they scale similarly. As listed in Table 2, 15 samples were prepared and examined for each type of grease on ageing. The calculated penetration depth of $\mathrm{Li} / \mathrm{M}$ against generated entropy density is presented in Figure 6-b, together with the data rebuilt from the results of Rezasoltani and Khonsari (Figure 6-a).

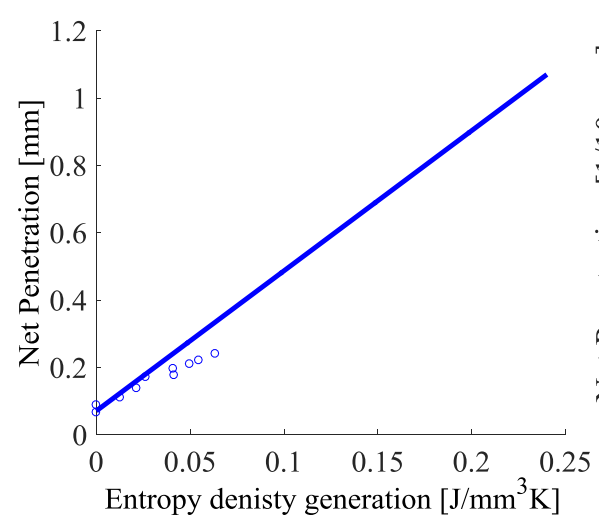

(a)

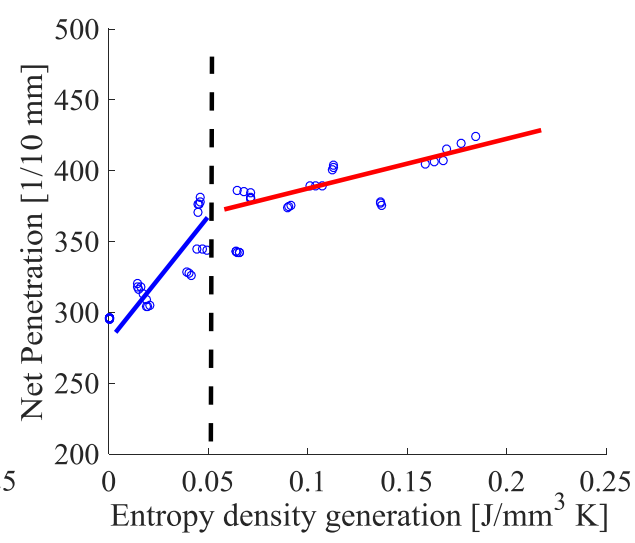

(b)

Figure 6 Comparison of penetration values against entropy density generation during the ageing process (a) Reproduced from literature (1); (b) Results from the current study (Li/M) In the present case (Figure 6-b), a linear relationship can be observed in the early stage of ageing process, i.e. $S_{g}<0.05 \mathrm{~J} / \mathrm{mm}^{3} \mathrm{~K}$. After this, the degradation behaviour changes. Again linear behaviour is observed, however, with a different slope. The results from Rezasoltani and Khonsari also show a deviation from the linear fit at higher values of entropy density. However, this was less pronounced. The ageing behaviour shown in Figure 6-b can be translated into a fast deterioration phase at the early stage, and a slower deterioration phase afterwards.

Figure 7 and Figure 8 show the variation of the zero-shear-viscosity with entropy generation per unit volume for $\mathrm{Li} / \mathrm{M}$ and $\mathrm{Li} / \mathrm{SS}$ respectively, when subjected to three different shear rates. Again two phases can be seen: a progressive degradation at the first stage, followed by a rather slow deterioration afterwards. This agrees with the penetration depth variation against entropy generation per unit volume illustrated in Figure 6. Similar trends were also found from the literature survey (30-32). 


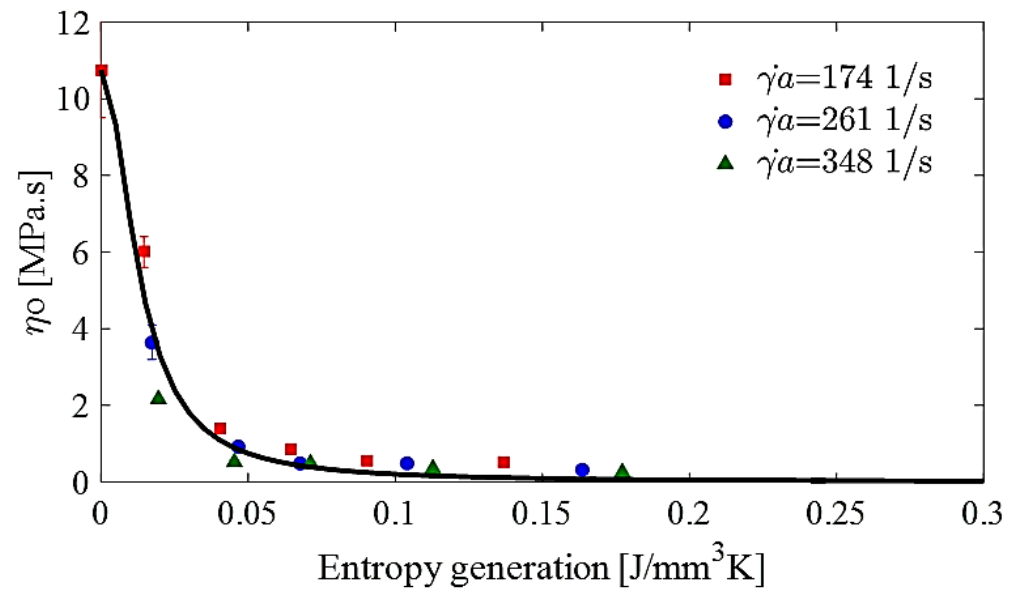

Figure 7 Zero shear viscosity variation versus generated entropy density for $\mathrm{Li} / \mathrm{M}$

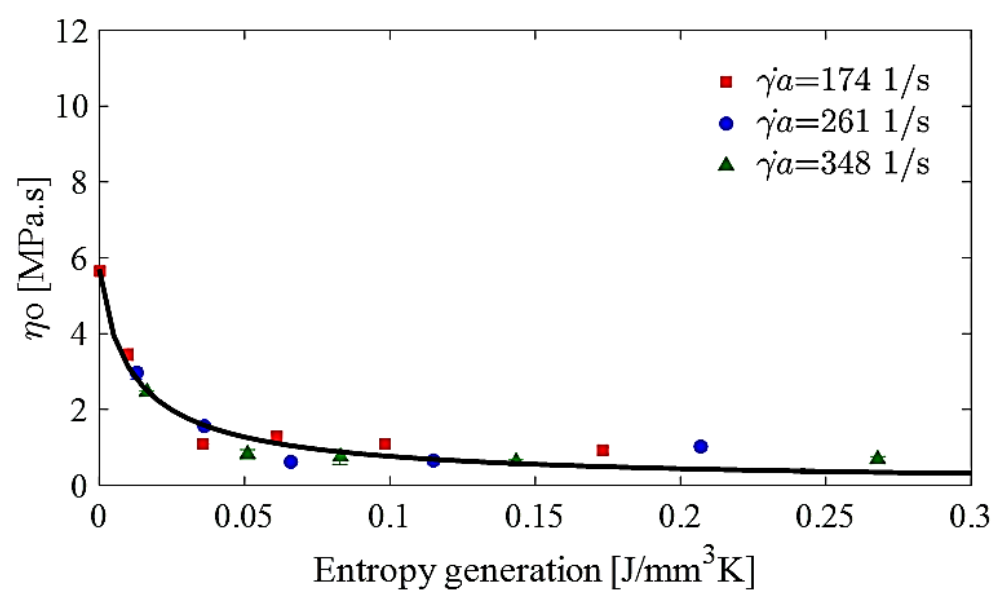

Figure 8 Zero shear viscosity variation versus generated entropy density for Li/SS

The viscosity versus entropy generation trend of lithium thickened grease is similar to the viscosity versus shear rate (shear thinning) behaviour of lubricating greases. At relatively low shear (or energy), the grease has an initial high viscosity (here indicated as $\eta_{i}$ ). However, when mechanical degradation starts, the sample begins to soften and after subjected to a certain amount of entropy $\left(S_{g}=0.05 \mathrm{~J} / \mathrm{mm}^{3} \mathrm{~K}\right)$, the viscosity levels out again with a feeble degradation rate. 
Therefore, the formula of the Cross equation (19), which is used to describe shear thinning behaviour, was borrowed to describe the relationship between variation of zero-shearviscosity and the entropy density generation during ageing:

$$
\eta_{o}=\frac{\eta_{i}-\eta_{\infty}}{1+K \cdot S_{g}{ }^{m}}+\eta_{\infty}
$$

where $\eta_{i}$ is the initial zero-shear-viscosity for fresh samples, and $\eta_{\infty}$ is the viscosity for infinitely long shearing, which is calculated using Batchelor's equation $\eta_{\infty}=\eta_{b}(1+$ $\left.2.5 \varphi+6.2 \varphi^{2}\right)(33)$; the base oil viscosity $\eta_{b}$ and the phase volume $\varphi$ are tabulated in Table $1 ; S_{g}$ is the generated entropy per unit volume during ageing; $K$ is the coefficient of degradation and $m$ is the exponent of degradation.

Equation ( 6 ) fits the data obtained from all three shear rates very well $\left(R^{2}=0.99\right)$, see Figure 7 and Figure 8. This model has also been applied to the other three selected rheological properties: storage modulus $G^{\prime}$, cross-over stress $\tau_{c}$, and yield stress $\tau_{y-o s C}$ from the oscillatory test in the form of equation ( 7 ), called here the 'Grease Ageing Equation':

$$
Y=\frac{Y_{i}-Y_{\infty}}{1+K \cdot S_{g}{ }^{m}}+Y_{\infty},
$$

where $Y$ represents the rheological properties, $Y_{i}$ represents the initial rheological value for fresh grease, $Y_{\infty}$ represents the second stage value for the long time aged sample, $K$ and $m$ are the coefficient of degradation and the exponent of degradation respectively.

Each grease will have its own ageing master curve, or 'grease ageing equation' with its specific parameters, see Table 4.

Table 4 Parameters for the Grease Ageing Equation

\begin{tabular}{|c|c|c|c|c|c|c|}
\hline \multicolumn{2}{|c|}{} & $Y_{i}$ & $Y_{\infty}$ & $K$ & $m$ & $R^{2}$ \\
\hline \multirow{2}{*}{$\eta_{0}(P a \cdot s)$} & $\mathrm{Li} / \mathrm{M}$ & $1.1 \times 10^{7}$ & 0.34 & $4.5 \times 10^{3}$ & 1.9 & 0.99 \\
\cline { 2 - 7 } & $\mathrm{Li} / \mathrm{SS}$ & $5.7 \times 10^{6}$ & 0.11 & $5.0 \times 10$ & 0.89 & 0.99 \\
\hline \multirow{2}{*}{$G^{\prime}(P a)$} & $\mathrm{Li} / \mathrm{M}$ & $9.0 \times 10^{4}$ & $2.2 \times 10^{3}$ & $5.9 \times 10^{3}$ & 2.2 & 0.99 \\
\cline { 2 - 7 } & $\mathrm{Li} / \mathrm{SS}$ & $8.0 \times 10^{4}$ & $9.3 \times 10^{3}$ & $1.0 \times 10^{3}$ & 1.6 & 0.98 \\
\hline \multirow{2}{*}{$\tau_{c}(P a)$} & $\mathrm{Li} / \mathrm{M}$ & $1.2 \times 10^{3}$ & $1.0 \times 10^{2}$ & $4.0 \times 10^{3}$ & 2.2 & 0.99 \\
\cline { 2 - 8 } & $\mathrm{Li} / \mathrm{SS}$ & $7.2 \times 10^{2}$ & $2.7 \times 10$ & $4.0 \times 10^{2}$ & 1.2 & 0.99 \\
\hline \multirow{2}{*}{$\tau_{y-\text { OSC }}(P a)$} & $\mathrm{Li} / \mathrm{M}$ & 70 & 3 & $1.8 \times 10$ & 1.1 & 0.91 \\
\cline { 2 - 8 } & $\mathrm{Li} / \mathrm{SS}$ & 50 & 6 & $6.6 \times 10^{2}$ & 1.9 & 0.95 \\
\hline
\end{tabular}




\section{Grease Ageing Mechanism}

The generation of entropy demonstrates a dissipative process, which brings disorder to the system, and in this case, probably the collapse of the grease micro-structure. According to the literature, for fibrous structured greases, their consistency and rheological properties are closely related to the geometry and distribution of the network structure formed by the fibres $(5,6,25,34)$.

As was shown in Figure 6-b, there are two ageing phases with different degradation rates. According to Bryant et al. (35), the entropy generation rate is closely related to the system degradation rate. Here the system degradation rate is measured by the changes in rheological properties per unit of time (macroscopically), and the change of the thickener network (microscopically). The entropy generation rate per unit of volume can be expressed as:

$$
\dot{S}_{g}=\frac{\text { Torque } \times \omega / V_{a}}{\text { Temperature }}
$$

The entropy generation rate per unit volume and the degradation rate of the zero-shearviscosity $\eta_{0}$ for Li/M during the ageing tests are plotted against the ageing time in Figure 9. AFM measurements of the grease were taken at different points in time and are also shown in Figure 9. The cartoons are interpretations of the AFM pictures, which will help in the explanation of the results. 

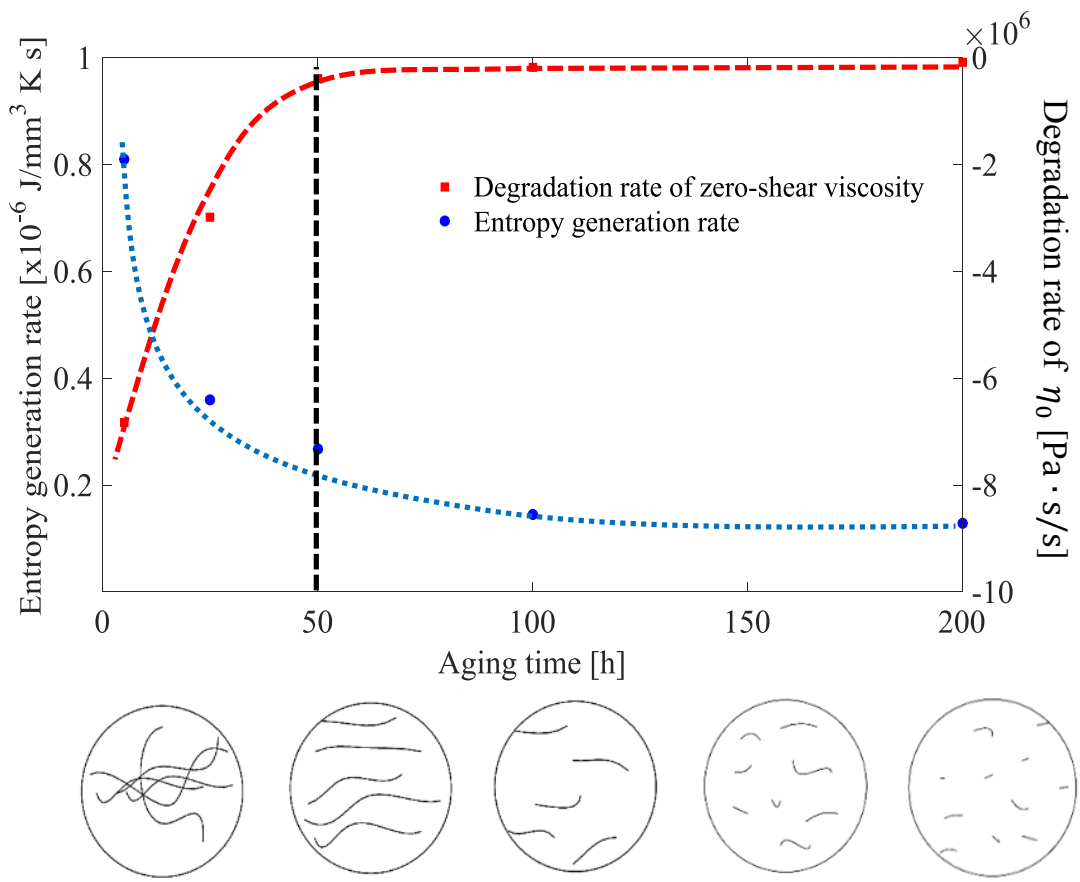

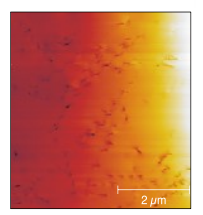

Fresh
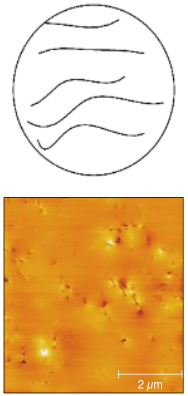

$5 \mathrm{hr}$

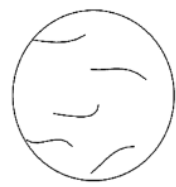

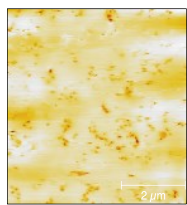

$25 \mathrm{hr}$
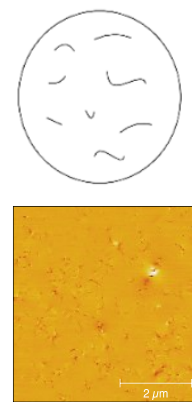

$50 \mathrm{hr}$
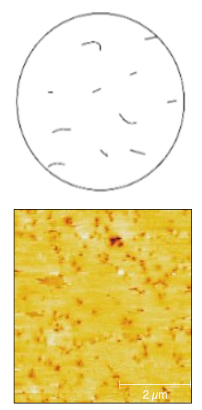

$100 \mathrm{hr}$

Figure 9 Ageing of Li/M; Cartoon and AFM results for different ageing stages

Figure 9 shows the entropy generation rate, rheology and micro-structure of Li/M during ageing. Although only the degradation rate for zero-shear-viscosity is shown, the plots for cross-over stress, storage modulus and yield stress are very similar. The thickener micro-structure for fresh $\mathrm{Li} / \mathrm{M}$ is visualised as a twisted fibrous network where the fibres are typically $0.1-0.2 \mu \mathrm{m}$ wide and up to $3 \mu \mathrm{m}$ long. Initially the sample shows a high consistency. When the mechanical degradation is initiated, energy is dissipated into the system (high $\dot{S}_{g}$ ), disrupting the network crosslinks, and aligning the fibres (as presented in the first two cartoon and AFM results). This results in a fast degradation in grease properties. This stage can be characterized by the 'coefficient of degradation $K$ ' (values of $K$ are listed in Table 4) and it ends when the fibrous network becomes fragmented (until 50h as shown in Figure 9). 
After this fast degradation stage, the aged sample becomes a mixture of particle-like microfragments of thickener (with average length of $0.1 \mu \mathrm{m}$ ) dispersed in the oil, and the deterioration process slows down (the degradation rate is approaching zero after $100 \mathrm{~h}$ ageing, see Figure 9). Such behaviour suggests that once the fibrous structure is completely destroyed, the grease rheology will become stable. With the deceleration of the ageing process, the entropy generation rate becomes smaller and remains constant.

However, the existence of micro-fragments (or 'nano size thickener fibres' as they are called by Yoshiyuki et al. (34)) still gives the aged grease a higher consistency compared to that of the bled oil (see the second stage values $Y_{\infty}$ for the aged samples presented in Table 4). According to the R2F bearing tests performed by Cann et al. (10), small volumes of 'viscous liquid' were found in the cage pockets, which was assumed to lubricate the rolling track; the infrared spectroscopy showed that this lubricant was a mixture of oil and thickener, and more viscous liquid was found along with the running. Such viscous liquid can be considered as the aged grease at the second stage, where it has both better flowability compared to the fresh grease (for lubricant replenishment) and higher viscosity compared to the base oil (for film construction).

Spiegel (31) described the fragmented thickener as spherical particles, and modelled the second stage mechanical ageing using a Wöhler curve. His theory suggests that when subjected to continuous shear, these spherical particles start rolling and that the governing ageing mechanism is fatigue. Considering the results shown in Figure 9, in the second stage, the thickener structure has become fragmented during the second phase and the grease ages at much smaller rate compared to the first ageing phase. Currently, the grease rheology during ageing is assumed to end up at an infinite value $Y_{\infty}$ as shown in Table 4, Figure 7 and Figure 8. A similar ageing mechanism is also observed for Li/SS. To confirm Spiegel's theory, pro-longed ageing tests will be needed.

\section{Conclusion}

In this study, the mechanical shear degradation of lithium thickened grease was evaluated using a housemade ageing rig and a commercial rheometer. It was found that this grease loses its original consistency during ageing and shows a two-phases ageing behaviour. In the first phase, primarily re-orientation and breakage of the thickener network take place, 
resulting in a progressive drop of the grease rheological properties. After this, the ageing is dominated by the breakage of smaller fibre fragments, and the grease degrades at a much slower rate (currently considered as stable). A 'grease shear ageing equation' (equation ( 7 )) was introduced to describe such two-phase behaviour. By taking use of the entropy concept, this equation is capable to cover the change of grease rheological properties when aged at different shear rates. This ageing behaviour is closely related to the entropy generation rate and the change of the thickener network during the ageing process: due to the breakage of the thickener structure, grease degrades, and the ageing rate is positively correlated to the entropy generation rage. According to Rezasoltani and Khonsari (1), the shear ageing at various shear rates and temperatures can be described by a single (master) curve using the entropy concept. In the current study, the entropy concept was confirmed using ageing at different shear rates. The current test rig does not make it possible to vary the ageing temperature. It is therefore recommended to further study the impact of temperature on the grease shear ageing behaviour.

\section{Acknowledgements}

The authors would like to thank SKF Engineering and Research Centre for the financial support of this work.

\section{References}

(1) Rezasoltani A, Khonsari MM. On the correlation between mechanical degradation of lubricating grease and entropy. Tribology Letters 2014;56(2):197-204.

(2) Lugt PM. Grease Lubrication in Rolling Bearings. The Atrium, Southern Gate, Chichester, West Sussex, PO19 8SQ, United Kingdom: Wiley \& Sons; 2013.

(3) Salomonsson L, Stang G, Zhmud B. Oil/ thickener interactions and rheology of lubricating greases. Tribology Transactions 2007;50(3):302-309.

(4) Lundberg J, Höglund E. A new method for determining the mechanical stability of lubricating greases. Tribology International 2000;33(3):217-223.

(5) Bondi A, Cravath AM, Moore RJ, Peterson WH. Basic factors determining the structure and rheology of lubricating grease. The Institute Spokesman 1950;13(12):12-18.

(6) Moore RJ, Cravath AM. Mechanical breakdown of soap-base greases. Industrial \& Engineering Chemistry 1951;43(12):2892-2897. 
(7) Lundberg J. Grease lubrication of roller bearings in railway waggons. Part 1: field tests and systematic evaluation to determine the optimal greases. Industrial Lubrication and Tribology 2000;52(1):36-43.

(8) Lundberg J, Berg S. Grease lubrication of roller bearings in railway waggons. Part 2: laboratory tests and selection of proper test methods. Industrial Lubrication and Tribology 2000;52(2):76-85.

(9) Mérieux J, Hurley S, Lubrecht AA, Cann PM. Shear-degradation of grease and base oil availability in starved EHL lubrication. Tribology Series 2000;38:581-588.

(10) Cann P, Doner JP, Webster MN, Wikstrom V. Grease degradation in rolling element bearings. Tribology Transactions 2001;44(3):399-404.

(11) Paszkowski M. Identification of the thixotropy of lithium greases. 16th International Colloquium Tribology; 2008.

(12) Schramm G. A practical approach to rheology and rheometry. Karsruhe etc.]: Karsruhe etc. : Haake; 1994.

(13) Ito H, Tomaru M, Suzuki T. Physical and chemical aspects of grease deterioration in sealed ball bearings. Lubrication Engineering (STLE) 1988;44(10):872-879.

(14) Cyriac F, Lugt PM, Bosman R, Padberg C, Venner C. Effect of thickener particle geometry and concentration on the grease EHL film thickness at medium speeds. Tribology Letters 2016;61(2):1-13.

(15) Czarny R. The influence of surface material and topography on the wall effect of grease. Lubrication Science 2002;14(2):255-274.

(16) Paszkowski M. Assessment of the effect of temperature, shear rate and thickener content on the thixotropy of lithium lubricating greases. Proceedings of the Institution of Mechanical Engineers, Part J: Journal of Engineering Tribology 2013;227(3):209-219.

(17) Deutsches Institut für Normung. Testing of lubricants - Determination of shear viscosity of lubricating greases by rotational viscosimeter - Part 1: System of cone/plate. 2007;DIN 51810-1:2007-07.

(18) Paszkowski M, Olsztyńska-Janus S, Wilk I. Studies of the kinetics of lithium grease microstructure regeneration by means of dynamic oscillatory rheological tests and FTIRATR spectroscopy. Tribology Letters 2014;56(1):107-117.

(19) Cross MM. Rheology of non- Newtonian fluids: A new flow equation for pseudoplastic systems. Journal of colloid science 1965;20(5):417-437.

(20) Cyriac F, Lugt PM, Bosman R. On a new method to determine the yield stress in lubricating grease. Tribology Transactions 2015;58(6):1021-1030.

(21) Rezasoltani A, Khonsari M. Reply to Comment by Chung on "On the correlation between mechanical degradation of lubricating grease and entropy". Tribology Letters 2015;60(1):1-4. 
(22) Tolman RC, Fine PC. On the irreversible production of entropy. Reviews of Modern Physics 1948;20(1):51-77.

(23) Godec D. Alexander Ya. Malkin, Avraam I. Isayev: Rheology - Concepts, Methods \& Applications. Polimeri 2006;27(1):59.

(24) Hoefnagels JPM. Overview of Microscopic Characterization Techniques. 2014.

(25) Sanchez MC, Franco J, Valencia C, Gallegos C, Urquiola F, Urchegui R. Atomic force microscopy and thermo- rheological characterisation of lubricating Greases. Tribology Letters 2011;41(2):463-470.

(26) Paszkowski M, Olsztyńska-Janus S. Grease thixotropy: Evaluation of grease microstructure change due to shear and relaxation. Industrial Lubrication and Tribology 2014;66(2):223-237.

(27) Hurley S, Cann P. Examination of grease structure by SEM and AFM techniques. NLGI Spokesman 2001;65(5):17-26.

(28) Delgado MA, Franco JM, Valencia C, Kuhn E, Gallegos C. Transient shear flow of model lithium lubricating greases. Mechanics of Time-Dependent Materials 2009;13(1):6380 .

(29) Spiegel K, FRICKE J, MEIS K. Zusammenhang zwischen Penetration und Fliessgrenze bei Schmierfetten. Tribologie und Schmierungstechnik 1991;38(6):326-331.

(30) Plint M, Alliston-Greiner A. A new grease viscometer: a study of the influence of shear on the properties of greases. NLGI spokesman 1992;56(2):7-15.

(31) Spiegel K, Fricke J, Meis K. Die Fließeigenschaften von Schmierfetten in Abhängigkeit von Beanspruchung, Beanspruchungsdauer und Temperatur. Int.Coll.Tribology, Esslingen 2000.

(32) Kuhn E. Experimental grease investigations from an energy point of view. Industrial Lubrication and Tribology 1999;51(5):246-251.

(33) Barnes HA, Hutton JF, Walters K. An introduction to rheology. Elsevier; 1989.

(34) Yoshiyuki S, Yusuke N, Yusuke I, Hiroki S, Yukitoshi F. Characterization of nano size thickener fiber in grease by SAXS. World Tribology Congress; 2013.

(35) Bryant MD, Khonsari MM, Ling FF. On the thermodynamics of degradation. The Royal Society of London A: Mathematical, Physical and Engineering Sciences: The Royal Society; 2008. 
Paper B 


\section{A master curve for the shear degradation of lubricating greases with a fibrous structure}

Yuxin Zhou ${ }^{1}$, Rob Bosman ${ }^{1}$ and Piet M. Lugt ${ }^{1,2}$

${ }^{1}$ University of Twente, Enschede, The Netherlands

${ }^{2}$ SKF Research and Technology Development, Nieuwegein, The Netherlands

\section{List of symbols}

\begin{tabular}{|c|c|}
\hline$C_{e}$ & Correcting factor for the bearing ageing energy (-) \\
\hline$C_{T}$ & Arrhenius correction factor $(-)$ \\
\hline$E_{b}$ & Bearing friction energy density $\left(\mathrm{J} / \mathrm{mm}^{3}\right)$ \\
\hline$E_{g w}$ & Input work density inside the grease worker $\left(\mathrm{J} / \mathrm{mm}^{3}\right)$ \\
\hline$E_{m}$ & Corrected energy density during the Couette ageing procedure $\left(\mathrm{J} / \mathrm{mm}^{3}\right)$ \\
\hline$F_{a}$ & Axial load applied in the R0F+ test $(N)$ \\
\hline$F_{r}$ & Radial load applied in the R0F+ test $(N)$ \\
\hline$F_{g w}$ & Drag force generated inside the grease worker $(N)$ \\
\hline$K$ & Coefficient of degradation (-) \\
\hline$L_{50}$ & $\begin{array}{l}\text { Estimated bearing life at which } 50 \% \text { of the bearing population has failed } \\
\text { (h) }\end{array}$ \\
\hline$L_{\text {piston }}$ & Length of a stroke in the grease worker $(m)$ \\
\hline$M$ & Torque $(\mathrm{Nm})$ \\
\hline$M_{r r}$ & Rolling frictional moment generated from the $\mathrm{R} 0 \mathrm{~F}+$ bearing $(\mathrm{Nm})$ \\
\hline$M_{s l}$ & Sliding frictional moment generated from the R0F+ bearing $(\mathrm{Nm})$ \\
\hline$N$ & Rotational speed (rpm) \\
\hline$n$ & Degradation exponent (-) \\
\hline$R^{2}$ & Goodness value of the fitting (-) \\
\hline$R_{a}$ & Surface roughness of the measuring plates (Centre Line Average, $\mu m$ ) \\
\hline$S_{g}$ & Generated entropy per unit volume during ageing $\left(\mathrm{J} / \mathrm{mm}^{3} \mathrm{~K}\right)$ \\
\hline$t$ & Grease ageing time $(s)$ \\
\hline$t_{b}$ & $\mathrm{R} 0 \mathrm{~F}+$ bearing running time $(s)$ \\
\hline$T$ & Applied temperature during ageing $\left({ }^{\circ} \mathrm{C}\right)$ \\
\hline
\end{tabular}




\begin{tabular}{|c|l|}
\hline$T_{0}$ & Reference temperature $\left({ }^{\circ} \mathrm{C}\right)$ \\
\hline$V_{a}$ & Grease volume inside the Couette Ageing Machine $\left(\mathrm{mm}^{3}\right)$ \\
\hline$V_{b}$ & Grease filling volume inside the R0F+ test bearings $\left(\mathrm{mm}^{3}\right)$ \\
\hline$V_{g w}$ & Grease volume inside the grease worker $\left(\mathrm{mm}^{3}\right)$ \\
\hline$W$ & Input work during the Couette ageing procedure $(\mathrm{J})$ \\
\hline$Y$ & Rheological properties of the grease during ageing $(-)$ \\
\hline$Y_{i}$ & Initial rheological value for fresh grease $(-)$ \\
\hline$Y_{\infty}$ & Second stage rheological value after infinitely long ageing $(-)$ \\
\hline$\dot{\gamma}_{a}$ & Ageing shear rate $\left(\mathrm{s}^{-1}\right)$ \\
\hline$\dot{\gamma}_{p s}$ & Shear rate for pre-shear $\left(\mathrm{s}^{-1}\right)$ \\
\hline$\tau_{y}$ & Yield stress obtained from the oscillatory strain sweep test $(\mathrm{Pa})$ \\
\hline
\end{tabular}

\begin{abstract}
In this article, the mechanical ageing behaviour of lubricating greases with a fibrous structure is studied by ageing fresh samples at controlled shear rates and temperatures in a house made Couette Ageing Machine. The rheological properties of fresh and aged samples were evaluated in a plate-plate rheometer. In the absence of oxygen, no chemical reactions occurred. The results showed that shear degradation is accelerated by increasing the temperature. This thermal effect can be described by an Arrhenius law. A 'Grease Ageing Master Curve' was created to describe the influence of shear and temperature on the mechanical ageing of fibrous structured grease. Next, the model was validated using a conventional grease worker test. Finally, the model was applied to full ball bearings using an $\mathrm{R} 0 \mathrm{~F}+$ bearing test rig. The 'Master Curve' forms an important contribution to the development of grease life models.
\end{abstract}

\title{
Keywords
}

Grease ageing, rolling bearing, lubrication

\section{Introduction}

Grease is widely used as a lubricant in rolling bearings. It is often preferred over oil as it does not easily leak out of the bearing and has good sealing properties (1). After the 
churning phase, the grease forms reservoirs from which lubricant is released to the contacts to separate the rolling elements from the rings by a lubricant film. At some point in time, the grease is no longer able to lubricate which is called the end of grease life. Generally, the limited lifespan of the grease is determining the life of the bearing. This can be overcome by re-lubrication and a reasonable re-lubrication interval can be calculated using grease life models (1). Generally, grease life is determined by two effects: mechanical deterioration (the dominating mechanism at low and moderate temperature, e.g., below $70^{\circ} \mathrm{C}$ ) and chemical deterioration (mainly at high temperature, e.g., higher than $\left.120^{\circ} \mathrm{C}\right)(1,2)$. The present paper addresses the first aspect: mechanical degradation.

The mechanical degradation of the grease is caused mainly by pressure and shear. Grease may soften during ageing and possibly leak out of the bearing (3); on the other hand, thickening/stiffening may occur, resulting in a loss of oil bleeding capacity $(1,4,5)$. This grease ageing behaviour is highly dependent on the operating/working conditions (including temperature), the grease chemical composition and the grease thickener microstructure.

Spiegel (6) assumed a particle thickener micro-structure and described the degradation process using a fatigue model. Moore and Cravath (7) aged soap based greases using the roll stability test to study the breakdown of the thickener structure. They proposed an exponential model indicating that the decreasing rate of the change in grease consistency is proportional to the breakage rate of the thickener structure, i.e., the thickener geometry was used as a gauge to monitor the grease ageing process. Czarny (8) developed an empirical equation describing the drop of grease viscosity in terms of the number of shear cycles applied. Using Czarny's equation, Plint, et al. (9) proposed a 'half-life' parameter to describe the grease ageing inside a grease worker: the 'half-life' was defined as the time at which the grease has lost half of its initial viscosity. However, these empirical models are often limited to the specific ageing test rigs and a universal ageing model which is capable of describing the grease ageing in various conditions still remains an open gap.

To give a common description of degradation dynamics, Bryant et al. (10) employed entropy as a fundamental measure of degradation and applied this thermodynamic concept to characterize the degradation process of adhesive and fretting wear. Rezasoltani and 
Khonsari applied this theory on the mechanical ageing of grease (11). By shearing lithium complex greases in a rheometer at relatively low temperatures $\left(25-45^{\circ} \mathrm{C}\right)$, a linear relationship between the generated entropy and the grease ageing behaviour (change of consistency) was found. They later used this concept to build a shear life model (12), in which the grease life was determined by the time at which a critical consistency would be reached. In an earlier paper (13), the current authors also used this 'entropy concept' to develop a Master Curve for the shear degradation of grease. However, when performing pro-longed ageing tests in a Couette Ageing Machine, the results showed that this linear ageing behaviour was not able to fully describe the grease shear ageing process: the grease ageing rate was found to decrease in time, ultimately showing asymptotic behaviour where the ageing process practically ends. This is plausible: after all, since the size of the thickener fibres decreases in time, there is a reduced probability for breakage of these fragmented fibres, resulting in a continuous reduction in the ageing rate (7). Similar grease ageing behaviour was shown in the literature $(1,6)$. Therefore, an exponential ageing equation was proposed (13).

The mechanical ageing tests described above were performed at relatively low temperatures, i.e., at the low ends of the 'green temperature window'(1), where chemical degradation is not dominating. Apart from oxidation, grease will also experience 'thermal degradation' (14). Couronne and Vergne (5) worked on the thermal ageing of lithium thickened greases. Their rheological evaluation and micro-structure measurements showed that at elevated temperature $\left(150^{\circ} \mathrm{C}\right)$, lithium grease was weakened, even in the absence of oxidation. Plint et al. (9) sheared lithium grease in a self-made viscometer. They observed that when ageing at high temperatures, the influence of shearing on the grease viscosity loss is more pronounced. Cyriac et al. (15) studied the temperature dependency of the yield stress for various greases and found that for both lithium and polyurea thickened greases, the yield stress reduces with a factor of two by a certain temperature increase. A drop of grease yield stress at higher temperature was also shown in the work of (16-18). Ide et al. (19) predicted the grease life of lithium soap thickened grease using thermogravimetry tests. They concluded that the activation energy based on Arrhenius' law is an appropriate parameter in grease life prediction. To summarize: to capture the mechanical ageing of grease, not only 
the mechanical work put into the grease (shear) but also temperature plays a role. A grease ageing master curve should therefore take both factors into account.

The current paper extends the work that was earlier published in (13) where the shear degradation was described at a fixed temperature. Now also the influence of temperature on shear degradation will be included. The results will show that elevated temperatures accelerate the ageing due to the possible change of thickener properties $(4,5,20)$, which is not well described by the entropy concept $(12,13)$. It will be shown that the grease degradation is determined by the energy density where the Arrhenius equation should be used to include thermal effects, called 'corrected energy density', $E_{m}$, here. Oxidation did not occur, which was confirmed by FTIR measurements. Based on this, a modified Grease Ageing Master Curve has been developed and validated using a conventional grease worker test (ASTM D217) equipped with a load sensor to measure the work exerted on the grease.

At the end of this paper, the Master Curve will be applied to the ageing in full bearings, i.e., grease aged using a $\mathrm{R} 0 \mathrm{~F}+$ grease tester equipped with deep groove ball bearings. The results show that although grease ageing is more complex inside rolling bearings, the overall ageing behaviour demonstrates a similar trend as described by the proposed curve. Based on this, a potential application of the Master Curve on grease life prediction inside a deep groove ball bearing will be illustrated.

\section{Material and Method}

\section{Tested grease}

Commercial greases based on two types of thickeners combined with different base oils were tested, i.e. a lithium complex soap grease with PAO base oil, denoted by LiX/PAO and polyurea thickened grease with ester base oil, denoted by PU/E. Both of the two greases have a fibre-like thickener structure. Some relevant information about these greases is summarized in Table 1. The micro-structure of the grease thickener was obtained using atomic force microscopy (AFM) in tapping mode. 
Table 1 Composition and properties of the tested greases

\begin{tabular}{|c|c|c|c|c|c|c|c|}
\hline Grease & $\begin{array}{c}\text { Thicken } \\
\text { er }\end{array}$ & $\begin{array}{l}\text { Mass } \\
\text { fractio } \\
\mathrm{n} \text { of } \\
\text { the } \\
\text { thicke } \\
\text { ner }\end{array}$ & $\begin{array}{c}\text { Base } \\
\text { oil }\end{array}$ & $\begin{array}{c}\text { Base } \\
\text { oil } \\
\text { viscosi } \\
\text { ty at } \\
\mathbf{4 0}^{\circ} \mathrm{C} / \\
\mathbf{1 0 0}^{\circ} \mathrm{C}\end{array}$ & $\begin{array}{l}\text { NL } \\
\text { GI }\end{array}$ & $\begin{array}{c}\text { AFM phase } \\
\text { contrast }\end{array}$ & $\begin{array}{c}\text { AFM } \\
\text { topography } \\
\text { image }\end{array}$ \\
\hline $\begin{array}{c}\mathrm{LiX} / \mathrm{PA} \\
\mathrm{O}\end{array}$ & $\begin{array}{l}\text { Lithium } \\
\text { complex }\end{array}$ & 0.20 & PAO & $\begin{array}{c}191 / 42 \\
\mathrm{cSt}\end{array}$ & $2-3$ & & \\
\hline $\mathrm{PU} / \mathrm{E}$ & $\begin{array}{c}\text { Polyure } \\
\text { a }\end{array}$ & 0.26 & $\begin{array}{l}\text { Synthet } \\
\text { ic ester }\end{array}$ & $\begin{array}{c}70 / 9.4 \\
\mathrm{cSt}\end{array}$ & $2-3$ & & \\
\hline
\end{tabular}

\section{Shear ageing test}

During practical usage, grease will experience both shear and thermal stress. To perform grease ageing both at controlled shear rates and temperatures, a new ageing machine was designed and built. The machine is here referred to as the 'Couette Ageing Machine'.

Figure 1 and Figure 2 show a schematic overview of the ageing setup. To ensure homogeneous shear, the grease will be sheared between a cylindrical housing and a biconical bob. The angle of the conical ends was chosen such that a similar shear rate field will occur in the conical and cylindrical section of the working head (21). One of the challenges is keeping the grease in the Couette geometry, as due to the 'Weissenberg effect', the grease will flow upwards in the gap. This was accomplished by driving the rotating bob via a magnetic-coupling through a stainless-steel lid. Additionally, grease leakage, evaporation of base oil and oxidation of the grease are limited due to the airtight seal created by the lid and an o-ring. To ensure a proper alignment of the bob, two small ball bearings are placed inside the ageing head. Before an ageing test, fresh grease is injected 
via the grease fitting (Figure 2). Once completely full, the ageing head is closed and immersed in the thermal bath.

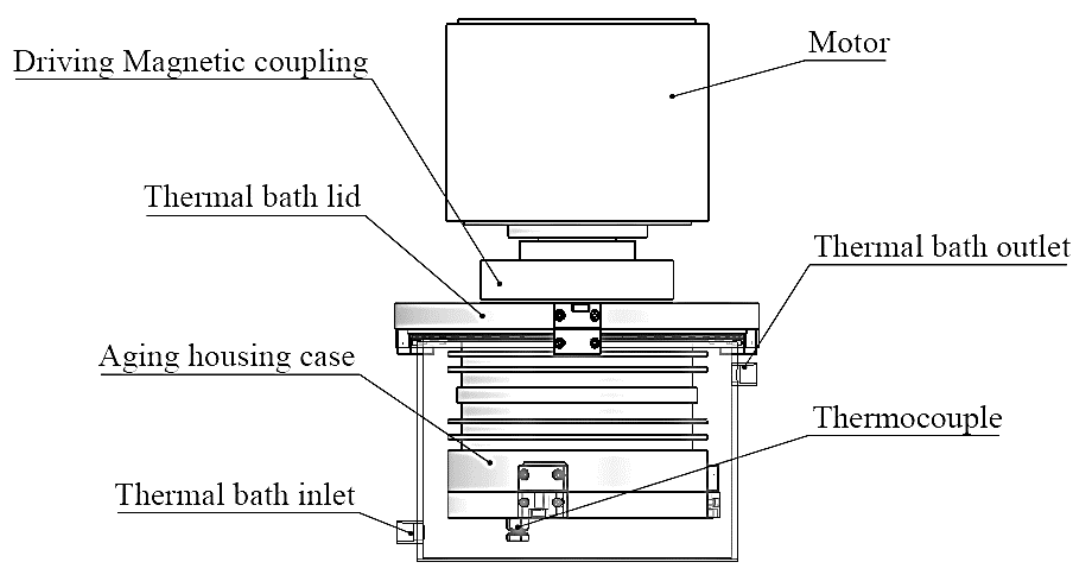

Figure 1 Schematic drawing of the Couette Ageing Machine

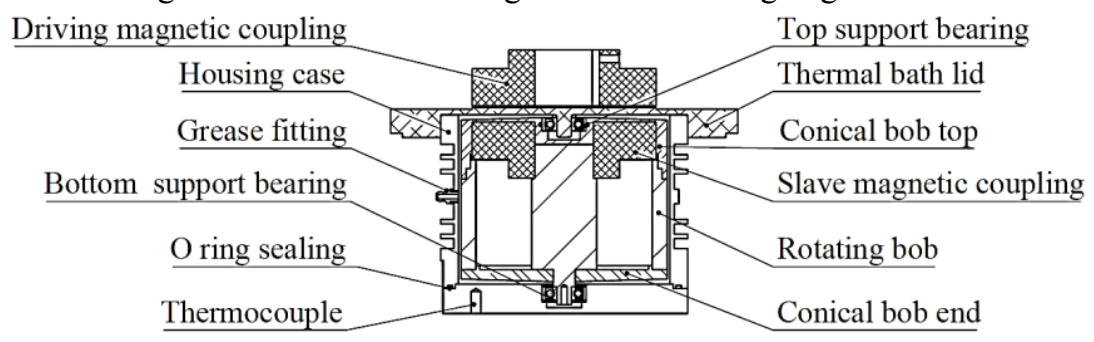

Figure 2 Schematic drawing of the ageing head

During ageing, the temperature is recorded from the thermocouple at the bottom of the housing case, see Figure 1 and Figure 2. From the motor current, the torque and therefore the generated drag when shearing the grease can be calculated by subtracting the 'reference torque value', which was recorded when running the Couette Ageing Machine with no grease filling inside the ageing head.

To study the influence of temperature on ageing, grease will be aged at controlled temperatures for specific ageing periods. The ageing temperatures were chosen as $50^{\circ} \mathrm{C}$, $85^{\circ} \mathrm{C}$ and $120^{\circ} \mathrm{C}$. The highest ageing temperature was selected as $120^{\circ} \mathrm{C}$, which is considered as the highest acceptable working temperature for standard lithium soap 
thickened grease in ball bearings (5). The shear rate was selected equal to one of the values applied in the previous paper: $\dot{\gamma}_{a}=175 \mathrm{~s}^{-1}$ (13). The input work $W$ was calculated as:

$$
W=\int \frac{M \cdot N \cdot 2 \pi}{60} d t
$$

where the torque $M$ (in $N \cdot m$ ) and rotational speed $N$ (in $r p m$ ) were collected from the motor; $t$ is the ageing time in seconds.

To verify that the ageing process is independent from the applied shear rate (presented in the early work (13)), ageing tests were performed on fresh PU/E using various shear rates. The ageing conditions in the Couette Ageing Machine are listed in Table 2.

Table 2 Shear ageing condition

\begin{tabular}{|c|c|c|c|}
\hline \multirow{6}{*}{$\begin{array}{c}\text { Ageing at constant shear } \\
\text { rate } \\
\dot{\gamma}_{a}=175 s^{-1}\end{array}$} & \multirow{3}{*}{$\mathrm{PU} / \mathrm{E}$} & $50^{\circ} \mathrm{C}$ & $5 \mathrm{~h}, 25 \mathrm{~h}$ \\
\hline & & $85^{\circ} \mathrm{C}$ & $5 \mathrm{~h}, 8 \mathrm{~h}, 40 \mathrm{~h}$ \\
\hline & & $120^{\circ} \mathrm{C}$ & $5 \mathrm{~h}, 10 \mathrm{~h}, 50 \mathrm{~h}$ \\
\hline & \multirow{3}{*}{$\mathrm{LiX} / \mathrm{PAO}$} & $50^{\circ} \mathrm{C}$ & $5 \mathrm{~h}, 10 \mathrm{~h}, 25 \mathrm{~h}, 50 \mathrm{~h}$ \\
\hline & & $85^{\circ} \mathrm{C}$ & 10h, 19h, 50h \\
\hline & & $120^{\circ} \mathrm{C}$ & $10 \mathrm{~h}, 17 \mathrm{~h}, 29 \mathrm{~h}$ \\
\hline \multirow{2}{*}{ Mixed ageing (PU/E) } & \multicolumn{3}{|c|}{$\begin{array}{l}\text { Aged at } 85^{\circ} \mathrm{C}, 350 \mathrm{~s}^{-1} \text { for } 1 \mathrm{~h} \text {, followed by aged at } 50^{\circ} \mathrm{C} \text {, } \\
175 \mathrm{~s}^{-1} \text { for } 1 \mathrm{~h} \text {. }\end{array}$} \\
\hline & \multicolumn{3}{|c|}{$\begin{array}{l}\text { Aged at } 50^{\circ} \mathrm{C}, 175 \mathrm{~s}^{-1} \text { for } 2 \mathrm{~h} \text {, followed by aged at } 25^{\circ} \mathrm{C} \text {, } \\
350 \mathrm{~s}^{-1} \text { for } 2 \mathrm{~h} .\end{array}$} \\
\hline
\end{tabular}

\section{Thermal ageing test}

Thermal ageing tests were performed by inserting 11 grams of fresh grease into a glass bottle, sealed by aluminum foil. The sealed samples were subsequently heated in an oven at various temperatures. This makes it possible to investigate the influence of only temperature on the grease ageing properties. Similar temperatures and time spans were selected as were used for the Couette Ageing Machine tests. The test conditions are shown in Table 3. 
Table 3 Thermal ageing conditions

\begin{tabular}{|c|c|c|}
\hline Temperature & LiX/PAO & PU/E \\
\hline $50^{\circ} \mathrm{C}$ & & \\
\hline $85^{\circ} \mathrm{C}$ & $2 \mathrm{~h}, 5 \mathrm{~h}, 8 \mathrm{~h}, 20 \mathrm{~h}, 100 \mathrm{~h}$ & $2 \mathrm{~h}, 5 \mathrm{~h}, 10 \mathrm{~h}, 20 \mathrm{~h}, 40 \mathrm{~h}, 120 \mathrm{~h}$ \\
\hline $120^{\circ} \mathrm{C}$ & $2 \mathrm{~h}, 5 \mathrm{~h}, 8 \mathrm{~h}, 20 \mathrm{~h}, 100 \mathrm{~h}$ & $2 \mathrm{~h}, 5 \mathrm{~h}, 10 \mathrm{~h}, 20 \mathrm{~h}, 40 \mathrm{~h}, 120 \mathrm{~h}$ \\
\hline & $2 \mathrm{~h}, 5 \mathrm{~h}, 8 \mathrm{~h}, 20 \mathrm{~h}, 100 \mathrm{~h}$ & $2 \mathrm{~h}, 5 \mathrm{~h}, 10 \mathrm{~h}, 20 \mathrm{~h}, 40 \mathrm{~h}, 120 \mathrm{~h}$ \\
\hline
\end{tabular}

\section{$R 0 F+t e s t$}

To study the grease ageing inside a bearing, fresh PU/E was aged using an SKF R0F+ test rig. The $\mathrm{R} 0 \mathrm{~F}+$ is a test rig designed to determine grease life, where two pairs of deep groove ball bearings (two test bearings and two support bearings) are tested under specific temperature, speed and load for prolonged running $(1,22)$. In these grease ageing tests, the bearings were shielded and filled with approximately $30 \%$ of the bearing free volume using fresh PU/E (giving an initial fill volume of $V_{b}=1.6 \times 10^{3} \mathrm{~mm}^{3}$ ). To avoid bearing failures (since the goal is to study grease degradation), the applied load should be relatively low, however high enough to prevent skidding.

Two test conditions were selected, under which the bearings were run for specific periods of time but always shorter than the estimated grease life. The R0F+ test conditions are shown in Table 4. Afterwards, the worked PU/E was collected from the bearing and mixed to form a homogenous structure, since the volumes are too small to collect grease from specific locations inside the bearing. Most of the grease was collected on the inner surface of the shield as shown in Figure 3.

Table $4 \mathrm{R} 0 \mathrm{~F}+$ tetst condition

\begin{tabular}{|c|c|c|c|c|c|}
\hline & $\begin{array}{c}\text { Running } \\
\text { temperature } \\
\left({ }^{\circ} \mathrm{C}\right)\end{array}$ & $\begin{array}{c}\text { Axial load } \\
F_{a}(N)\end{array}$ & $\begin{array}{c}\text { Radial load } \\
F_{r}(N)\end{array}$ & $\begin{array}{c}\text { Rotational speed } \\
N(\text { rpm })\end{array}$ & $\begin{array}{c}\text { Running time } \\
\text { (hours })\end{array}$ \\
\hline $\begin{array}{c}\text { Condition } \\
1\end{array}$ & \multirow{2}{*}{120} & 500 & 50 & 10000 & 22,195 \\
\cline { 1 - 5 } & & 270 & 70 & 15000 & $100,235,600$ \\
\hline \begin{tabular}{c} 
Condition \\
\cline { 3 - 6 }
\end{tabular} & & \multicolumn{3}{|c}{} \\
\hline
\end{tabular}



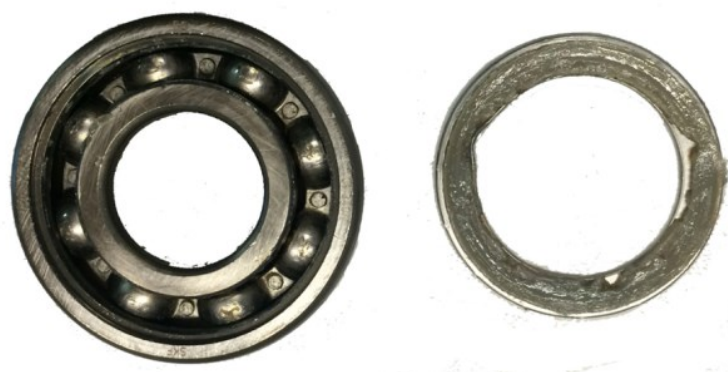

Figure 3 Sample collection after R0F+ test

\section{Sample characterization}

To evaluate the change of grease properties from the ageing tests, the yield stress was measured for fresh and aged grease samples in an MCR 501 Anton-Paar rheometer using a plate-plate geometry, with $1 \mathrm{~mm}$ measuring gap (sufficiently high compared to the tested grease fibre length) and roughened surfaces (top plate: $R_{a}=1.5 \mu \mathrm{m}$; bottom plate: $R_{a}=$ $2.3 \mu \mathrm{m})$ to decrease wall-slip effects. Once the sample was loaded, pre-shear was applied following the DIN standard (23) $\left(\dot{\gamma}_{p s}=100 s^{-1}\right.$ for $60 \mathrm{~s}$ at $\left.25^{\circ} \mathrm{C}\right)$. After 30 minutes relaxation time, oscillatory strain sweep measurements were performed, where the shear strain ranged from $10^{-3} \%$ to $10^{3} \%$ at $1 \mathrm{~Hz}$ and $25^{\circ} \mathrm{C}$. Based on the stress-strain curve, the yield stress $\tau_{y}$ was obtained at the point where a pre-defined deviation from the linear stress-strain behaviour takes place (24). For every tested sample, at least two rheological measurements were performed. In the rest of this paper, the ageing results will be plotted as a marker indicating the average value with the corresponding measuring spread. In addition, to check if chemical reactions took place during ageing, FTIR measurements were carried out for both fresh and aged samples.

\section{Results and Discussion}

\section{Entropy concept trial}

In our previous paper (13), the entropy concept was applied to describe the ageing process of lithium soap grease (with a fibrous thickener structure) at multiple shear rates. There was no data to show that the concept would properly include the effect of temperature. Therefore, additional tests on the Couette Ageing Machine for different temperatures have 
now been conducted. The entropy density $S_{g}$ is calculated by dividing the input work $W$ over the grease sample volume $V_{a}$ and the ageing temperature $T$ (11):

$$
S_{g}=\frac{W / V_{a}}{T} .
$$

The yield stress variation during ageing for both $\mathrm{LiX} / \mathrm{PAO}$ and $\mathrm{PU} / \mathrm{E}$ is plotted against the entropy generation density in Figure 4. This figure shows different ageing curves for different temperatures which implies that the 'entropy generation density' is not the suitable parameter to describe ageing.

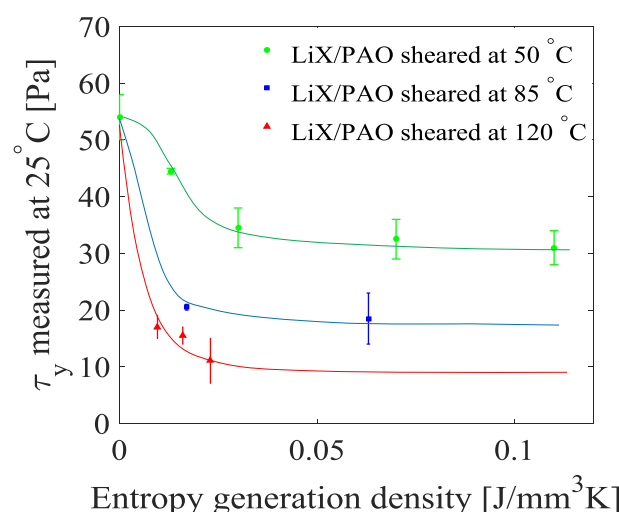

(a)

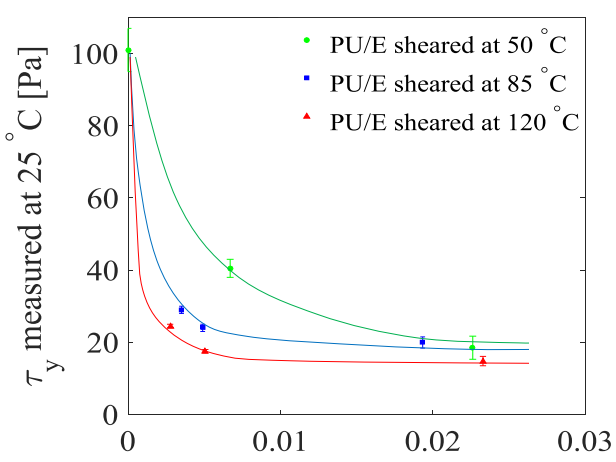

Entropy generation density $\left[\mathrm{J} / \mathrm{mm}^{3} \mathrm{~K}\right]$

(b)

Figure 4 Yield stress vs Entropy generation density at various ageing temperatures for $\mathrm{LiX} / \mathrm{PAO}(\mathrm{a})$ and PU/E(b)

In order to include thermal effects in the shear ageing model, first pure thermal ageing will be addressed, so in the absence of shear.

\section{Thermal ageing results}

To study only the effect of the elevated temperature on grease ageing, time sweep isothermal ageing tests were performed on fresh $\mathrm{LiX} / \mathrm{PAO}$ and $\mathrm{PU} / \mathrm{E}$ at $50^{\circ} \mathrm{C}, 85^{\circ} \mathrm{C}$ and $120^{\circ} \mathrm{C}$. According to the FTIR spectra, no extra peak is observed, confirming the absence of oxidation, see Figure 5. 


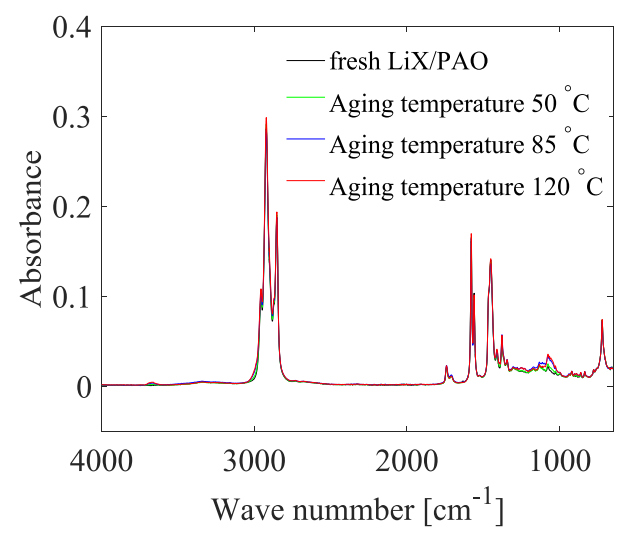

(a)

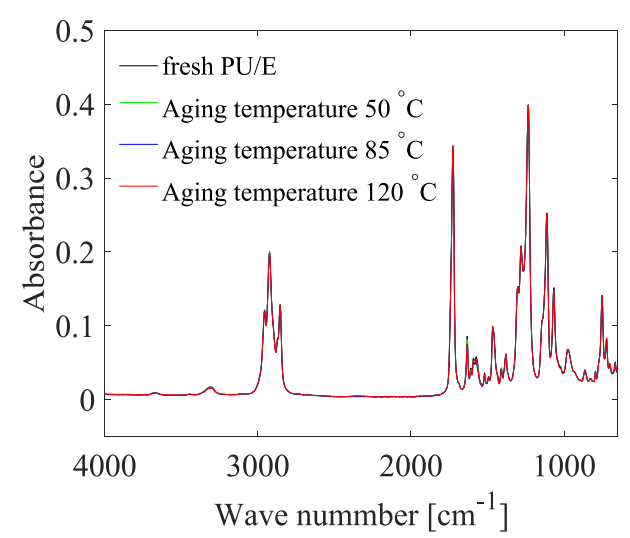

(b)

Figure 5 FTIR comparison between the fresh and thermal aged $\mathrm{LiX} / \mathrm{PAO}(\mathrm{a})$ and $\mathrm{PU} / \mathrm{E}(\mathrm{b})$

The thermal ageing results are shown in Figure 6, where the yield stress versus the logarithmic heating time at different temperatures was plotted. Clearly, for each temperature, the yield stress shows a descending trend versus the heating time. In addition, when baked at higher temperature, the ageing rate increases, which agrees with the Couette Ageing Machine test observation as shown in Figure 4.

Couronne and Vergne (5) attributed this thermal effect on grease ageing to the variation of thickener structure. They concluded that high temperature makes the fibres more 'brittle' and thereby, the breakage of such fibres will be easier. Salomonsson et al. (4) have similar observations: after 7 days ageing inside a beaker at $120^{\circ} \mathrm{C}$, the thickener fibre length decreased from $1 \mu \mathrm{m}$ to $0.1 \mu \mathrm{m}$, while the average fibre diameter increased from $30 \mathrm{~nm}$ to $50 \mathrm{~nm}$. Huang et al. (25) attributed the fibre shortening of lithium soap-based grease to the loss of physical bonding of thickener molecules at high temperature $\left(120^{\circ} \mathrm{C}\right)$. These observations may very well explain why grease deteriorates faster at higher temperature: thermal weakening. 


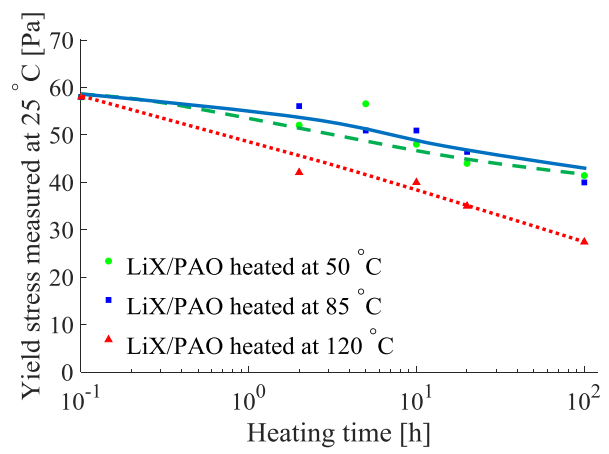

(a)

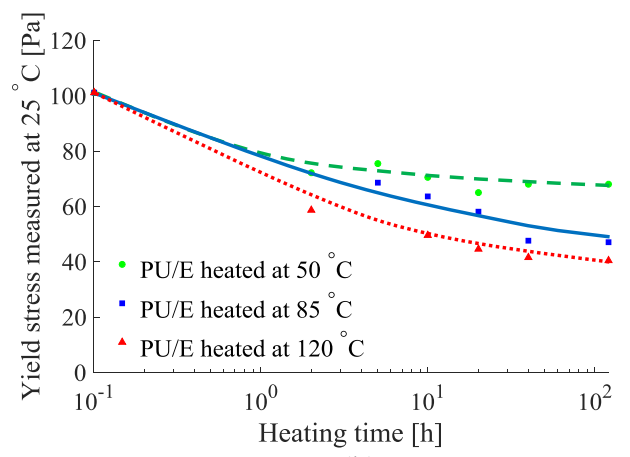

(b)

Figure 6 Yield stress (measured at $25^{\circ} \mathrm{C}, 1 \mathrm{~Hz}$ ) for purely thermal aged samples:

$$
\text { (a)LiX/PAO; (b)PU/E }
$$

The three isothermal ageing curves in Figure 6 could be merged together by correcting the thermal ageing time $t$ (in the unit of hour) with an 'Arrhenius correction factor' $C_{T}$ at a reference temperature $T_{0}$ : for $\mathrm{LiX} / \mathrm{PAO} C_{T}=2^{\frac{T-T_{0}}{15}}$ and for PU/E $C_{T}=2^{\frac{T-T_{0}}{10}}$. In the current study, the room temperature $25^{\circ} \mathrm{C}$ is selected as the reference value, so $T_{0}=25^{\circ} \mathrm{C}$. In this way, the isothermal heating time is transferred to the heating time at reference temperature and a temperature independent curve is fit, see Figure 7.

The fitting results shown in Figure 7 suggest that for LiX/PAO, the thermal effect on the change of yield stress can be expressed as

$$
\tau_{y}=-2.3 \ln \left(t \cdot C_{T}\right)+56
$$

and for $\mathrm{PU} / \mathrm{E}$ is

$$
\tau_{y}=-4.5 \ln \left(t \cdot C_{T}\right)+90 .
$$

This reduction in yield stress with increasing temperature is likely to be one of the reasons for the reduction in grease life with increasing temperature. It is apparent that the factor of 10 and $15^{\circ} \mathrm{C}$ for a reduction in yield stress with a factor of 2 is similar to the reduction in grease life with a factor of $2(1,26)$. 


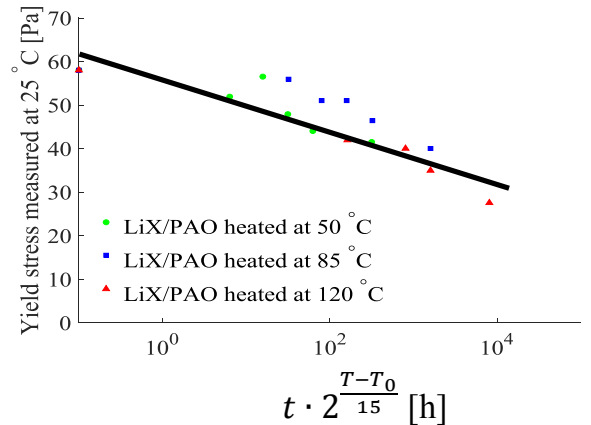

(a)

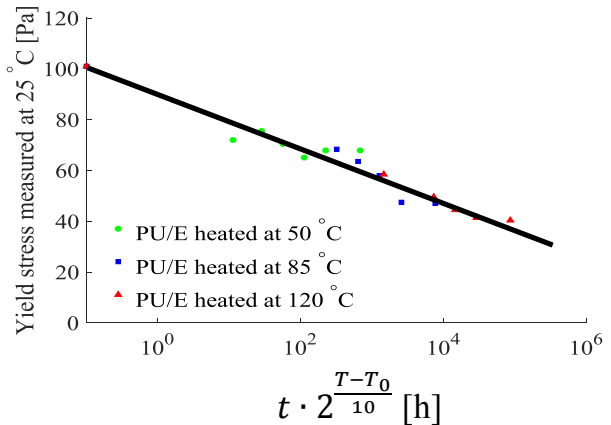

(b)

Figure 7 Pure thermal ageing results using the Arrhenius correction factor: (a)LiX/PAO; (b)PU/E

\section{A Master Curve for grease ageing}

It was shown above that in the absence of oxygen, the grease thermal ageing can be described as a function of temperature by correcting the isothermal heating time using the Arrhenius correction factor $C_{T}$. When evaluating the grease ageing inside the Couette Ageing Machine, the input work was calculated by integrating the product of torque and speed over the ageing time (equation 1). Since both thermal ageing behaviour in the oven and shear ageing behaviour in the Couette Ageing Machine are described as a function of time, it is allowed to use the applied work with an Arrhenius temperature correction (here termed as 'corrected energy density $E_{m}$ '), giving a Master Curve for the mechanical ageing of grease, taking both temperature and shear effects into account.

The corrected energy density $E_{m}$ then reads:

$$
E_{m}=\frac{C_{T} \cdot W}{V_{a}}
$$

where $W$ is the mechanical work, $C_{T}$ is the Arrhenius correction factor which was derived from the pure thermal ageing tests and $V_{a}$ is the grease volume inside the Couette Ageing Machine. Here the reference temperature is again $T_{0}=25^{\circ} \mathrm{C}$. Note that the unit for $E_{m}$ is $\mathrm{J} / \mathrm{mm}^{3}$.

The ageing results for PU/E and LiX/PAO in terms of $E_{m}$ are presented in Figure 8 and Figure 9. As shown in the figures, when plotted against the corrected energy density $E_{m}$, 
the ageing behaviour shows a similar trend as that for the shear degradation of lithium grease in the previous study (13): a progressive degradation phase at the beginning and slower degradation afterwards. Therefore, the previous developed grease ageing model is applicable in an adapted form, where the generated entropy density $S_{g}$ is replaced by the corrected energy density $E_{m}$ :

$$
Y=\frac{Y_{i}-Y_{\infty}}{1+K \cdot E_{m}{ }^{n}}+Y_{\infty},
$$

where $Y$ represents the rheological property (in this case the yield stress), with the index $i$ representing the initial rheological value for fresh grease and $\infty$ representing the second stage value for the long time aged sample; $K$ and $n$ are the coefficient of degradation and the exponent of degradation obtained from the curve fitting. This ageing model fits well for both PU/E and LiX/PAO, see Figure 8 and Figure 9 as well as Table 5. Clearly, when applying the corrected energy density $E_{m}$, the grease ageing behaviour inside the Couette Ageing Machine can now be described independent of the ageing shear rate and ageing temperature.

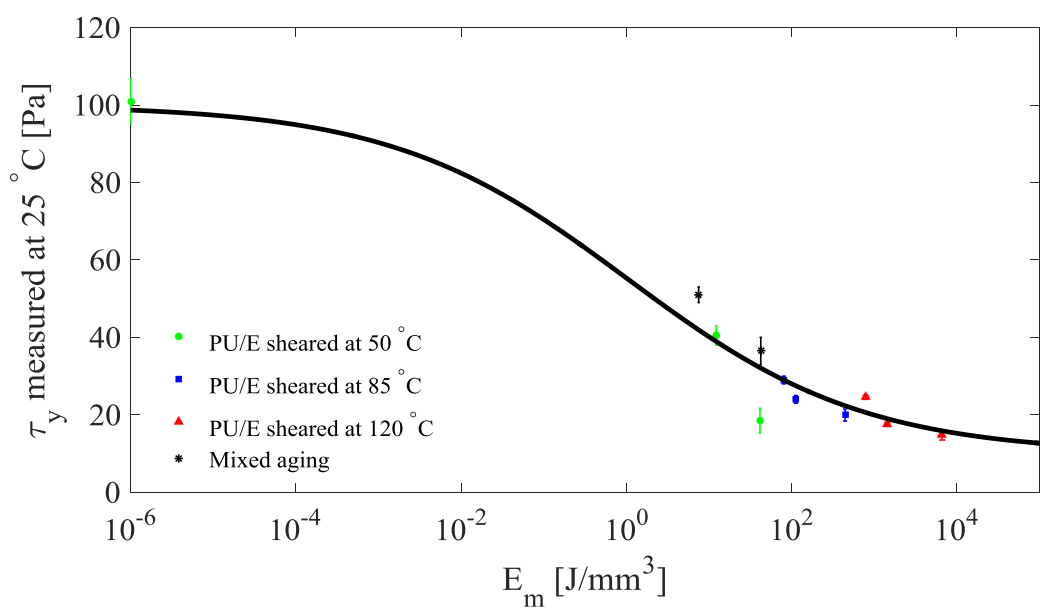

Figure 8 Yield stress vs $E_{m}$ for PU/E aged inside the Couette Ageing Machine 


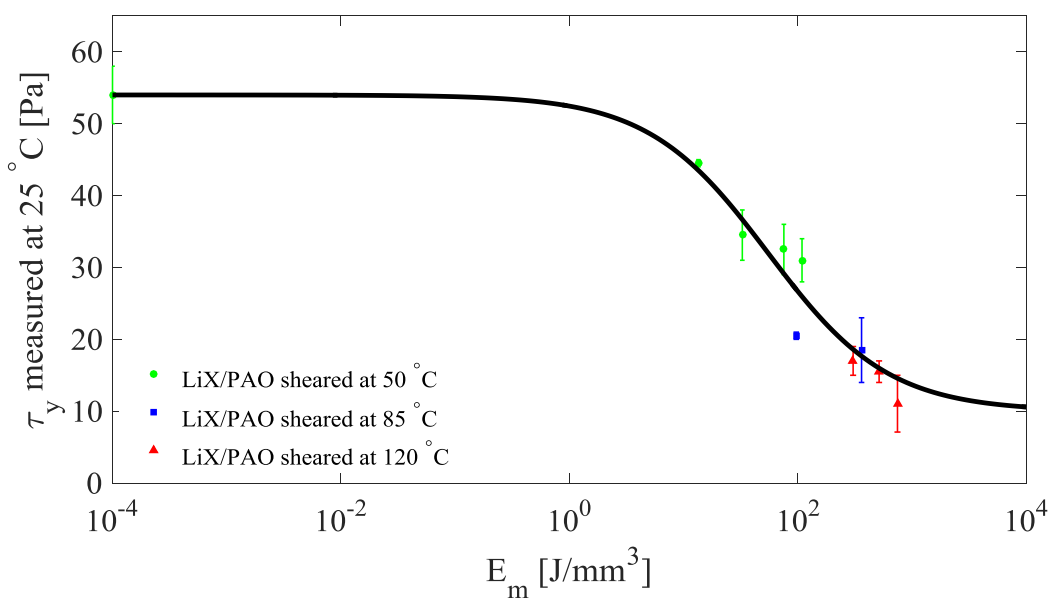

Figure 9 Yield stress vs $E_{m}$ for LiX/PAO aged inside the Couette Ageing Machine Table 5 Parameters for the Master Curve Equation

\begin{tabular}{|c|c|c|c|c|c|}
\hline & $Y_{i}\left(\tau_{y} P a\right)$ & $Y_{\infty}\left(\tau_{y} P a\right)$ & $K$ & $n$ & Goodness value $R^{2}$ \\
\hline $\mathrm{LiX} / \mathrm{PAO}$ & 54 & 10 & 0.04 & 0.89 & 0.94 \\
\hline $\mathrm{PU} / \mathrm{E}$ & 100 & 10 & 1.1 & 0.34 & 0.97 \\
\hline
\end{tabular}

A grease with a higher degradation coefficient $K$ and exponent $n$ is more fragile and sensible to shear. Reaching the second phase of grease degradation inside a bearing does not mean that the fragmented thickener, together with the base oil, will no longer function as a lubricant. On the contrary, it was earlier shown that grease with smaller thickener particles generates thicker films than grease with larger thickener particles (27). However, the destruction of the thickener network will have an effect on greasee bleed and grease consistency, which again will have an impact on the grease performance and may determine the grease life inside a bearing.

\section{Validation of the Master Curve ageing model}

So far, the grease ageing model has been developed based on samples prepared in the house made Couette Ageing Machine, where grease is subjected to uniform shear only. To check if this concept can be more widely applied, the Master Curve was also applied to a conventional scaled grease worker where fresh grease was aged at the reference 
temperature $25^{\circ} \mathrm{C}$ varying the number of strokes as listed in Table 6 (DIN ISO D217). This validation test was only carried out using PU/E.

Table 6 Ageing strokes for PU/E inside the DIN grease worker

\begin{tabular}{|c|c|c|c|c|c|}
\hline Number of strokes & 130 & 655 & 6550 & 13100 & 131000 \\
\hline
\end{tabular}

To measure the input energy for the grease worker, the generated drag load $F_{g w}$ during the ageing process was recorded by a load cell mounted under the grease worker container. The input energy density $E_{g w}$ was calculated by summing the product of the load $F_{g w}$ and the length of a stroke $L_{\text {piston }}$ during the ageing process, divided by the grease volume inside the container $V_{g w}$ :

$$
E_{g w}=\frac{\sum F_{g w} \cdot L_{p i s t o n}}{V_{g w}} .
$$

The yield stress of fresh and aged PU/E was plotted against the input energy and the result fits well with the grease ageing Master Curve, see Figure 10. This suggests that the Master Curve is generally applicable for prediction/describing the mechanical ageing of grease.

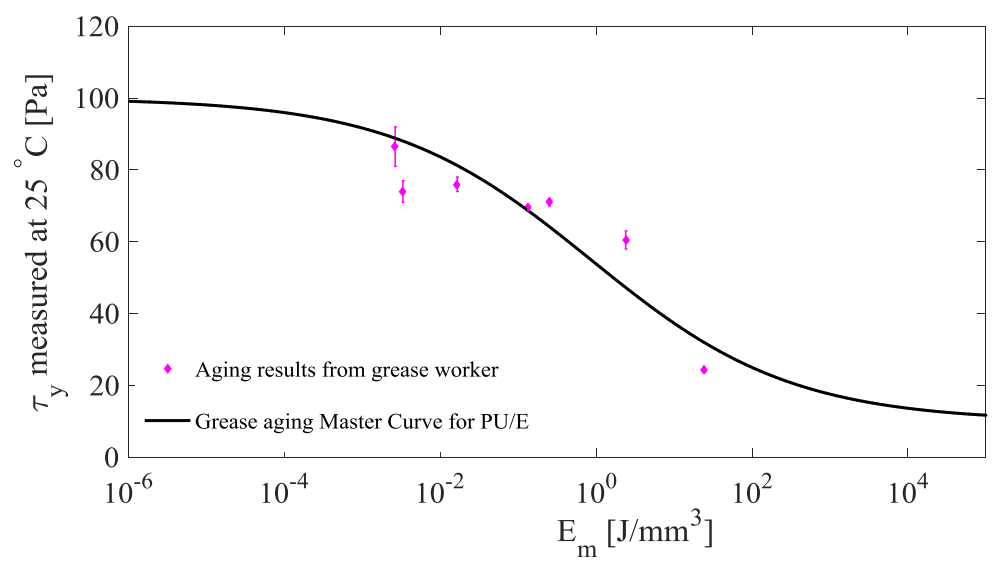

Figure 10 Validation of grease ageing Master Curve for PU/E inside a grease worker 


\section{Application of the ageing Master Curve to a bearing}

In this section, the Master Curve will be applied to grease ageing inside a rolling bearing. The grease flow inside a rolling bearing consists of two phases. After filling the bearing with grease and starting-up, the grease will first experience a 'churning phase', where a large fraction of the grease will be churned and moved towards the 'unswept area'. During this phase excessive shear on the grease takes place. At the end of this phase, most of the grease has ended up under the cage, on the shield/ seal inner surface and bearing shoulders. During the next phase, a fraction of the grease from the reservoirs may fall back into the contact area by e.g. vibrations, cage scraping or shear caused by (gently) touching the rolling elements $(28,29)$. In this phase only a fraction of the grease will be sheared. Hence the grease will not be uniformly aged inside a rolling bearing and the calculation of the imposed mechanical work on the grease in a rolling bearing will not be straightforward.

The ageing test in a rolling bearing was performed via the R0F+ test, using PU/E grease in a deep groove ball bearings (6204-2Z) for different periods of running time under two test conditions (Table 4). The yield stress for the grease after the bearing test are shown in Table 7. The yield stress decreases as a function of time, similar to ageing the grease in the Couette Ageing Machine or grease worker.

Table $7 \mathrm{R} 0 \mathrm{~F}+$ test results for PU/E

\begin{tabular}{|c|c|c|c|c|c|}
\hline \multicolumn{2}{|c|}{ Sample } & $\begin{array}{c}\text { Bearing } \\
\text { frictional } \\
\text { torque } M(N \cdot \\
m)\end{array}$ & $\begin{array}{l}\text { Correcting } \\
\text { factor } C_{e}\end{array}$ & $\begin{array}{l}\text { Bearing friction } \\
\text { energy density } E_{b} \\
\quad\left(\mathrm{Jmm}^{-3}\right)\end{array}$ & $\begin{array}{c}\text { Yield stress } \\
\text { measured at } \\
25^{\circ} \mathrm{C}(\mathrm{Pa})\end{array}$ \\
\hline \multicolumn{2}{|c|}{ Fresh PU/E } & 0 & 0 & 0 & 100 \\
\hline \multirow{2}{*}{$\begin{array}{c}\text { Condition } \\
1 \\
\end{array}$} & $22 \mathrm{~h}$ & \multirow{2}{*}{$3.4 \times 10^{-2}$} & \multirow{5}{*}{$2.0 \times 10^{-4}$} & $1.7 \times 10^{3}$ & 63 \\
\hline & $195 \mathrm{~h}$ & & & $1.5 \times 10^{4}$ & 58 \\
\hline \multirow{3}{*}{$\begin{array}{c}\text { Condition } \\
2\end{array}$} & $100 \mathrm{~h}$ & \multirow{3}{*}{$2.6 \times 10^{-2}$} & & $9.0 \times 10^{3}$ & 43 \\
\hline & $235 \mathrm{~h}$ & & & $2.1 \times 10^{4}$ & 52 \\
\hline & $600 \mathrm{~h}$ & & & $5.4 \times 10^{4}$ & 30 \\
\hline
\end{tabular}

The friction energy density inside the bearing $E_{b}$ was calculated by integrating the product of frictional torque $M$ and angular speed over time (equation 1) divided by the total initial grease filling volume $V_{b}$. For the R0F+ shielded bearing, the frictional torque $M$ is obtained by making use of the SKF model (30): 


$$
M=M_{r r}+M_{s l},
$$

where $M_{r r}$ is the rolling frictional moment and $M_{s l}$ is the sliding frictional moment.

The SKF friction torque model was developed for steady state running condition, i.e., after the 'churning phase' where the friction torque is more or less stable. Each of the R0F+ tests was started with a freshly greased bearing. Therefore, the tests include primarily the starting fraction of a bearing service life and the friction torque $M$ was considered constant during the running time. The calculated frictional torque $M$ and the bearing friction energy density $E_{b}$ for the R0F+ tests are given in Table 7.

In Figure 11 the results are plotted as the yield stress measured at $25^{\circ} \mathrm{C}$ versus the friction energy density $E_{b}$. The result does not fit onto the Master Curve. The reasons are obvious: the aged PU/E was collected from the $6204-2 \mathrm{Z}$ as a mixture of grease from the various parts of the bearing, i.e., from the areas where grease was subjected to shear but also from the areas where the grease was stationary. Therefore, a fraction of the grease will be aged and for sure this volume will be smaller than the total initial fill, which is clearly different from the ageing inside the Couette Ageing Machine.

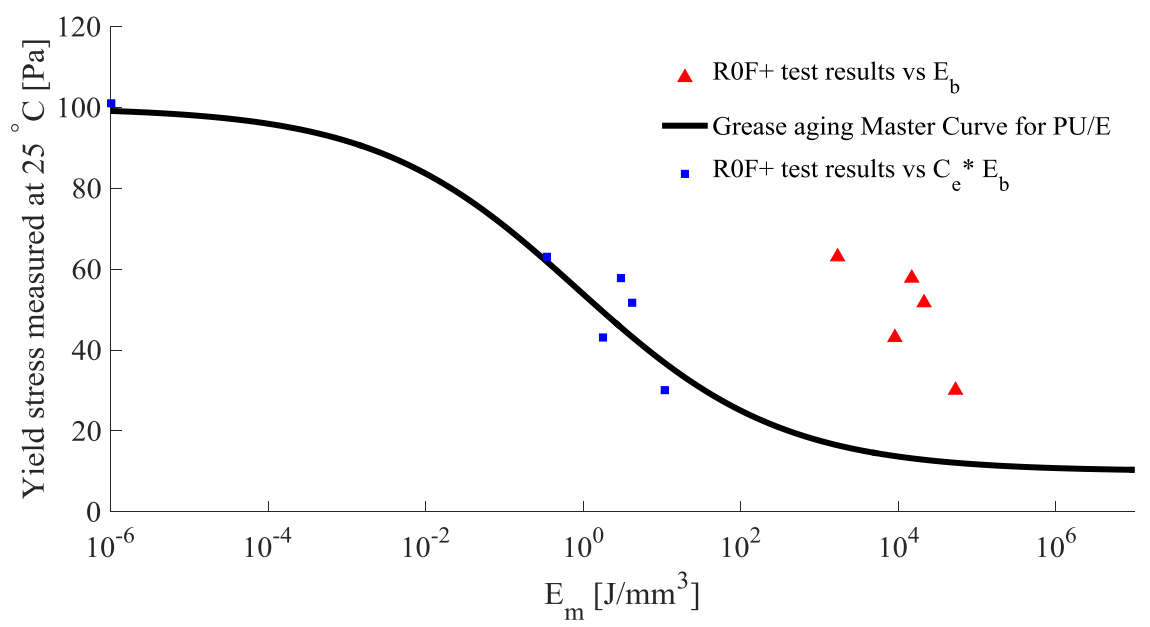

Figure $11 \mathrm{PU} / \mathrm{E}$ R0F+ results and the Couette ageing fit curve

A good fit was obtained by multiplying the frictional energy density with a correcting factor $C_{e}=2.0 \times 10^{-4}$ so that the bearing frictional energy density $E_{b}$ can be translated to the corrected input energy density $E_{m}$ inside the Couette Ageing Machine:

B-19 


$$
E_{m}=C_{e} \cdot E_{b} .
$$

It is no surprise that the $C_{e}$ value is small. After all, the bearing friction energy density $E_{b}$ is calculated based on a combination of sliding and rolling friction moment (equation 6), which is larger than the energy dissipated in only shearing the grease. Additionally, inside the bearing, a major fraction of the grease is quite immobile after the churning phase and it is not the total volume of grease that will be severely sheared. This correcting factor $C_{e}$ is thus applied to correct the grease ageing energy and to compensate for the uncertainty in the stressed grease volume and the shear of grease inside the bearing. It is apparent that with the corrected energy $\left(C_{e} \cdot E_{b}\right)$, the $\mathrm{R} 0 \mathrm{~F}+$ results follow the Master Curve (Figure 11). Therefore, the ageing Master Curve can be translated to the bearing running time $t_{b}$ by making use of equation 1 and 7 :

$$
E_{m}=C_{e} \cdot E_{b}=C_{e} \cdot \frac{\frac{M \cdot N \cdot 2 \pi}{60} \cdot t_{b}}{V_{b}},
$$

where the unit of the bearing running time $t_{b}$ is seconds.

Based on the Master Curve parameters in Table 5 and equation 8, the translated grease ageing curve for $\mathrm{PU} / \mathrm{E}$ in terms of the $\mathrm{R} 0 \mathrm{~F}+$ bearing running time $t_{b}$ reads:

$$
\tau_{y}=\frac{100-10}{1+1.1 \cdot\left(C_{e} \cdot \frac{\frac{M \cdot N \cdot 2 \pi}{60} \cdot t_{b}}{V_{b}}\right)^{0.34}}+10 .
$$

In Figure 12, the translated grease ageing curve for each test condition is plotted with the corresponding $\mathrm{R} 0 \mathrm{~F}+$ results versus the bearing running time. The two translated curves are very close to each other. This is logical, because the difference in the current two R0F+ running conditions and the corresponding bearing frictional torque $M$ is small (see Table 4 and Table 7), resulting in similar translated curves.

The grease life calculated from the SKF grease life model (30) is also plotted on the grease ageing curve in Figure 12, together with the corresponding yield stress value calculated from equation 9: in the case of $15000 \mathrm{rpm}$, the grease life inside a $6204-2 \mathrm{Z}$ bearing is expected to be $L_{50}=4500 \mathrm{~h}$, when the yield stress would drop to $29 \mathrm{~Pa}$; in the case of $10000 \mathrm{rpm}, L_{50}=11500 \mathrm{~h}$, when the yield stress would drop to $25 \mathrm{~Pa}$. 


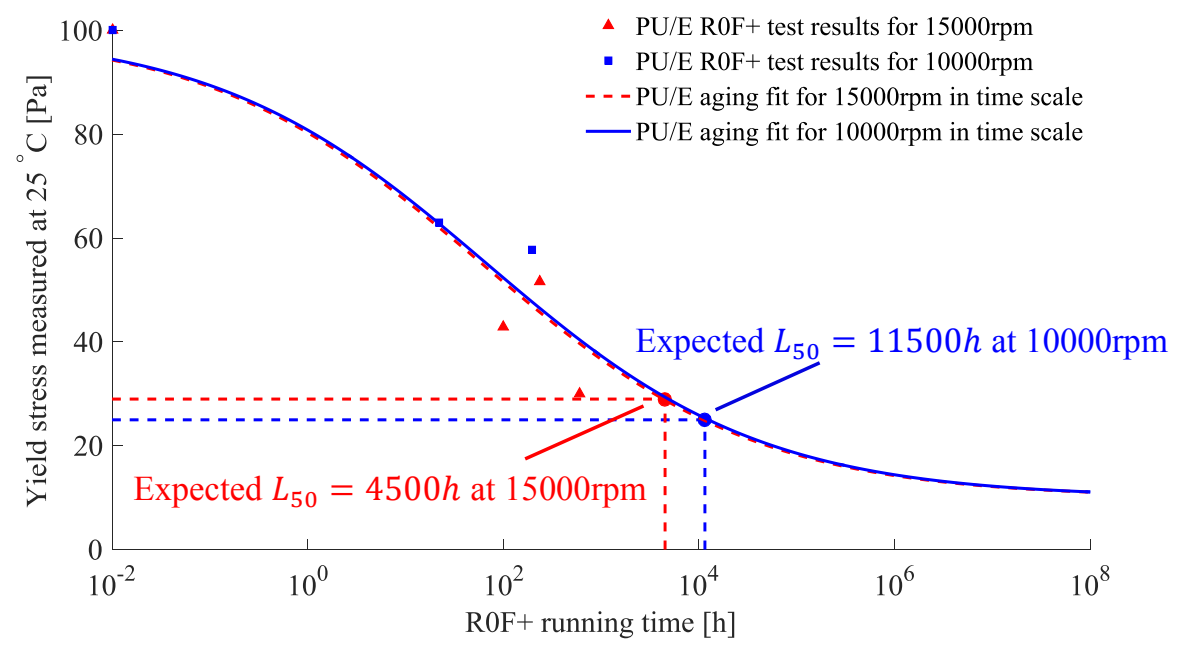

Figure $12 \mathrm{PU} / \mathrm{E}$ grease ageing curve based on the R0F+ results

It is tempting to use the Master Curve, with critical yield stress as a method to predict grease life. The end-of-grease-life for both operating conditions in the R0F+ test is according to the Master Curve reached at an critical value of the yield stress, which is close to the lower limit and suggests that the end of grease life is given by the point in time where the active fraction of the grease has almost lost its consistency. However, this critical yield stress may not be unique. It may be grease, bearing and operating condition dependent. The evaluation can only be made if the mechanical work the grease experiences inside the bearing is known in detail. This needs to be further investigated in future research and can only be explored using rolling bearing grease life tests.

\section{Conclusion}

In this study, the influence of shear and temperature on the ageing of fibrous structured greases has been studied by ageing grease inside a housemade Couette Ageing Machine under controlled shear rate and temperature. The change in rheological properties are a function of the energy per stressed volume. The results demonstrate that increasing temperature accelerates the mechanical ageing process and that this thermal effect can be described using an Arrhenius correction factor. Based on this, a grease ageing model is constructed using the imposed energy corrected for temperature, leading to a Master Curve for the mechanical ageing of grease. The Master Curve was validated using a grease worker. 
It was subsequently applied to grease aged inside deep groove ball bearings showing that the concept also applies to grease ageing in a rolling bearing. This Master Curve could be used as a potential building block or screening method for grease life. It is important to mention that the current model only describes shear degradation. A full grease life model should not only include all ageing components but also their impact on the lubrication performance and can only be validated using rolling bearing grease life tests.

\section{Acknowledgement}

The authors would like to thank SKF Research and Technology Development for technical and financial support.

\section{References}

(1) Lugt PM. Grease Lubrication in Rolling Bearings. The Atrium, Southern Gate, Chichester, West Sussex, PO19 8SQ, United Kingdom: John Wiley and Sons; 2013.

(2) Ito H, Tomaru M, Suzuki T. Physical and chemical aspects of grease deterioration in sealed ball bearings. Lubrication Engineering (STLE) 1988;44(10):872-879.

(3) Lundberg J, Höglund E. A new method for determining the mechanical stability of lubricating greases. Tribology International 2000;33(3):217-223.

(4) Salomonsson L, Stang G, Zhmud B. Oil/ thickener interactions and rheology of lubricating greases. Tribology Transactions 2007;50(3):302-309.

(5) Couronne I, Vergne P. Couronne I, Vergne P. Rheological behavior of greases: Part II-Effect of thermal aging, correlation with physico-chemical changes. Tribology Transactions 2000;43(4):788-794.

(6) Spiegel K, Fricke J, Meis K. Die Fließeigenschaften von Schmierfetten in Abhängigkeit von Beanspruchung, Beanspruchungsdauer und Temperatur. International Colloquium Tribology, Esslingen, Germany 2000.

(7) Moore RJ, Cravath AM. Mechanical breakdown of soap-base greases. Industrial \& Engineering Chemistry 1951;43(12):2892-2897.

(8) Czarny R. Einfluss der Thixotropie auf die rheologischen Eigenschaften der Schmierfette. Tribologie und Schmierungstechnik 1989;36(3):134-140.

(9) Plint M, Alliston-Greiner A. A new grease viscometer: a study of the influence of shear on the properties of greases. NLGI spokesman 1992;56(2):7-15.

(10) Bryant MD, Khonsari MM, Ling FF.On the thermodynamics of degradation. The Royal Society of London A: Mathematical, Physical and Engineering Sciences: The Royal Society; 2008. 
(11) Rezasoltani A, Khonsari MM. On the correlation between mechanical degradation of lubricating grease and entropy. Tribology Letters 2014;56(2):197-204.

(12) Rezasoltani A, Khonsari MM. An engineering model to estimate consistency reduction of lubricating grease subjected to mechanical degradation under shear. Tribology International 2016;103:465-474.

(13) Zhou Y, Bosman R, Lugt PM. A Model for shear degradation of lithium soap grease at ambient temperature. Tribology Transactions 2016 12/21:1-10.

(14) Hurley S, Cann P, Spikes H. Lubrication and reflow properties of thermally aged greases. Tribol Trans 2000;43(2):221-228.

(15) Cyriac F, Lugt PM, Bosman R. Impact of water on the rheology of lubricating greases. Tribology Transactions 2016;59(4):679-689.

(16) Karis TE, Kono RN, Jhon MS. Harmonic analysis in grease rheology. Journal of applied polymer science 2003;90(2):334-343.

(17) Gow GM. The CEY to grease rheology. In International Tribology Conference 1990, Brisbane 2-5 December 1990: Putting Tribology to Work; Reliability and Maintainability through Lubrication and Wear Technology; Preprints of Papers 1990 (p. 202). Institution of Engineers, Australia.

(18) Froishterer G. Rheological and thermophysical properties of greases. CRC Press; 1989.

(19) Ide A, Asai Y, Takayama A, Akiyama M. New life prediction method of the grease by the activation energy. Tribology Online 2011;6(1):45-49.

(20) Bondi A, Cravath AM, Moore RJ, Peterson WH. Basic factors determining the structure and rheology of lubricating grease. The Institute Spokesman 1950;13(12):12-18.

(21) Malkin AI, Malkin AY, Isayev AI. Rheology: concepts, methods \& applications. Elsevier; 2017.

(22) Lugt PM, Kommer A, Lindgren H, Deinhofer L. The ROF methodology for grease life testing. NLGI Spokesman 2013;77(1):18-27.

(23) Deutsches Institut für Normung. Testing of lubricants - Determination of shear viscosity of lubricating greases by rotational viscosimeter - Part 1: System of cone/plate. 2007;DIN 51810-1:2007-07.

(24) Cyriac F, Lugt PM, Bosman R. On a new method to determine the yield stress in lubricating grease. Tribology Transactions 2015;58(6):1021-1030.

(25) Huang L, Guo D, Cann P, Wan GT, Wen S. T Thermal oxidation mechanism of polyalphaolefin greases with lithium soap and diurea thickeners: effects of the thickener. Tribology Transactions 2016;59(5):801-809.

(26) Kawamura T, Minami M, Hirata M. Grease life prediction for sealed ball bearings. Tribology Transactions 2001;44(2):256-262. 
(27) Cyriac F, Lugt PM, Bosman R, Padberg C, Venner C. Effect of thickener particle geometry and concentration on the grease EHL film thickness at medium speeds. Tribology Letters 2016;61(2):1-13.

(28) Cann P, Lubrecht A. An analysis of the mechanisms of grease lubrication in rolling element bearings. Lubrication Science 1999;11(3):227-245.

(29) Lugt PM, Velickov S, Tripp JH. On the chaotic behavior of grease lubrication in rolling bearings. Tribology Transactions 2009;52(5):581-590.

(30) SKF group. SKF rolling bearings catalogue. 2016. 

Paper C 


\section{An experimental study on film thickness in a rolling bearing for fresh and aged lubricating greases}

Yuxin Zhou ${ }^{1}$, Rob Bosman ${ }^{1}$ and Piet M. Lugt ${ }^{1,2}$

${ }^{1}$ University of Twente, Enschede, the Netherlands

${ }^{2}$ SKF Research and Technology Development, Nieuwegein, the Netherlands

\section{List of symbols}

\begin{tabular}{|c|c|}
\hline$A_{\text {Hertz }}$ & Hertzian contact area $\left(m^{2}\right)$ \\
\hline$C_{\text {bearing }}$ & The bearing capacitance $(F)$ \\
\hline$C$ & Bearing dynamic load rating $(N)$ \\
\hline$C_{i}$ & Capacitance formed by the ball and the inner ring $(F)$ \\
\hline$C_{o}$ & Capacitance formed by the ball and the outer ring $(F)$ \\
\hline$d_{m}$ & Mean diameter $(m)$ \\
\hline$E^{\prime}$ & Reduced Young's Modulus $(\mathrm{Pa})$ \\
\hline$F_{a}$ & Axial load $(N)$ \\
\hline $\bar{G}$ & Material parameter in the Hamrock-Dowson equation (-) \\
\hline$h$ & Grease film thickness at the stable stage $(m)$ \\
\hline$h_{\text {grease }}$ & Calibrated grease film thickness $(m)$ \\
\hline$h_{\text {oil }}$ & Calculated oil film thickness $(m)$ \\
\hline$L_{10}$ & $\begin{array}{l}\text { Estimated bearing life at which } 10 \% \text { of the bearing population has failed } \\
\text { (h) }\end{array}$ \\
\hline$N$ & Rotational speed of the bearing ( $\mathrm{rpm})$ \\
\hline$P$ & Equivalent bearing load $(N)$ \\
\hline$T$ & Running temperature $\left({ }^{\circ} \mathrm{C}\right)$ \\
\hline$R_{q}$ & Arithmetical root mean square height deviation of an assessed profile $(\mathrm{m})$ \\
\hline$R_{x}, R_{y}$ & Reduced contact radii $(m)$ \\
\hline $\bar{u}$ & Mean entrainment speed of the contact surfaces $(\mathrm{m} / \mathrm{s})$ \\
\hline $\bar{U}$ & Speed parameter of the Hamrock-Dowson equation (-) \\
\hline$V_{\text {cap }}$ & Lubcheck output voltage $(V)$ \\
\hline$W$ & Load on each rolling element $(N)$ \\
\hline
\end{tabular}




\begin{tabular}{|c|l|}
\hline $\bar{W}$ & Load parameter in the Hamrock-Dowson equation (-) \\
\hline$Z$ & Number of balls (-) \\
\hline$\alpha$ & Pressure-viscosity coefficient of the lubricating oil $\left(\mathrm{Pa}^{-1}\right)$ \\
\hline$\eta$ & Lubricating oil viscosity $(\mathrm{Pa} \cdot \mathrm{s})$ \\
\hline$\varepsilon_{0}$ & Lubricant dielectric constant in vacuum $(\mathrm{F} / \mathrm{m})$ \\
\hline$\varepsilon_{r}$ & Lubricant dielectric constant in the contact area $(\mathrm{F} / \mathrm{m})$ \\
\hline
\end{tabular}

\begin{abstract}
The lubricating film formation of greases has been widely studied using single contact ballon-disc configurations. Howeverthe film formation with grease is, other than for oil, governed by starvation, which in a full bearing is clearly different from that of the single contact. In this paper, film thickness measurements for various greases in a shielded deep groove ball bearing will be presented. The results were obtained using a house made film thickness measurement rig based on the 'electric capacitance method'. It will be shown that the film thickness may deviate from the theoretical elastohydrodynamic film thickness calculated from the bled oil and that the film thickness is not constant in time. It will also be shown that the film thickness for longer times is not only determined by the traditional properties such as oil viscosity and grease bleed but also by shear degradation of its microstructure.
\end{abstract}

\title{
Introduction
}

The performance of a bearing is determined to a large extent by the generated film thickness between the rolling elements and the raceway. If the film is insufficiently thick to separate the surfaces, direct contact occurs, leading to wear and/or a reduction of bearing life. The prediction of the lubricant film for grease lubrication is more difficult than for oil lubrication due to the rather complex lubrication mechanism given by starvation, replenishment, changes in lubricant properties (mechanical ageing, oxidation, loss of bleeding property), etc., which is still not fully understood (1).

Extensive studies have been performed on grease lubrication using single contact configurations, where the rolling element-ring contacts inside a bearing are simulated in a ball-on-disc or disc-on-disc apparatus (2-8). However, in this simplification many effects 
that have a major impact on film formation in a rolling bearing are ignored. Lubrication effects that cannot be adequately simulated by single contact tests include the large number of over-rollings, centrifugal forces, vibrations, cage scraping $(9,10)$, as well as by the slow change of the grease properties due to shear, oxidation and oil loss. Single contact measurements are very valuable but should ideally be combined with film thickness measurements in full bearings (1).

Mérieux et al. (11) gave four types of grease film thickness evolutions based on film thickness measurements in a single contact running at a constant speed: fully flooded; starved; starved with stabilization; starved with recovery. They particularly studied the fourth situation and attributed the film recovery to an increased lubricant availability due to grease shear degradation. The first condition was observed by Ward et al. (12) for a pair of axially loaded angular contact ball bearings fully packed with grease, where no significant film thickness decay was observed during 400 hours of running time. Continuous film thickness decrease was found when a reduced grease fill was used. The third condition was observed by Wilson (13) for a radially loaded roller bearing, which was attributed to temperature variation and partial starvation.

The film thickness for grease lubricated bearings is generally calculated using the base oil properties under fully flooded conditions (14). It was shown by Morales et al. (15) and Dong et al. (16) that, particularly at very low speeds, a large discrepancy occurs where grease generates thicker films than that of the base oil, which is attributed to the thickener contribution and can be modelled with an 'effective viscosity' that is greater than the viscosity of the base oil (14).

Wikström \& Jacobson (9) suggested a lubricant feed-loss mechanism for a grease lubricated roller bearing: the film thickness is given by a balance between the lubricant feed by grease bleeding, replenishment and drop feed from the roller adhered lubricant and the lubricant loss due to oxidation, polymerization, evaporation, surface spreading and drop loss. Cann \& Lubrecht (17) suggested other replenishment mechanisms in a grease lubricated bearing: bulk grease migration due to ball spin, vibrations, cage effects and capillary reflow of the bled oil due to possible shock loads or machine start-stops. 
Baker (18) studied the influence of grease bleeding on bearing life. He concluded that a high bleed rate will prolong bearing life, but excessive bleeding (e.g. at high temperatures) will quickly 'dry-out' the grease and will therefore have a negative effect on the bearing life. Dalmaz \& Nantua (19) found that with an identical thickener, greases with a higher base oil viscosity will increase the life of double row angular contact ball bearings. However, Ohno et al. (20) observed that for thrust ball bearings, grease with higher base oil viscosity will aggravate starvation and therefore reduce the bearing life.

Other than the grease film thickness observations mentioned above, there appears to be little published material on actual film thickness measurements in grease lubricated full bearings. In this paper film thickness measurements will be described in a deep groove ball bearing using a house made film thickness measurement rig based on the electric capacitance method, a method earlier used in $(9,13,15,20-25)$.

Since the grease lubrication mechanism varies in time (churning phase, bleeding phase etc.) and is also known to be dynamic $(1,26)$, the grease films were measured during relatively long running time (100 hours). A comparison will be made between the measured grease film thickness and the theoretical fully flooded film thickness calculated using the Hamrock and Dowson equation (27) using the grease bled oil properties. In addition, to study the long-term behaviour, the influence of grease shear degradation on the film thickness was studied by using mechanically aged greases.

\section{Material and Method}

\section{Sample preparation}

The film thickness tests were first performed for six commercial lubricating greases, with different base oils and thickener materials/structures. To study the influence of grease shear degradation on the bearing film thickness, fresh polyurea grease (denoted as 'PU/E') was aged inside a house made 'Couette Ageing Machine' with different ageing levels (28). Afterwards, the bearing film thickness was measured using the aged PU/E samples. The goal of this test was not only to study the impact of grease ageing on film thickness but also to study the film formation of greases with the same chemical composition but different 
grease bleed, consistency and micro-structure. Detailed information on the grease composition is shown in Table 1.

Table 1 Composition and properties of the tested greases

\begin{tabular}{|c|c|c|c|}
\hline Fresh Grease & NLGI & Thickener type & Base oil type \\
\hline $\mathrm{CaS} / \mathrm{PAO}$ & $1-2$ & Calcium sulphonate complex & PAO \\
\hline $\mathrm{CaS} / \mathrm{M}$ & 2 & Calcium sulphonate complex & Mineral oil \\
\hline $\mathrm{Li} / \mathrm{M}$ & 3 & Lithium & Mineral oil \\
\hline $\mathrm{Li} / \mathrm{SS}$ & 2 & Lithium & PAO \\
\hline $\mathrm{LiX} / \mathrm{PAO}$ & $2-3$ & Lithium complex & Ester \\
\hline $\mathrm{PU} / \mathrm{E}$ & $2-3$ & Polyurea & \\
\hline
\end{tabular}

\section{Sample characterization}

As mentioned above, grease bleeding is considered to be a major property determining the film thickness. Large volumes of grease are required for measuring grease bleed using the standardized methods such as DIN 51817/ IP 121 (1). In this work, grease bleed was measured using the SKF Grease Test Kit (29), which only uses $125.6 \mathrm{~mm}^{3}$ of grease. As shown in Figure 1-a, the grease sample was positioned in the centre of a piece of blotting paper. The tested sample is heated on a heater in the open air at $60^{\circ} \mathrm{C}$ for two hours. During this time, the base oil spreads through the paper forming an 'oil stain'. Next, the surface area of the oil stain is measured with unit $\mathrm{mm}^{2}$, which is a measure for the grease bleed rate.

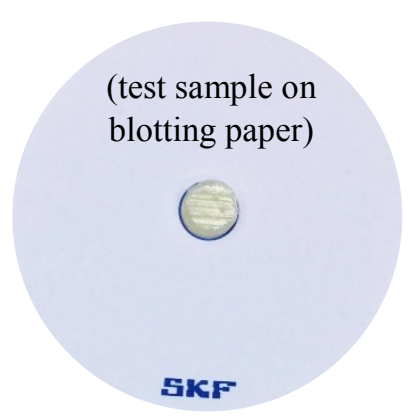

(a)

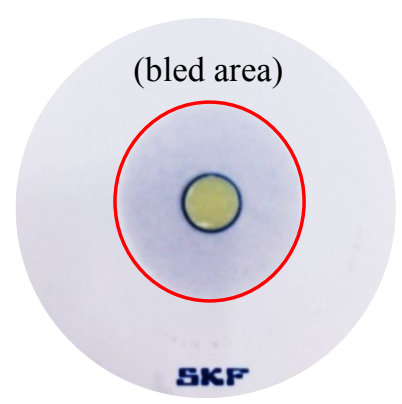

(b)

Figure 1 SKF grease bleed test: (a) Before the test; (b) After the test

In addition to grease bleeding, the grease rheology was measured. There are numerous rheological parameters that can be measured but in this study the yield stress is considered, 
which is the most important parameter related to the mobility of the grease. Here the grease yield stress was obtained from the rheological oscillatory strain sweep measurements at $25^{\circ} \mathrm{C}$, following the method proposed by Cyriac et al. (30). The values for grease bleed and yield stress are shown in Table 2. For the calculation of the fully flooded oil film thickness, the bled oil viscosity and the pressure-viscosity coefficient (calculated by minimizing the error between the ball-on-disc film thickness and the calculated Hamrock and Dowson film thickness (27) following Van Leeuwen's method (31) (32)) are listed in Table 2.

Table 2 Grease and bled oil properties

\begin{tabular}{|c|c|c|c|c|}
\hline Grease sample & $\begin{array}{c}\text { Grease bleed } \\
\left(\mathrm{mm}^{2}\right)\end{array}$ & $\begin{array}{c}\text { Yield stress } \\
(\mathrm{Pa})\end{array}$ & $\begin{array}{c}\text { Kinematic } \\
\text { viscosity at } \\
40^{\circ} \mathrm{C} / 100^{\circ} \mathrm{C} \\
(\mathrm{cSt})\end{array}$ & $\begin{array}{c}\text { Pressure- } \\
\text { viscosity } \\
\text { coefficient } \\
\alpha \\
\left(10^{-9} \mathrm{~Pa}^{-1}\right)\end{array}$ \\
\hline Fresh CaS/PAO & 269 & 106 & $320 / 30$ & 17 \\
\hline Fresh CaS/M & 115 & 154 & $420 / 26$ & 27 \\
\hline Fresh Li/M & 899 & 57 & $100 / 10$ & 27 \\
\hline Fresh Li/SS & 1357 & 35 & $42 / 7$ & 24 \\
\hline Fresh LiX/PAO & 479 & 54 & $191 / 42$ & 17 \\
\hline Fresh PU/E & 615 & 101 & $70 / 9$ & 24 \\
\hline
\end{tabular}

To indicate the ageing level of the sheared PU/E, the changes of grease bleed and yield stress are plotted versus the input ageing energy in Figure 2. This figure shows that the samples that are used here reflect the full spectrum of shear degradation. 


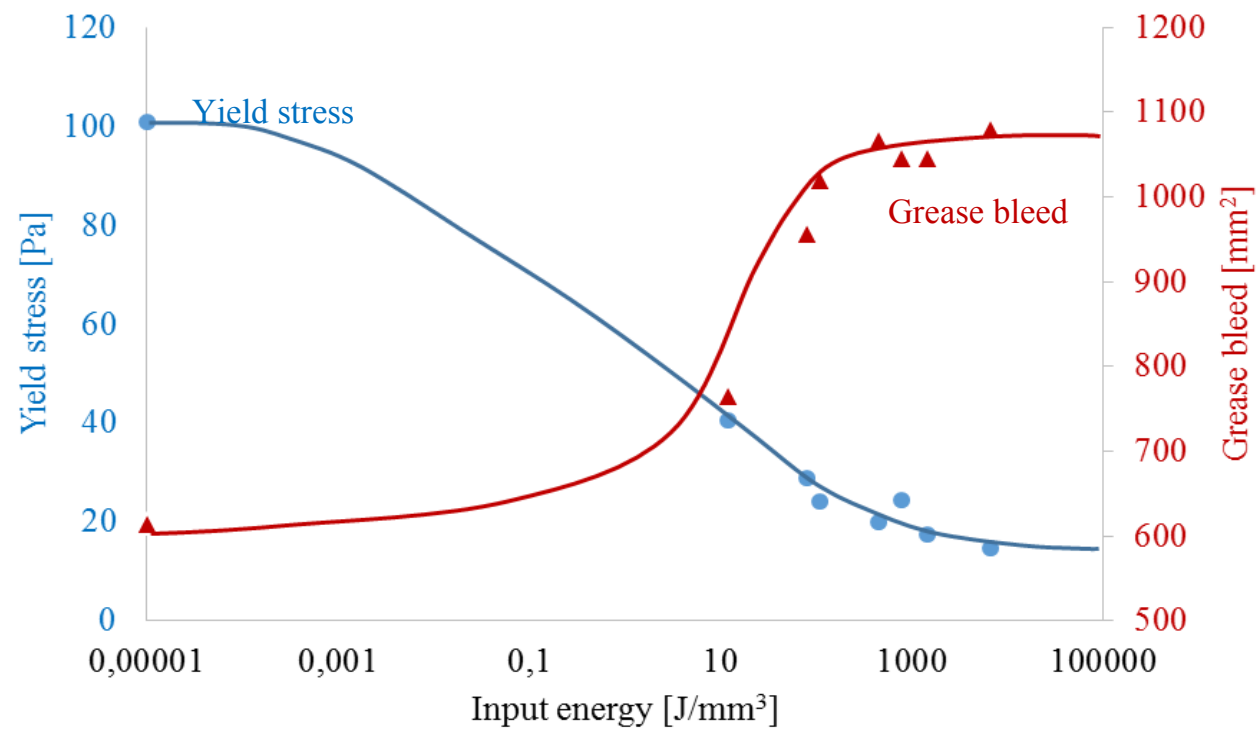

Figure 2 Condition of the PU/E samples plotted on a grease ageing Master Curve for PU/E grease (33) in combination with the grease bleed properties

After the test, the grease was collected from the bearing shields and in the vicinity of the running track. The absence of oxidation was confirmed using Fourier-Transform Infra-Red spectroscopy (results not shown).

\section{Film thickness measuring rig}

In this paper, the grease film thickness evolution in a full deep groove ball bearing 6209$2 \mathrm{Z} / \mathrm{C} 3$ was studied with inner ring rotation. The bearing test rig is shown in Figure 3. The outer ring of the tested bearing was clamped inside the bearing case which was in turn bolted to a frame with elastic hinges. The bearing inner ring was driven via the shaft by an electric motor (not shown in Figure 3) through a magnetic coupling. To ensure proper alignment, the shaft was supported by a tapered roller bearing mounted to the outer frame.

To obtain a uniform pressure distribution and film thickness for each rolling element, a pure axial load $F_{a}$ was applied. The load was set as $\frac{C}{P}=40$, giving an axial load of $F_{a}=513 \mathrm{~N}$. The speed was $N=2500 \mathrm{rpm}$, corresponding to $N d m=162500 \mathrm{~mm} / \mathrm{min}$ (product of speed and mean diameter), which is relatively low but in the same order as used in standard test rigs such as the $\mathrm{R} 0 \mathrm{~F}+$ grease life test (34). The tests were run for 100 hours using six 
different fresh greases (Table 1) to ensure that the grease will undergo all relevant phases. In addition, 10-hour tests (sufficiently long to reach a steady state film) were carried out for the aged PU/E greases.

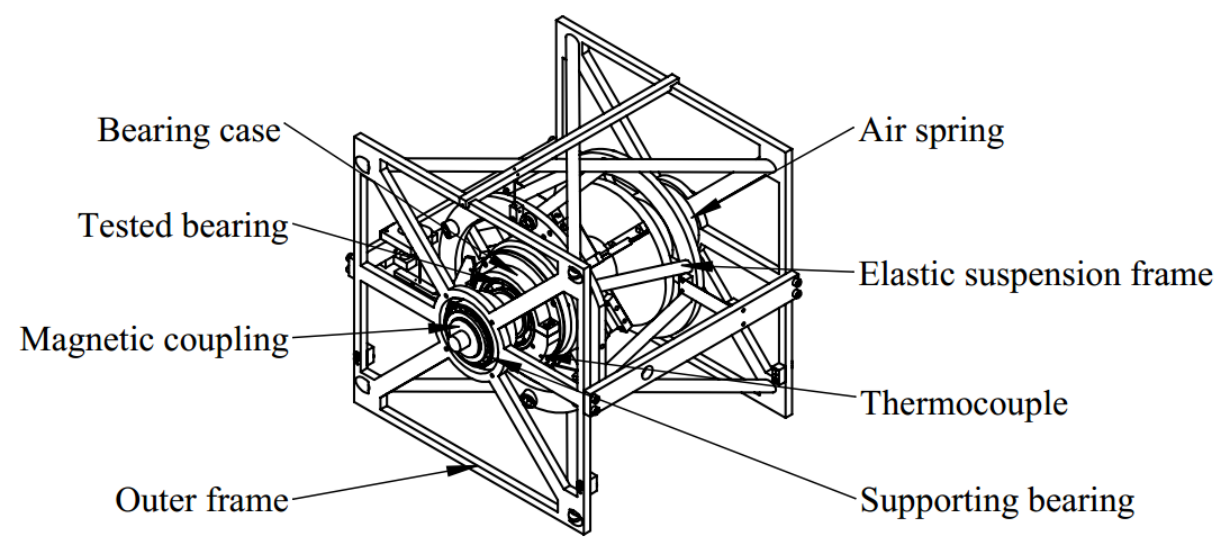

Figure 3 Bearing test rig

The bearing was run at room temperature and the self-induced temperature was recorded by a thermocouple attached to the bearing outer ring through a hole in the bearing case. In addition, the applied load was calculated from the air pressure of the air spring. For each test, $30 \%$ of the bearing free volume was filled with the grease sample from both sides. Afterwards, the bearing was closed by the shields. Before and after each test, the bearing was weighted to measure possible leakage.

The bearing film thickness was obtained using Lubcheck Mk3 (35), by measuring the capacitance of the bearing $C_{\text {bearing }}$, which was treated as the sum of $Z$ capacitors in parallel, each one determined by the lubricant film between the inner ring-ball $\left(C_{i}\right)$ and ball-outer ring $\left(C_{o}\right)$ ( $Z$ is the number of the balls). Figure 4 shows the basic principle of the film thickness measuring rig. The bearing inner ring was connected to the Lubcheck via a mercury contact attached to the rotating shaft. The stationary bearing outer ring was connected to the Lubcheck directly. The rotor and stator were electrically isolated by the lubricant film. A compensation box (with capacitors) was connected in-between to compensate the inductance of the connecting leads. The Lubcheck output voltage $V_{\text {cap }}$ can be considered as a measure for the average of the inner and outer ring film thickness. To transfer the Lubcheck signal $V_{\text {cap }}$ to the bearing film thickness, a calibration was performed 
using Wilson's method (13) but using the bled oil under the same running conditions as in the grease film thickness measurements, for details see the Appendix.

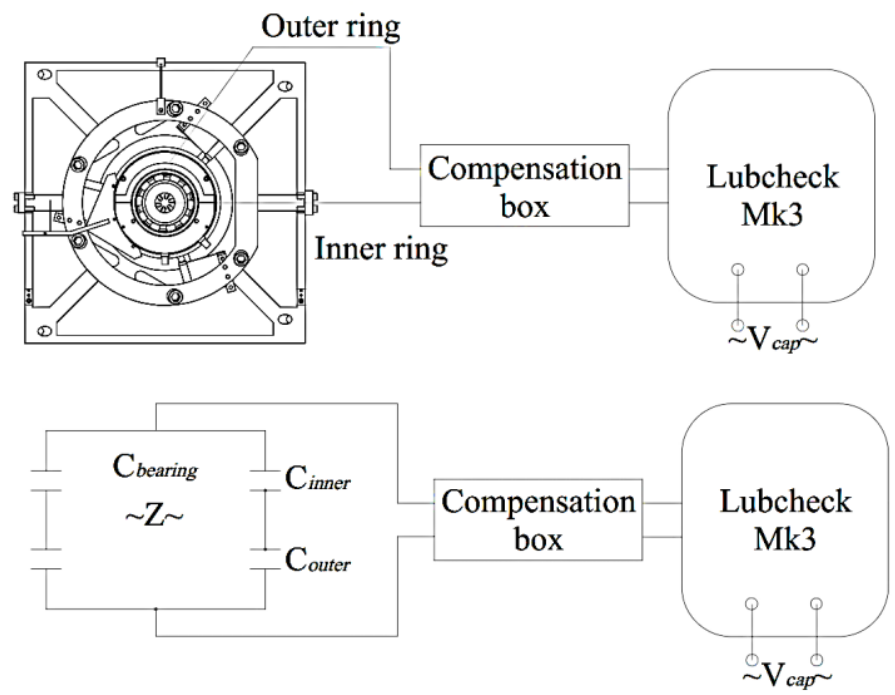

Figure 4 Film thickness measuring rig principle

\section{Film thickness for fresh greases}

\section{Overall film thickness profile}

The grease film thickness $h_{\text {grease }}$ results obtained from the 100 hours of continuous running tests are presented in Figure 5. Note that the bearing is starting up in approximately the first $5 \sim 10$ seconds $\left(2 \times 10^{-3}\right.$ hours). It is only after this time that the speed is constant. Figure 5 also shows the running temperature $T$ and the predicted fully flooded film thickness according to the Hamrock and Dowson equation (27), denoted by 'oil film thickness' $h_{\text {oil }}$ :

$$
\frac{h_{o i l}}{R_{y}}=2.69 \times 10^{9} \bar{U}^{0.67} \bar{G}^{0.53} \bar{W}^{-0.067}\left(1-0.61 e^{-0.75\left(\frac{R_{x}}{R_{y}}\right)^{0.64}}\right) \text {, }
$$

with

$$
\bar{U}=\frac{\bar{u} \cdot \eta}{E^{\prime} \cdot R_{y}}, \bar{G}=\alpha \cdot E^{\prime}, \bar{W}=\frac{W}{E^{\prime} \cdot R_{y}{ }^{2}} .
$$


Here $h_{\text {oil }}$ is the calculated EHL film thickness;

$\bar{u}$ is the mean entrainment speed calculated from the bearing kinematics assuming pure rolling (36);

$\eta$ is the temperature dependent bled oil viscosity calculated using the Walther equation (37);

$\alpha$ is the bled oil pressure-viscosity coefficient;

$E^{\prime}$ is the reduced Young's Modulus of the contact material;

$R_{x}, R_{y}$ are the reduced radii of the contact;

$W$ is the load for each rolling element.

The viscosity in this equation is calculated using the bled oil viscosity at the measured bearing temperature. The speeds and loads are constant. Hence, a variation in $h_{\text {oil }}$ is caused only by a variation in temperature. 


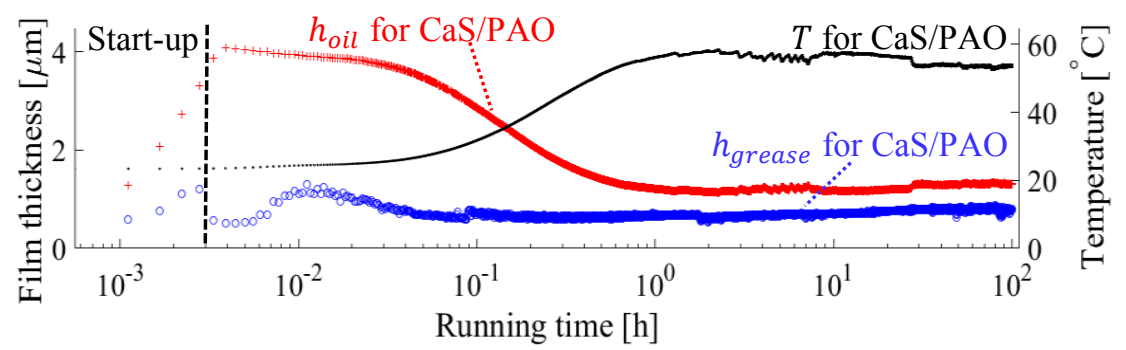

(a)

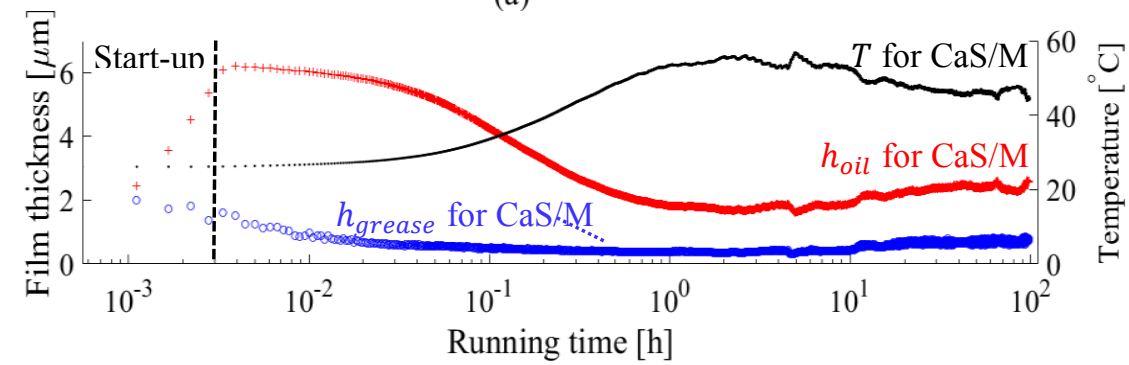

(b)

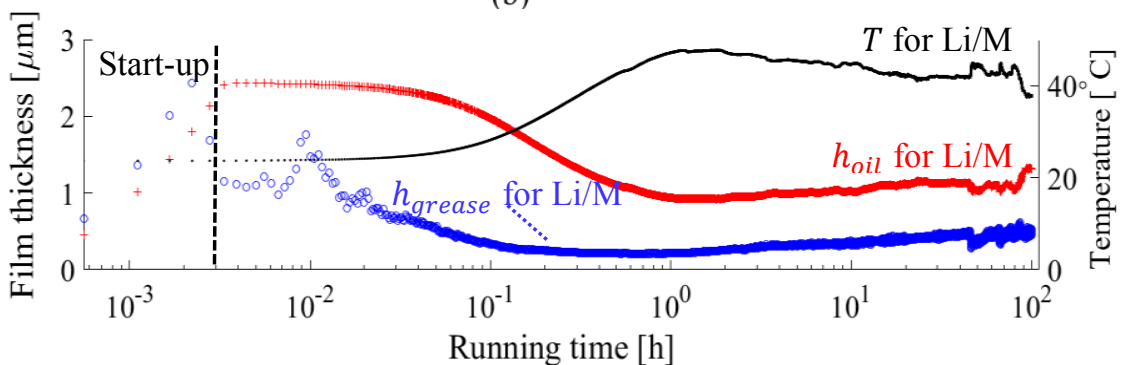

(c) 


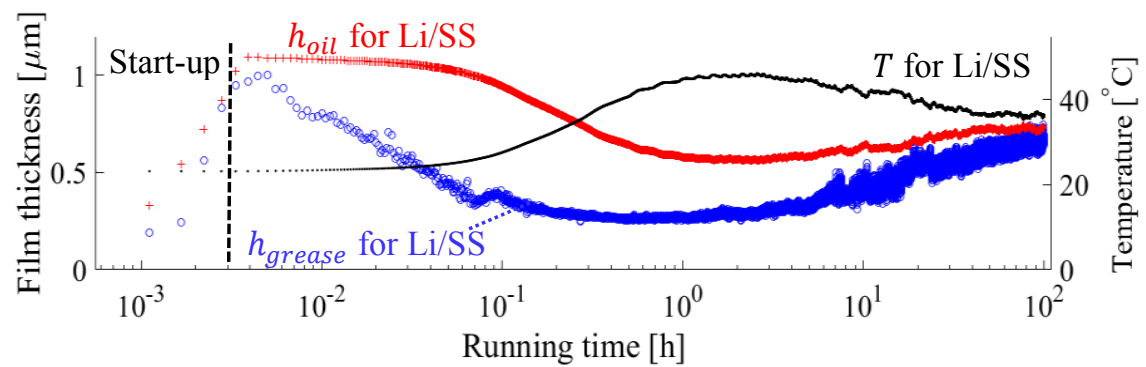

(d)

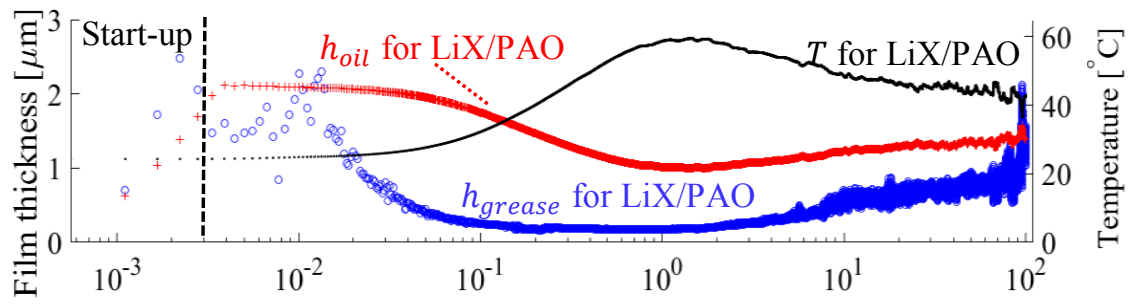

Running time [h]

(e)

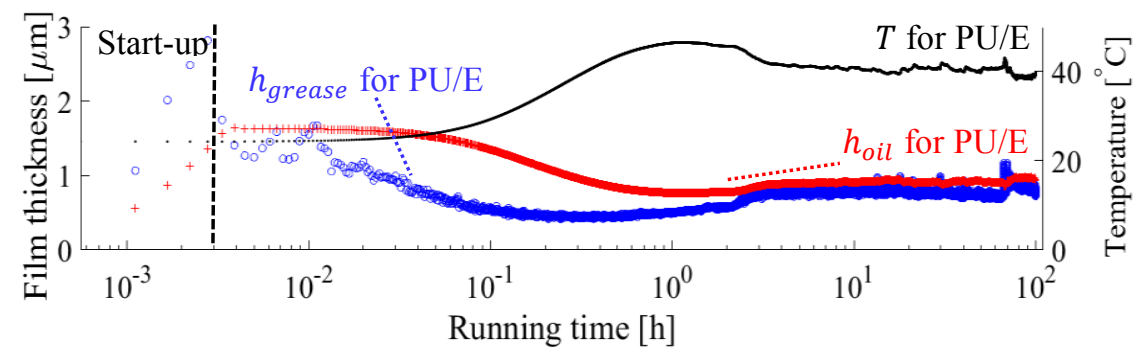

(f)

Figure 5 Film thickness profile of CaS/PAO (a); CaS/M (b); Li/M (c); Li/SS (d); LiX/PAO (e); PU/E (f)

After starting up, the large grease film thickness suggests the occurrence of fully flooded conditions. For a freshly greased bearing, after starting up there will be a lot of bulk grease in the inlet of the contacts, which will be fully flooded with grease and not only oil. The film thickness will be approximately equal to that generated by the bled oil (see also Cousseau et al. (38)).

The initial large grease film is followed by a sharp decrease. Wilson (13) attributed such a fast decrease to the rising temperature resulting in a lower viscosity. However, the grease film thickness decrease is more pronounced than the calculated temperature-dependent oil film thickness. This is ascribed to starvation: the subsequent decrease of the grease film thickness is a result of progressive grease channelling and migration due to side-flow (12). 
This will ultimately result in a reduced availability of lubricant at the inlet area leading to a decreasing film thickness.

Figure 5 shows three greases (Li/SS in Figure 5-d, LiX/PAO in Figure 5-e and PU/E in Figure 5-f) for which the film thickness is initially equal to the bled oil film thickness, after which it deviates from this, but ultimately approaches the bled oil film thickness again in the bleeding phase. For Li/SS this can be ascribed to high grease bleed (see Table 2). For $\mathrm{LiX} / \mathrm{PAO}$ this can be attributed to a micro-churning induced event as explained in the next section. For PU/E this can be ascribed to shear degradation in the churning phase $(1,13)$. This shear degradation will contribute to the mobility of the grease (39). It was shown in (28) that PU/E is an ageing sensitive grease (low shear stability). Despite its relatively low bleeding rate, a good film recovery can be observed after the churning phase (Figure 5-f). More details about the influence of ageing on PU/E film thickness will be presented later. The film thickness measurements with $\mathrm{CaS} / \mathrm{M}$ and $\mathrm{CaS} / \mathrm{PAO}$, however, show severe starvation (Figure 5-a and Figure 5-b), which can be ascribed to the combination of a low grease bleed and high shear stability. These observations are in line with the ball-on-disc measurements of Mérieux et al. (11) who also noted that grease with poor shear stability shows a film thickness recovery after an initial decay whilst shear stable grease shows continuous starvation without recovery.

To conclude, in the initial phase the film thickness may decrease sharply followed by recovery (a first 'event' in the film thickness). This is determined by the rates of starvation and lubricant feed, which again is determined by grease bleed and shear stability. When a 'feed and loss' balance is reached (9), the grease film thickness levels out at a more-or-less stable value. After the initial decay, no considerable grease film decreasing trend was observed during the 100 hours of running time. Obviously, this time may be long for a test but is extremely short in comparison with the expected long grease life at this relatively low running temperature, load and speed, e.g. $L_{10}=50000$ hours

\section{Film thickness events during the stable stage}

It is noteworthy that for LiX/PAO (Figure 5-e), PU/E (Figure 5-f) and Li/M (Figure 5-c), film thickness events are observed, coming back occasionally during the equilibrium stage. Such film thickness fluctuations were earlier observed by Lugt et al. in (26). They ascribed 
this dynamic behaviour to a decrease in film thickness due to starvation until metal-to-metal contact occurs causing heat development, softening of grease or increase in grease bleed resulting in replenishment and a thicker film again. However, this does not occur here. The film thickness perturbations take place in a situation where the film thickness is sufficiently thick to separate the two contacting surfaces: for LiX/PAO the equilibrium film thickness was $0.8 \mu \mathrm{m}$, for $\mathrm{PU} / \mathrm{E} 0.8 \mu \mathrm{m}$ and for $\mathrm{Li} / \mathrm{M} 0.44 \mu \mathrm{m}$. This is much greater than the roughness of the combined surfaces of the bearing which is about $R_{q}=0.07 \mu \mathrm{m}$.

One of the grease film events for LiX/PAO is plotted in Figure 6. Clearly, a similar film thickness increment took place as in the event immediately after starting up. An increase in film thickness just before the event seems to happen almost simultaneously with an increase in temperature. Similar event behaviour was observed for the PU/E and Li/M.

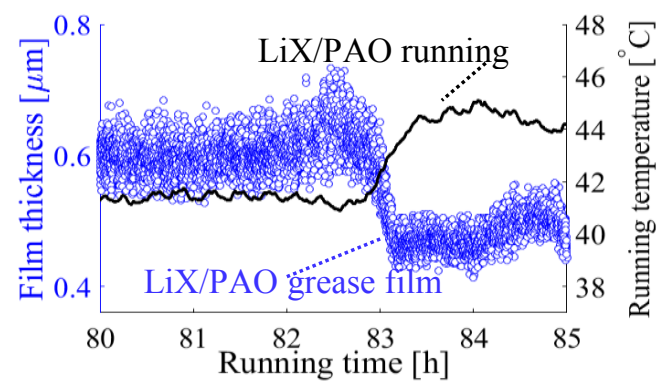

Figure $6 \mathrm{LiX} / \mathrm{PAO}$ film thickness event (zoom-in from Figure 5-e)

This phenomenon can be ascribed to churning. During running, a fraction of the grease from the reservoirs may incidentally fall back into the contact area because of creep flow, vibrations, centrifugal force and/or cage scraping $(13,14,26,40)$. The resulting (micro-) churning will lead to the generation of extra frictional heat (Figure 6). The introduction of bulk grease into the contact area will generate a thicker film, which subsequently drops rapidly due to an increase in temperature, followed by a slow recovery due to a temperature reduction, again caused by side flow and starvation. As shown in Figure 5-e, LiX/PAO was experiencing severe film thickness fluctuations at the end of the 100-hour running test. Once the test was finished, some remaining grease lumps were observed on the running track of the bearing, see Figure 7. This agrees with the (micro-) churning induced film thickness fluctuation mentioned above. 


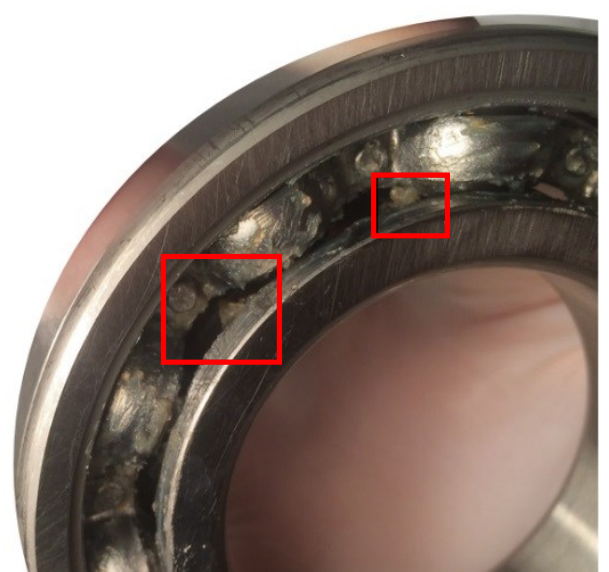

Figure 7 Grease lumps observed on the running track after 100 hours of running time for LiX/PAO

\section{Film thickness for mechanically aged grease}

In this section, film thickness results will be presented for both fresh and aged PU/E grease. As shown in Figure 2, mechanical degradation of this polyurea grease not only leads to softening but also results in an increase of grease bleeding. The change of grease properties will result in a change film build-up capability as shown in Figure 8. The film thickness results for PU/E at different ageing levels are summarized in Figure 9, where the grease film thickness $h$ (average measured film thickness after 5 to 10 hours of running time) and the degree of grease starvation $\frac{h_{\text {oil }}-h}{h_{\text {oil }}} \times 100 \%$ are plotted for fresh and aged PU/E versus oil bleed and yield stress.

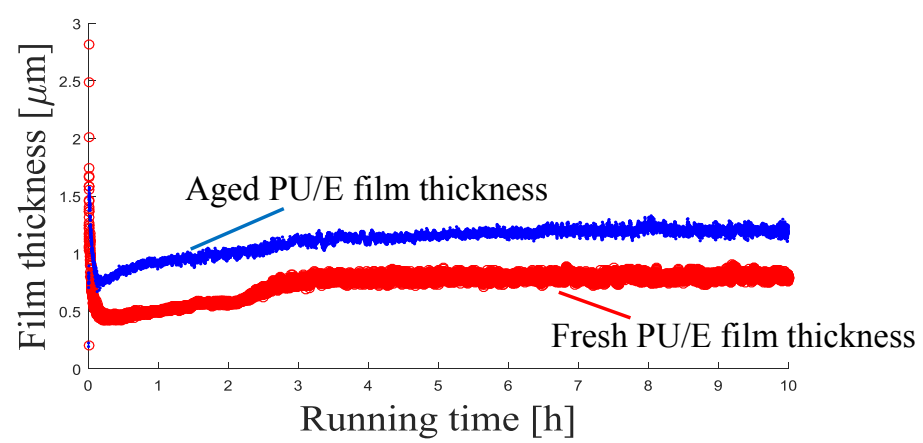

Figure 8 Film thickness profiles for fresh and aged PU/E 


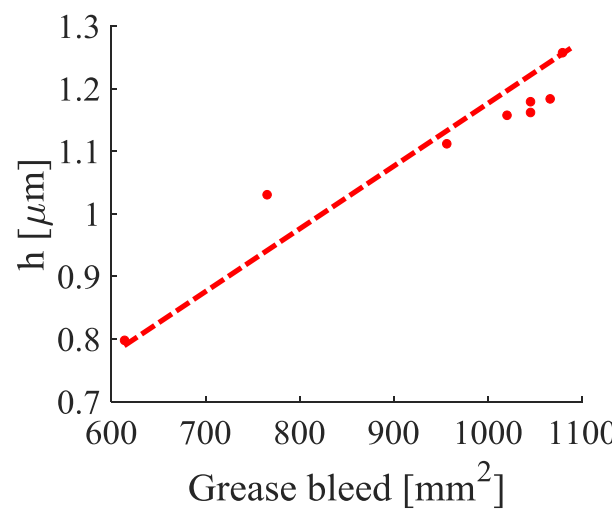

(a)

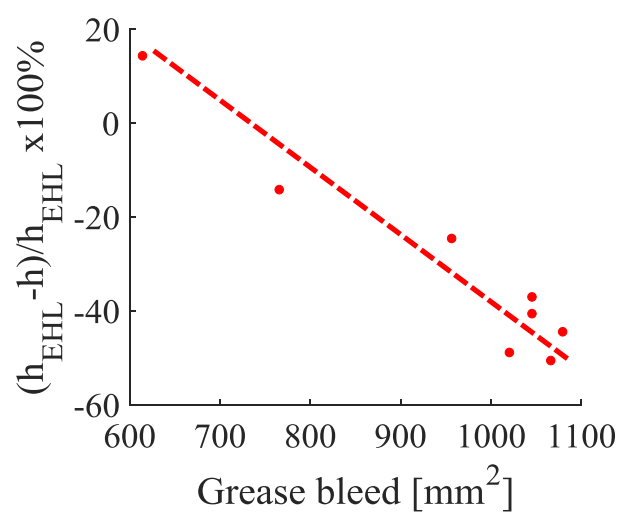

(c)

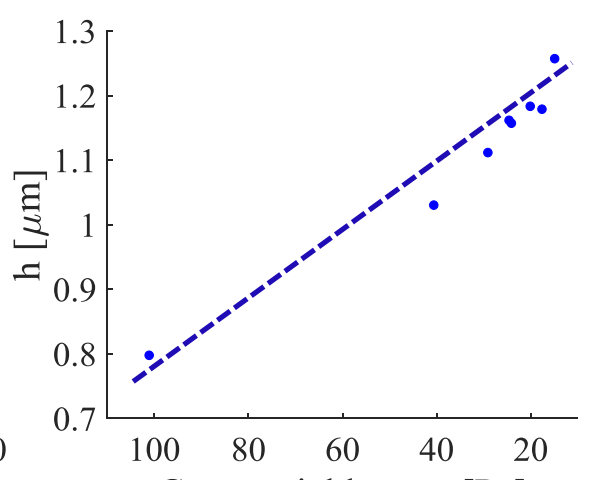

Grease yield stress $[\mathrm{Pa}]$

(b)

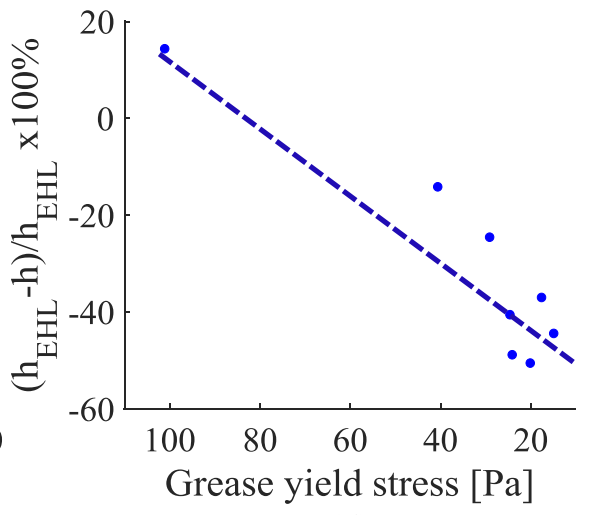

(d)

Figure 9 Film thickness results for fresh and aged PU/E vs grease bleed (a, c) and yield stress $(b, d)$ after 5 hours of running time.

The results show that the grease film thickness increases with increased ageing (so with increasing grease bleeding and decreasing yield stress). In addition, all of the aged PU/E samples generate thicker films compared to the predicted oil film thickness $\left(\frac{h_{\text {oil }}-h}{h_{\text {oil }}}<0\right)$. As the grease ageing continues, the progressively destroyed thickener network is no longer capable to hold oil, which increases the availability of free oil for replenishment (higher oil bleed) and thereby reduces starvation, see Figure 9-a and Figure 9-c. In addition, the resulting grease softening will again promote grease migration inside the bearing: it will be easier for the aged grease (with lower yield stress) to replenish the bearing raceway (41), see Figure 9-b and Figure 9-d. Ultimately, in the case of severe degradation, the original thickener material will be sheared into small fragments (a later paper will cover the change 
of PU/E micro-structure in more detail). The grease has softened so much that the reservoirs are no longer stable and the thickener particles will enter the inlet of the contacts. According to the empirical model presented by Cyriac et al. (31), an increase of $40 \%$ film thickness would be caused by a reduction of the thickener length by a factor of 4 . This agrees with the change of grease thickener micro-structure observed during the ageing process (33). Therefore, grease shear degradation contributes in three ways to a reduction of starvation: higher grease bleeding, more migration and the formation of smaller thickener particles which enter the contact area easier.

\section{Leakage study}

It is well known that the film thickness decreases over time (1). This decrease ultimately leads to the end of grease life. The film thickness measurements of the aged grease, however, suggest that with increased ageing, the film would only become thicker, which contradicts field observations. It is expected that starvation will ultimately occur again, because of leakage, oxidation, polymerization or evaporation. Since the temperatures are low in the current study, leakage is the most probable cause. During the aged-PU/E film thickness measurements, leakage was indeed observed by the grease accumulation around the gap between the shield and the inner ring.

According to Hiraoka (42), grease leakage is caused by three factors: centrifugal force, grease flow due to shear softening or high temperature, and the pushing-out force generated by the rolling motion. Immediately after starting up, the centrifugal force will overcome the grease yield stress and the adhesive force, throwing the grease to the bearing periphery. Once the grease reaches the outer ring edge, for a shielded bearing it can be expected that the accumulated grease at the outer ring inner diameter will push the grease towards the inner ring over the shield surface, see the grease track in Figure 10-a. The grease will then flow/leak though the non-contacting shield, an effect that may be enhanced by the elastic properties of the grease (43) (Figure 10-b). Grease leakage versus yield stress is presented in Figure 10-c. This graph shows that softening due to ageing facilitates the grease flow inside the bearing and results in higher leakage. This will again result in a reduction of the grease reservoir inside the bearing, thus reducing the lubricant feed to the contacts, and will ultimately lead to starvation and a decrease of the grease film thickness. 


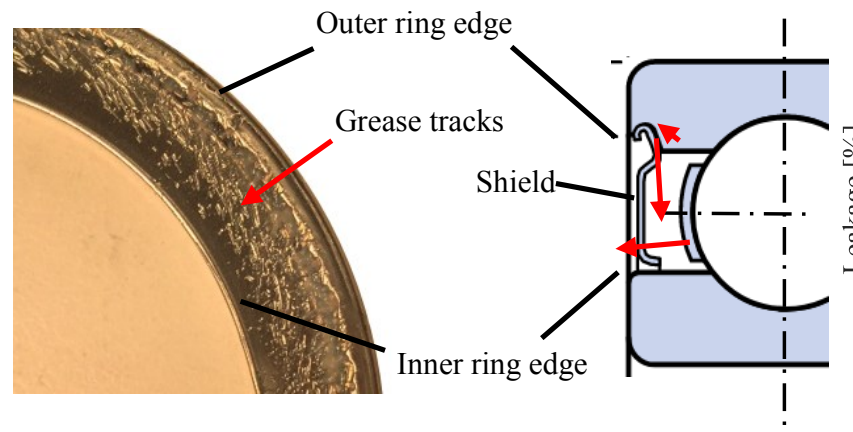

(a)

(b)

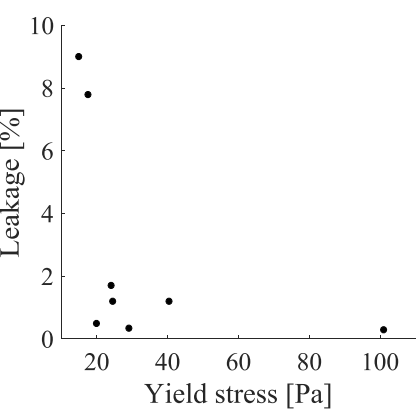

(c)

Figure 10 Bearing leakage study: (a) grease track on the shield inner surface, (b) schematic drawing of the grease flow inside a shielded bearing, (c) PU/E grease leakage vs shear degradation

To summarize, grease ageing will contribute to an increase in film thickness due to thickener breakdown leading to softening and increased grease bleed resulting in less or no starvation. In addition, it will lead to a reduced thickener fibre length which will cause an increased thickener particle entrainment in the contacts and further increase of the film thickness. However, this decay in grease consistency and increase of grease bleeding will also result in leakage and a drain of the grease reservoir, which will ultimately reduce the film thickness again. In the 100-hour running tests the initial $30 \%$ grease filling is sufficient to feed the contacts such that no film thickness decreasing trend was observed after the initial event. For future work, it is recommended to perform measurements with reduced filling of aged grease to verify the grease leakage effect on bearing film thickness.

\section{Discussion}

In this study, the measured grease film thickness inside an axially loaded deep groove ball bearing has been compared with the fully flooded ElastoHydrodynamicLubrication (EHL) film thickness of the bled oil at the self-induced running temperature.

All greases, except for the CaS greases initially show fully flooded films similar to the films that would be formed by bled oil. The severe starvation already in the start-up phase of the $\mathrm{CaS}$ greases is caused by the high yield stress in combination with very low grease bleed. The results show that the grease film thickness was quite constant for the $\mathrm{CaS}$ greases but not for the other greases; after starting-up, a fully flooded condition occurs, 
where grease is functioning as the lubricant. The grease channelling results in a rapid decrease of the film thickness, which decreases even further as the temperature increases. In the meantime, the grease reservoir starts bleeding oil. The grease shear degradation in the contacts and in the vicinity of the contacts in combination with an increased temperature will promote this grease bleed. Shear degradation will also lead to grease softening, which again facilitates replenishment. This results in an increase of the film thickness up to a relatively stable value, when the feed-and-loss mechanisms are in balance. After this, during the approximately stable stage, film thickness fluctuations are observed. This is attributed to an incidental release of bulk grease towards the contact areas due to vibrations, creep flow, centrifugal forces or cage scraping. Meanwhile, grease shear degradation will reduce the length of the grease fibres generating smaller particles, which are more easily entrained into the contacts than the long fibres ultimately leading to thick/thicker films. However, this softening of the grease will also result in leakage and a drain of the grease reservoir. It is expected that this will lead to thinner films after long running times (compared to the running times in the current study).

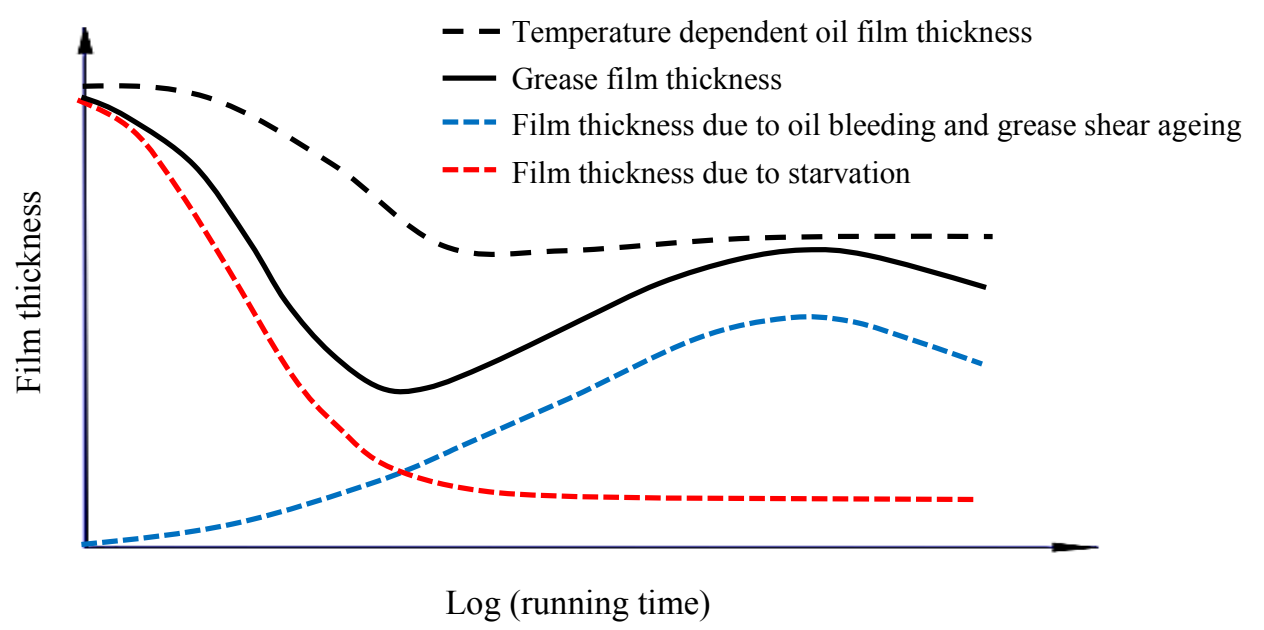

Figure 11 Grease film thickness variation inside a rolling bearing

Figure 11 shows schematically the film thickness evolution for greases with a fibrous microstructure, which were found to be ageing sensitive (28). The grease film thickness (black line) is the sum of the film thickness related to starvation (red dotted line) and the film thickness due to grease bleed and shear ageing (blue dotted line). Initially the film 
thickness is equal to that of the fully flooded oil film thickness, after which starvation occurs almost immediately. This would lead to a film collapse if the contacts were not to be fed by bled oil. A minimum film thickness occurs at the crossing point where the further decrease of film thickness is stopped by sufficient oil bleed. After this the film will grow until a balance of feed and loss of lubricant to the contact takes place. After much longer times the films will again decrease by leakage, oxidation, evaporation etc., where the dominating loss mechanism will be given by the operating conditions, for example at high temperatures this will be oxidation.

The CaS greases show a low grease bleed and high yield stress. They are very shear stable and will therefore maintain a low oil bleed and high yield stress throughout the test. The behaviour outlined in Figure 11 therefore does not apply to this grease type. This does not mean that these greases would not perform well in a rolling bearing. The calcite in these greases makes a viscous deposit of calcium carbonate (44), providing physically and chemically adsorbed layer (45) with very good boundary lubrication properties.

\section{Conclusions}

This study shows that the classic fully flooded EHL theory cannot be applied directly to the film thickness estimations of grease lubricated bearings. The lubrication mechanism is governed by starvation. This leads to very thin films but will be compensated by oil bleed and by the entrainment of thickener particles. Both effects are enhanced by shear degradation which will cause an increase of grease bleed and decrease of the thickener particle length. This will also lead to a reduction of the yield stress which will enhance the mobility of the grease. Shear degradation will also have negative effects for the performance of rolling bearings, which is, however, outside the scope of this paper.

The CaS greases show a different lubrication mechanism. For these greases thin hydrodynamic films were found, caused by a low oil bleed and the absence of shear degradation.

All film thickness measurements showed a dynamic behaviour. In addition to the first event after start-up, film thickness fluctuations were also found after longer times. This behaviour was reported earlier in cylindrical roller bearings running at relatively high speeds and was 
caused by film breakdown leading to (local) heat development (26). Under these relatively mild conditions these 'events' were likely to be caused by the release of grease lumps leading to (micro-) churning and heat development.

\section{Acknowledgement}

The authors would like to thank SKF Research and Technology Development for technical and financial support.

\section{References}

(1) Lugt PM. Grease Lubrication in Rolling Bearings. The Atrium, Southern Gate, Chichester, West Sussex, PO19 8SQ, United Kingdom: John Wiley and Sons; 2013.

(2) Åström H, Isaksson O, Höglund E. Video recordings of an EHD point contact lubricated with grease. Tribology International 1991;24(3):179-184.

(3) Cann P, Spikes H. Fourier-transform infrared study of the behavior of grease in lubricated contacts. Lubrication Engineering;(United States) 1992;48.

(4) Cann P, Spikes H. Film thickness measurements of lubricating greases under normally starved conditions. NLGI spokesman 1992;56(2):21-27.

(5) Dyson A, Wilson AR. Film thicknesses in elastohydrodynamic lubrication of rollers by greases. Proceedings of the Institution of Mechanical Engineers, Conference Proceedings: SAGE Publications Sage UK: London, England; 1969.

(6) Poon S. An experimental study of grease in elastohydrodynamic lubrication. Journal of Lubrication Technology 1972;94(1):27-34.

(7) Kageyama H, Machidori W, Moriuchi T. Grease lubrication in elastohydrodynamic contacts. NLGI Spokesman 1984;48(3):72-81.

(8) Wen SZ, Ying TN. A theoretical and experimental study of EHL lubricated with grease. Journal of tribology 1988;110(1):38-43.

(9) Wikström V, Jacobson B. Loss of lubricant from oil-lubricated near-starved spherical roller bearings. Proceedings of the Institution of Mechanical Engineers, Part J: Journal of Engineering Tribology 1997;211(1):51-66.

(10) Lugt PM. A Review on Grease Lubrication in Rolling Bearings. Tribology Transactions 2009;52(4):470-480.

(11) Mérieux J, Hurley S, Lubrecht A, Cann P. Shear-degradation of grease and base oil availability in starved EHL lubrication. Tribology Series 2000;38:581-588. 
(12) Ward P, Leveille A, Frantz P. Measuring the EHD film thickness in a rotating ball bearing. 39th Aerospace Mechanisms Symposium; 2008.

(13) Wilson A. The relative thickness of grease and oil films in rolling bearings. Proceedings of the Institution of Mechanical Engineers 1979;193(1):185-192.

(14) Cann P, Lubrecht A. An analysis of the mechanisms of grease lubrication in rolling element bearings. Lubrication Science 1999;11(3):227-245.

(15) Morales-Espejel G, Lugt PM, Pasaribu HR, Cen H. Film thickness in grease lubricated slow rotating rolling bearings. Tribology International 2014;74:7-19.

(16) Dong D, Komoriya T, Endo T, Kimura Y. Monitoring lubrication conditions with grease in ball bearings. International tribology conference; 2011.

(17) Cann P, Lubrecht A. The effect of transient loading on contact replenishment with lubricating greases. Tribology Series: Elsevier; 2003. p. 745-750.

(18) Baker A. Grease bleeding - a factor in ball bearing performance. NLGI spokesman 1958;22(9):271-277.

(19) Dalmaz G, Nantua R. An evaluation of grease behavior in rolling bearing contacts. Lubrication Engineering 1987;43(12):905-915.

(20) Ohno N, Tanimoto K, Kuwano N, Hirano F. Effect of the base oil viscosity of lithium soap greases on life of thrust ball bearings. Japanese journal of tribology 1998;43(12):15451556.

(21) Leenders P, Houpert L. Paper XXI(i) Study of the lubricant film in rolling bearings; effects of roughness. Tribology Series 1987 1987;11(Supplement C):629-638.

(22) Jablonka K, Glovnea R, Bongaerts J. Quantitative measurements of film thickness in a radially loaded deep-groove ball bearing. Tribology International 2018;119:239-249.

(23) Wittek E, Kriese M, Tischmacher H, Gattermann S, Ponick B, Poll G. Capacitances and lubricant film thicknesses of motor bearings under different operating conditions. Electrical Machines (ICEM), 2010 XIX International Conference on: IEEE; 2010.

(24) Gatzen M, Pape F, Bruening C, Gatzen H, Arlinghaus H, Poll G. Correlation between performance and boundary layers in high speed bearings lubricated with polymer-enhanced greases. Tribology International 2010;43(5):981-989.

(25) Franke E, Poll G. Service life and lubrication conditions of different grease types in high-speed rolling bearings. Tribology Series 1999;36:601-609.

(26) Lugt PM, Velickov S, Tripp JH. On the chaotic behavior of grease lubrication in rolling bearings. Tribology Transactions 2009;52(5):581-590. 
(27) Hamrock BJ, Dowson D. Elastohydrodynamic lubrication of elliptical contacts for materials of low elastic modulus. I: fully flooded conjunction. ASME Journal of Lubrication Technology 1978;100(2):236-245.

(28) Zhou Y, Bosman R, Lugt PM. A master curve for the shear degradation of lubricating greases with a fibrous structure. Accepted for publication Tribology Transactions 2018.

(29) Noordover A, David S, Fiddelaers F, Van Den Kommer A. Grease test kit and methods of testing grease 2016.

(30) Cyriac F, Lugt PM, Bosman R. On a new method to determine the yield stress in lubricating grease. Tribology Transactions s 2015;58(6):1021-1030.

(31) Cyriac F, Lugt PM, Bosman R, Padberg C, Venner C. Effect of thickener particle geometry and concentration on the grease EHL film thickness at medium speeds. Tribology Letters 2016;61(2):1-13.

(32) Van Leeuwen H. The determination of the pressure-viscosity coefficient of a lubricant through an accurate film thickness formula and accurate film thickness measurements. Proceedings of the Institution of Mechanical Engineers, Part J: Journal of Engineering Tribology 2009;223(8):1143-1163.

(33) Zhou Y, Bosman R, Lugt PM. A Model for shear degradation of lithium soap grease at ambient temperature. Tribology Transactions 2016 12/21:1-10.

(34) Lugt PM, Kommer A, Lindgren H, Deinhofer L. The ROF methodology for grease life testing. NLGI Spokesman 2013;77(1):18-27.

(35) Heemskerk R, Vermeiren K, Dolfsma H. Measurement of lubrication condition in rolling element bearings. ASLE Transactions 1982;25(4):519-527.

(36) Harris TA. Rolling bearing analysis. John Wiley and Sons; 2001.

(37) Walther C. The evaluation of viscosity data. Erdöl und Teer 1931;7:382-384.

(38) Cousseau T, Graça B, Campos A, Seabra J. Grease aging effects on film formation under fully-flooded and starved lubrication. Lubricants 2015;3(2):197-221.

(39) Cann P, Lubrecht A. Bearing performance limits with grease lubrication: the interaction of bearing design, operating conditions and grease properties. Journal of Physics D: Applied Physics 2007;40(18):5446.

(40) Cann P, Lubrecht A. Bearing performance limits with grease lubrication. World Tribology Congress III: American Society of Mechanical Engineers; 2005.

(41) Kaneta M, Ogata T, Takubo Y, Naka M. Effects of a thickener structure on grease elastohydrodynamic lubrication films. Proceedings of the Institution of Mechanical Engineers, Part J: Journal of Engineering Tribology. 2000;214:327-336. 
(42) Hiraoka N. On grease leakage from rolling bearings. Tribology International 2012;50:45-50.

(43) Baart P, Lugt PM, Prakash B. On the normal stress effect in grease-lubricated bearing seals. Tribology Transactions 2014;57(5):939-943.

(44) Giasson S, Espinat D, Palermo T. Study of microstructural transformation of overbased calcium sulphonates during friction. Lubrication Science 1993;5(2):91-111.

(45) Liu D, Zhao G, Wang X. Tribological performance of lubricating greases based on calcium carbonate polymorphs under the boundary lubrication condition. Tribology Letters 2012;47(2):183-194.

(46) Bader N, Furtmann A, Tischmacher H, Poll G. Capacitances and lubricant film thicknesses of grease and oil lubricated bearings. STLE Annual Meeting \& Exhibition; 2017.

\section{Appendix - Film thickness calibration}

In an axially loaded ball bearing, the films separating the balls from the rings are assumed to be long, thin and uniform. The rolling contacts can then be regarded as capacitor plates with the lubricant as the insulating medium. The thickness of the lubricant film is then equal to the distance between the capacitor plates. The film thickness can therefore be calculated using $(22,25)$ :

$$
h_{\text {bearing }}=\varepsilon_{0} \cdot \varepsilon_{r} \cdot \frac{A_{\text {Hertz }}}{C_{\text {bearing }}},
$$

where $\varepsilon_{0}$ is the lubricant dielectric constant in vacuum, $\varepsilon_{r}$ is the lubricant dielectric constant in the contact area, $A_{\text {Hertz }}$ is the total Hertzian contact area, $C_{\text {bearing }}$ is the bearing capacitance and $h_{\text {bearing }}$ is the average film thickness. It is complex to calculate the film thickness from this equation: firstly, the redundant capacitance at the inlet and outlet contact region will make it difficult to separate the capacitance at the Hertz contact area from the total bearing capacitance; secondly, the dielectric constants $\varepsilon_{0}$ and $\varepsilon_{r}$ for the tested lubricant are unknown. This was avoided by determining the grease film thickness directly by calibrating the Lubcheck signal $V_{\text {cap }}$ using the grease bled oils. It is assumed that, at these medium speeds, most of the lubricant inside the contacts consists of bled oil. In addition, it may be assumed that grease and bled oil under shear have similar dielectric constants (10\% difference as shown by Wilson (13)). Hence, an identical film thickness for both grease and its bled oil at the same running conditions will give a similar measured capacitance (Lubcheck signal). It was also assumed that the inlet and outlet of the contacts do not contribute significantly to the capacitance difference between the bled oil calibration and the grease film measurements. For the grease lubricated bearing this will play some role only in the case of severe starvation.

The bled oil was extracted from the tested grease sample using a centrifuge. The FTIR spectra comparison confirmed that there was no thickener material in the bled oil; in 
addition, the viscosity difference between the base oil and bled oil for these greases is negligible (31). The contact size and dielectric properties are pressure dependent (46). Therefore, the same load (axial force) was applied for the calibrating tests as for the grease film thickness measurements. The calibrating tests were performed using the same bearing but open (without shield) at $25^{\circ} \mathrm{C}$.

By doing a series of speed sweep calibrating tests under fully flooded conditions, the recorded Lubcheck signal $V_{c a p}$ was related to the calculated bled oil film thickness based on the Hamrock and Dowson equation. During calibration, oil was fed occasionally to the contact areas using a syringe and no significant Lubcheck signal fluctuations were observed. This confirmed that the calibrating tests were running in fully flooded conditions (13) and that the Hamrock and Dowson equation is applicable. For each bled oil, a calibration curve was made between the calculated film thickness and the Lubcheck signal $V_{c a p}$. 
Paper D 


\title{
On the shear stability of dry and water contaminated calcium sulphonate complex lubricating greases
}

\author{
Yuxin Zhou ${ }^{1}$, Rob Bosman ${ }^{1}$ and Piet M. Lugt ${ }^{1,2}$ \\ ${ }^{1}$ University of Twente, Enschede, the Netherlands \\ ${ }^{2}$ SKF Research and Technology Development, Nieuwegein, the Netherlands
}

\begin{abstract}
Calcium sulphonate complex greases have excellent extreme pressure, anti-wear and anticorrosion properties and are widely applied in rolling bearings, particularly in a humid environment. In this paper, the shear stability of dry and water contaminated lubricating calcium sulphonate complex greases will be described using a novel ageing method. Unlike lithium and polyurea greases, no shear softening is observed for the dry greases due to the good mechanical stability of the particle-like thickener structure. As for the water contaminated greases, no water separation was found during the pro-longed ageing. Instead, a homogeneous water/CaS thickener micellar structure is generated. These micelles function as 'apparent thickeners' and effectively increase the thickener concentration, which thickens the grease. This may explain why calcium sulphonate complex grease has excellent water absorption properties.
\end{abstract}

\section{Introduction}

Currently, calcium sulphonate complex grease is widely applied in high temperature, humid and heavy load operating conditions (1-3) and its use is growing. According to the $2014^{\text {th }}$ NLGI global annual grease production survey, the production of calcium sulphonate complex grease in 2014 increased almost twice compared to that in 2010 (4). It is manufactured by converting fluid overbased calcium sulphonate with amorphous calcium carbonate particles into calcium sulphonate grease where the calcium carbonate is mainly in the form of calcite, stabilized by calcium sulphonate $(4,5)$, forming a particle-like thickener structure (6-8). As shown in Figure 1, the thickener micelles/particles $(100-400 \mathrm{~nm}$ in diameter) are formed by aggregated calcite encapsulated by a shell of calcium sulphonate $(9,10)$. To reduce the thickener content, strengthen the stability of the aggregation and to improve the grease pumpability (5), 12-hydroxystearic acid is introduced as a complexing 
agent, forming calcium sulphonate complex grease (in this paper referred to as 'CaS grease') (4).

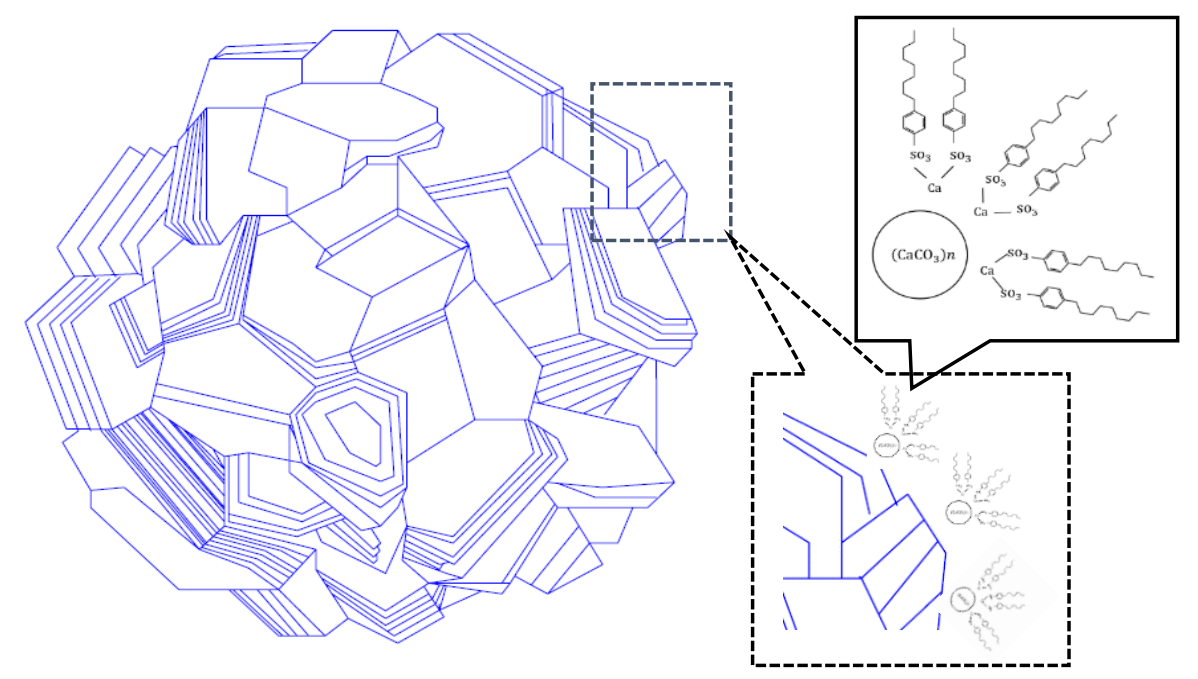

Figure 1 Micro-structure of the CaS grease thickener particle reproduced from $(2,11)$

Many lubricating greases show shear degradation caused by a disruption of the thickener network (12-15). This is reflected in the loss of consistency, possibly resulting in leakage, continuous churning, higher temperature, etc., leading to a reduction of the service life of rolling bearings (16). However, $\mathrm{CaS}$ grease has a particle-like thickener structure. According to the literature, shear decreases the particle size but does not change the overall structure $(2,17)$. In our previous work $(18,19)$, a Grease Ageing Master Curve was developed to describe the ageing behaviour of greases with a fibre-like structure (lithium and polyurea greases). The first objective of the present paper is to identify if this concept can be extended by including $\mathrm{CaS}$ grease. For this, the shear stability of $\mathrm{CaS}$ greases (so grease with a particle micro-structure) will be studied following the method described in (18).

$\mathrm{CaS}$ greases are often used in bearing applications where there is a risk of water ingress (20, 21) caused by poor sealing or a humid working environment. Water in grease may lead to (i) formation of free water, (ii) loss of grease consistency or (iii) no change in consistency (22, 23). It is very likely that shear will have an effect on this. In general, CaS greases have been 
found to have excellent water absorbing capabilities. Water will be completely emulsified into the grease, making the mixture milk-like $(24,25)$, see Figure 2.

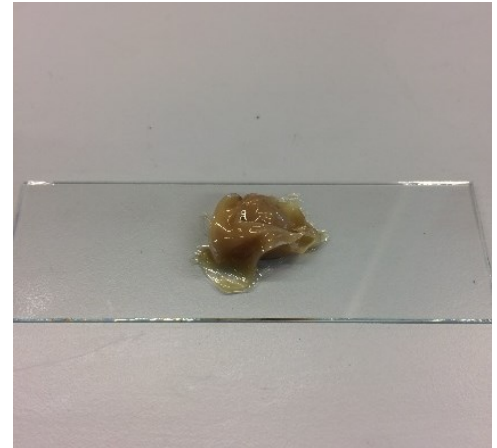

(a)

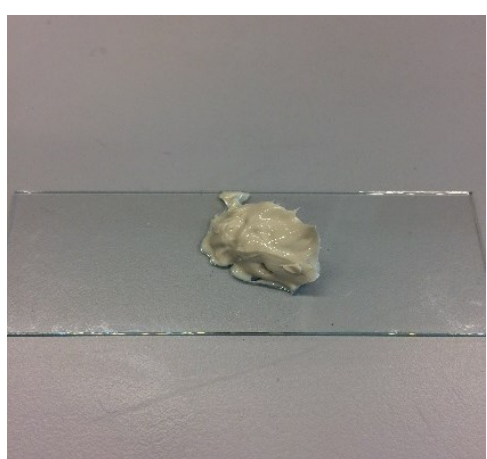

(b)

Figure 2 Appearance of $\mathrm{CaS}$ grease: (a) fresh; (b) mixed with $50 \%$ wt water in a grease worker for 500 strokes

Wet greases have different rheological properties and oil bleed, leading to a change of the grease film thickness (26), low temperature performances (27), tribological behaviour (28), etc. Under shear, free water may be released, leading to bearing damage such as corrosion (29), erosion (30), micro pitting (31), hydrogen embrittlement (32) and ice formation at low temperature (22). Authier (2) tested the CaS grease mechanical stability with $10 \%$ water using both the Roll Stability Test and a grease worker (100,000 strokes). The wet CaS grease maintains its original consistency after ageing. However, Leckner (21) found that with increasing water content, the $\mathrm{CaS}$ grease becomes thicker whilst the mechanical stability decreases. In addition to the above-mentioned goal to investigate if $\mathrm{CaS}$ greases follow the 'Ageing Master Curve', the shear ageing work on CaS will be extended in this paper by including the effect of water on the shear stability of $\mathrm{CaS}$, as suggested in (8). The underlying microstructural changes causing the macroscopic phenomena observed are investigated using Atomic Force Microscopy (AFM). This method was used earlier in understanding the microstructural change of water contaminated CaS grease (8). 


\section{Material and methods}

In this paper, two types of lubricating $\mathrm{CaS}$ greases were tested: one has a mineral oil as base oil, here denoted as $\mathrm{CaS} / \mathrm{M}$; the other one has a mixture of mineral and synthetic oil as base oil, denoted as CaS/MS, see Table 1.

Table 1 Properties of the tested greases

\begin{tabular}{|c|c|c|c|c|c|}
\hline Grease & Thickener & $\begin{array}{c}\text { Thickener } \\
\text { concentration } \\
(\%)\end{array}$ & Base oil & $\begin{array}{c}\text { Base oil viscosity } \\
\text { at } 40^{\circ} \mathrm{C} / 100^{\circ} \mathrm{C} \\
(\mathrm{cSt})\end{array}$ & $\begin{array}{c}\text { NLG } \\
\text { I }\end{array}$ \\
\hline $\mathrm{CaS} / \mathrm{M}$ & $\begin{array}{c}\text { Calcium } \\
\text { sulphonate } \\
\text { complex }\end{array}$ & 27 & Mineral oil & $420 / 26.5$ & 2 \\
\hline $\mathrm{CaS} / \mathrm{MS}$ & $\begin{array}{c}\text { Calcium } \\
\text { sulphonate } \\
\text { complex }\end{array}$ & 26 & Mineral/synthetic & $80 / 8.6$ & $1-2$ \\
\hline
\end{tabular}

To study the grease shear stability, shear ageing was performed using a house made Couette Ageing Machine. As shown in Figure 3, fresh greases were sheared between the rotating bob driven by a motor (connected to the bob by means of a magnetic coupling) and the stationary housing inside a thermal bath for different periods in time. During the ageing tests base oil evaporation, leakage and oxidation did not occur due to the air-tight environment created by the o-ring sealing and the closed ageing head. For details, the reader is referred to (18) 


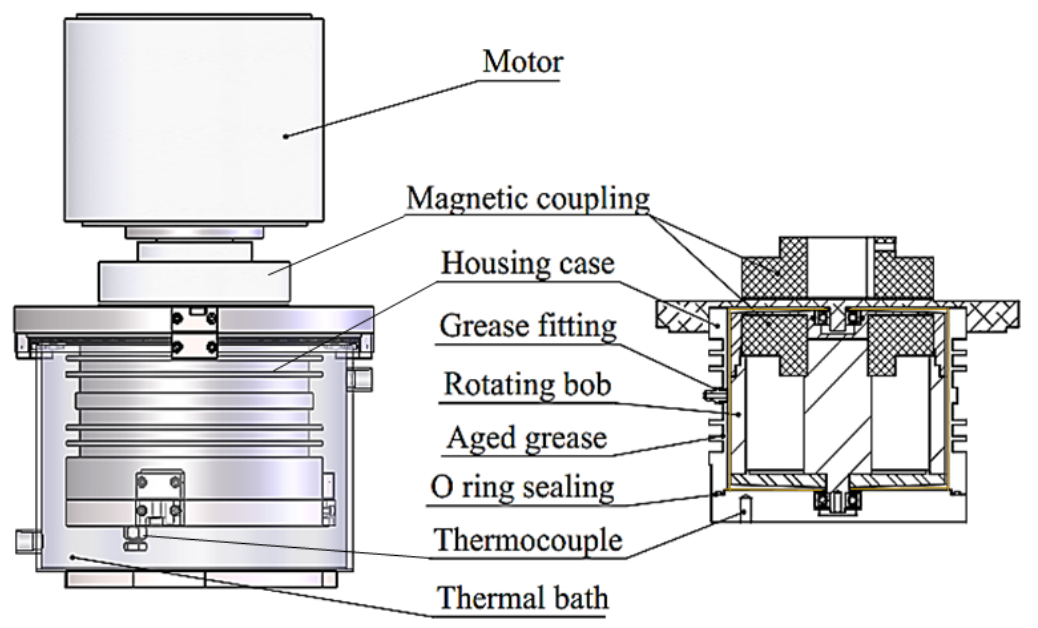

Figure 3 House made Couette Ageing Machine

The ageing temperature $T\left({ }^{\circ} \mathrm{C}\right)$, rotational speed $N(\mathrm{rpm})$ and torque $M(N \cdot \mathrm{m})$ were collected, from which the input work density $E$ is calculated as

$$
E=\frac{\int \frac{M \cdot N \cdot 2 \pi}{60} d t}{V}
$$

where $t$ is the ageing time in seconds and $V$ is the inserted grease volume in $\mathrm{mm}^{3}$.

It was shown in our earlier study on shear degradation of lithium based and polyurea based greases that the degradation rate was not only a function of shear but also of temperature. Actually, even without shear, degradation took place. Pure thermal degradation (in the absence of oxidation) was observed, reflected by a drop of the main rheological quantities such as the yield stress (18). To study only the effect of temperature on degradation of $\mathrm{CaS}$ grease, fresh greases were aged in a closed container inside an oven for 100 hours at different temperatures.

The working conditions for both combined shear/thermal ageing and pure thermal ageing are presented in Table 2. 
Table 2 Grease ageing conditions

\begin{tabular}{|c|c|c|c|c|c|}
\hline Sample & \multicolumn{3}{|c|}{ Couette ageing } & \multicolumn{2}{|l|}{ Thermal ageing } \\
\hline \multirow{3}{*}{$\mathrm{CaS} / \mathrm{M}$} & $120^{\circ} \mathrm{C}$ & $175 s^{-1}$ & $10 \mathrm{~h}, 42 \mathrm{~h}, 83 \mathrm{~h}, 167 \mathrm{~h}$ & \multirow{3}{*}{$120^{\circ} \mathrm{C}, 85^{\circ} \mathrm{C}, 50^{\circ} \mathrm{C}$} & \multirow{3}{*}{$100 \mathrm{~h}$} \\
\hline & $85^{\circ} \mathrm{C}$ & $175 s^{-1}$ & 10h, 31h, 62h, 125h & & \\
\hline & $50^{\circ} \mathrm{C}$ & $175 s^{-1}$ & $10 \mathrm{~h}, 25 \mathrm{~h}, 50 \mathrm{~h}, 100 \mathrm{~h}, 200 \mathrm{~h}$ & & \\
\hline \multirow{2}{*}{$\mathrm{CaS} / \mathrm{MS}$} & $120^{\circ} \mathrm{C}$ & $175 s^{-1}$ & $25 \mathrm{~h}, 100 \mathrm{~h}, 150 \mathrm{~h}$ & \multirow{2}{*}{$120^{\circ} \mathrm{C}, 50^{\circ} \mathrm{C}$} & \multirow{2}{*}{$100 \mathrm{~h}$} \\
\hline & $50^{\circ} \mathrm{C}$ & $175 s^{-1}$ & $50 \mathrm{~h}, 100 \mathrm{~h}, 150 \mathrm{~h}$ & & \\
\hline
\end{tabular}

To study the effect of water on ageing, water was added into fresh $\mathrm{CaS} / \mathrm{M}$ and $\mathrm{CaS} / \mathrm{MS}$ using a house made grease worker for 500 strokes at room temperature $\left(25^{\circ} \mathrm{C}\right)$, giving $10 \%$ wt and $50 \%$ wt water/grease mixture, defined as the ratio of the mass of water and the total mixture weight multiplied by $100 \% .10 \%$ wt was selected following the water stability test standard ASTM D7342 and 50\%wt was selected because this was found to be the water saturation level for the tested greases (33). To study the influence of water on the grease shear stability, pro-longed ageing was performed for 100,000 and 400,000 more strokes on the water/grease mixtures and on the dry greases. The input mechanical work per unit volume $E$ during the ageing cycles was calculated as a sum of the product of the grease worker dragging force $F_{g w}$ in $N$ (reduced with the friction force generated by the seal) and the piston displacement $L_{\text {piston }}$ in $m$ divided by the sample volume $V$ in $\mathrm{mm}^{3}$ (14):

$$
E=\frac{\sum F_{g w} \cdot L_{p i s t o n}}{V}
$$

The water/grease mixtures and the grease worker ageing conditions are presented in Table 3.

Table 3 Water mixture working conditions

\begin{tabular}{|c|c|c|}
\hline Sample & Water content & Number of working strokes \\
\hline $\mathrm{CaS} / \mathrm{M}$ & $0 \% \mathrm{wt} ; 10 \% \mathrm{wt} ; 50 \% \mathrm{wt}$ & $500 ; 100500 ; 400500$ \\
\hline $\mathrm{CaS} / \mathrm{MS}$ & $0 \% \mathrm{wt} ; 10 \% \mathrm{wt} ; 50 \% \mathrm{wt}$ & $500 ; 100500 ; 400500$ \\
\hline
\end{tabular}

The yield stress for the grease samples was measured using an MCR 501 Anton-Paar rheometer in plate-plate configuration at $25^{\circ} \mathrm{C}$, derived from oscillatory strain sweep D-6 
measurements at $25^{\circ} \mathrm{C}$. The measuring gap was $1 \mathrm{~mm}$ and pre-shear was applied prior to the rheological tests (the sample was sheared $100 s^{-1}$ for $60 \mathrm{~s}$ at $25^{\circ} \mathrm{C}$ following the DIN 51810-1 standard). The grease micro-structure was obtained from AFM measurements using an NX-10 PARK system in tapping mode. The force constant of the cantilever was $42 \mathrm{~N} / \mathrm{m}$ and the resonance frequency was $320 \mathrm{kHz}$. The detailed test procedure can be found in (19) for the yield stress measurements and in (8) for the AFM measurements. The absence of oxidation was confirmed using a Perkin Elmer Spectrum-100 Fourier Transform Infra-Red (FTIR) spectrometer.

\section{Results and discussion}

\section{Shear stability of CaS greases}

The change of the $\mathrm{CaS}$ grease yield stress during ageing in the Couette Ageing Machine is plotted as a function of the input work density $E$ in Figure 4 for different temperatures. Note that the ordinate is the yield stress measured at $25^{\circ} \mathrm{C}$. So this contains the values of the yield stress measured in a rheometer at $25^{\circ} \mathrm{C}$ after removing the grease from the Couette Ageing Machine. The samples were measured immediately after ageing to avoid thixotropic effects. As shown in Figure 4-a, CaS/M is mechanical stable (no change in yield stress) when aged at $50^{\circ} \mathrm{C}$. However, if this grease is shear-aged at elevated temperatures $\left(85^{\circ} \mathrm{C}\right.$ and $\left.120^{\circ} \mathrm{C}\right)$, it stiffens. Similar to $\mathrm{CaS} / \mathrm{M}, \mathrm{CaS} / \mathrm{MS}$ is very shear stable at $50^{\circ} \mathrm{C}$. However, where for $\mathrm{CaS} / \mathrm{M}$ the yield stress increases when ageing at higher temperatures, it slightly decreases with ageing energy for CaS/MS. The different ageing behaviour between $\mathrm{CaS} / \mathrm{M}$ and $\mathrm{CaS} / \mathrm{MS}$ is currently attributed to the different base oil and additive properties. 


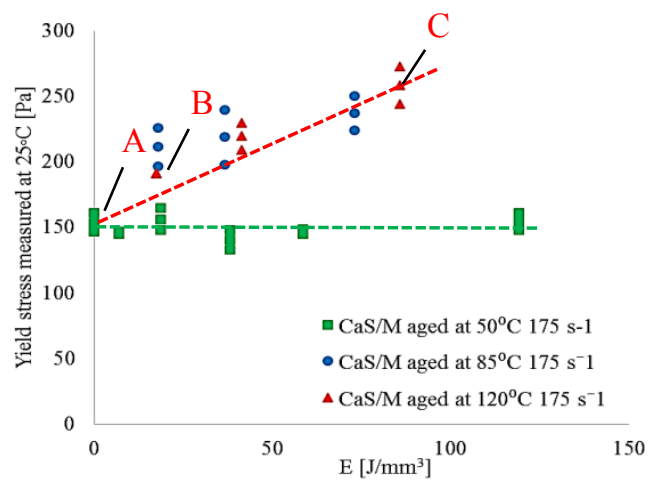

(a)

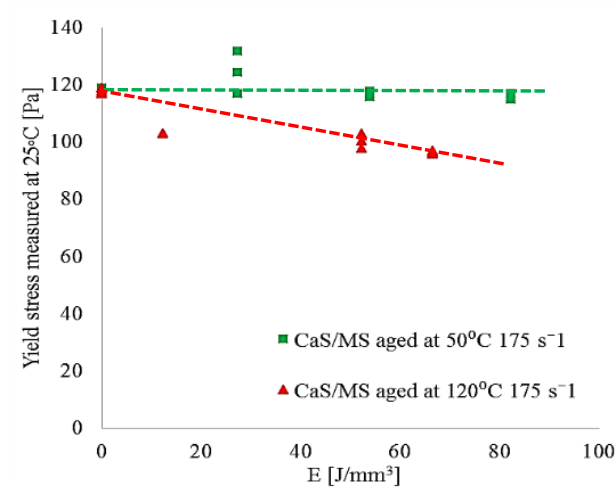

(b)

Figure 4 CaS grease Couette Ageing Test results: (a) CaS/M; (b) CaS/MS (the samples selected for AFM evaluation are labelled as A, B and C)

According to the pure thermal ageing test results shown in Figure 5, considering the measurement spread, the yield stress of $\mathrm{CaS}$ grease does not change much during the 100hour thermal ageing test. There is no significant difference between the micro-structure of fresh $\mathrm{CaS} / \mathrm{M}$ grease and that after the thermal ageing test, see Figure 6. Therefore, it is concluded that pure thermal heating does not change the CaS grease properties.

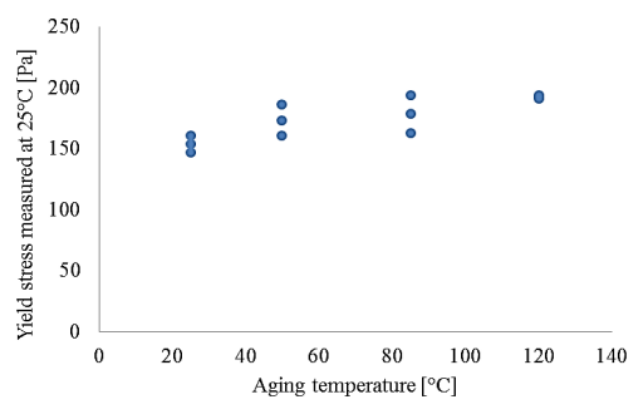

(a)

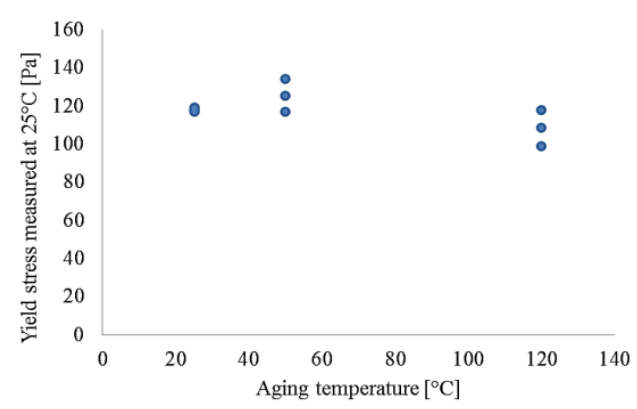

(b)

Figure 5 Grease thermal ageing results for (a)CaS/M (b)CaS/MS, with $25^{\circ} \mathrm{C}$ as the fresh grease 

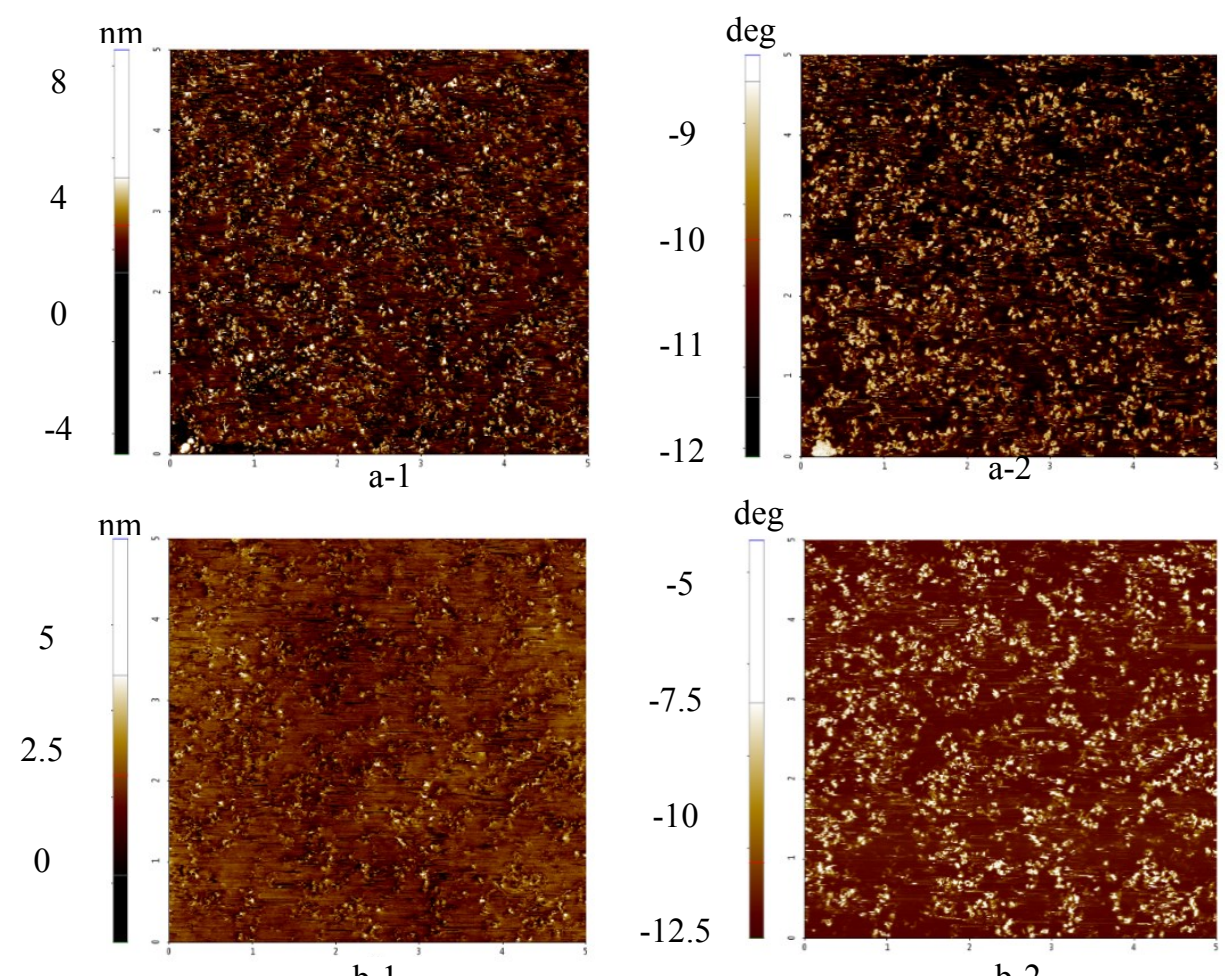

Figure 6 Micro-structure of (a) Fresh CaS/M, (b) CaS/M after $100 \mathrm{~h}$ heating at $120^{\circ} \mathrm{C}$; the left column is the height image and the right column is the phase image; image size: $5 \times$ $5 \mu m$

For greases with a fibre-like thickener structure, an Arrhenius factor obtained from the thermal ageing tests could be used to correct the input energy density $E$ and get a Master Curve (18), i.e., shifting curves obtained at different temperatures horizontally into a single curve. Since the yield stress of the $\mathrm{CaS}$ grease is not affected by thermal ageing, this Arrhenius factor correction is not valid for the current ageing results.

An explanation of the increasing yield stress shown in Figure 4-a could not be found. 'Thermal thickening' behaviour may be the result of the clustering of thickener particles caused by shearing at high temperature. However, according to the micro-structure of the stiffened CaS/M samples shown in Figure 7, no particle clustering can be observed, where the fresh and thickened $\mathrm{CaS} / \mathrm{M}$ have similar thickener geometry. Another possible explanation is that the elevated ageing temperature in the Couette Ageing Machine is close 
to the calcium sulphonate grease gelation temperature (approximately $90^{\circ} \mathrm{C}$ ). When the temperature exceeds $95^{\circ} \mathrm{C}$, a phase transformation of calcium carbonate may take place (7), which changes the mechanical properties of the $\mathrm{CaS}$ grease. However, according to the FTIR spectra for the thermal aged CaS/M samples (Figure 8), the calcite ( 713 and $\left.874 \mathrm{~cm}^{-1}\right)$ content remains stable and no extra vaterite $\left(745,859\right.$ and $\left.1070 \mathrm{~cm}^{-1}\right)$ is generated (5). Currently, the observed thermal stiffening of CaS/M cannot be explained. 

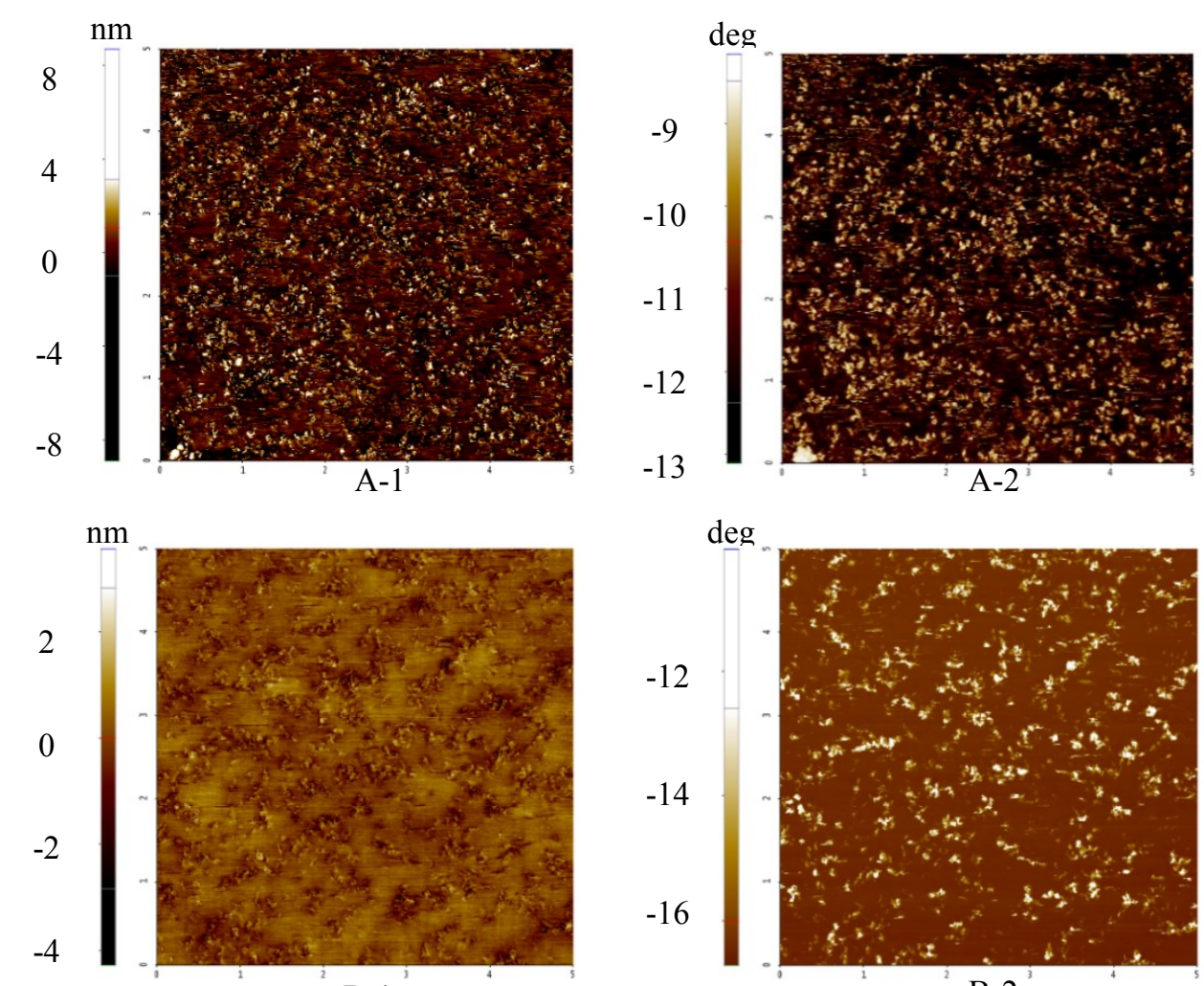

B-1
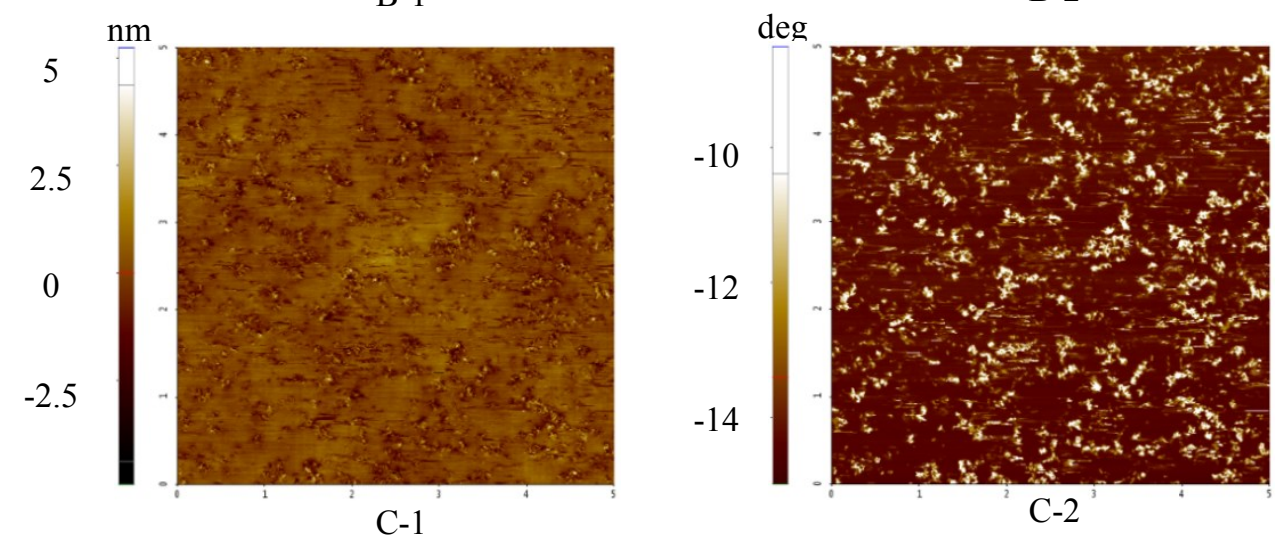

Figure 7 Micro-structure of the fresh and aged CaS/M samples selected from Figure 4-a: the left column is the height images and the right column is the phase images; image size: $5 \times 5 \mu m$ 


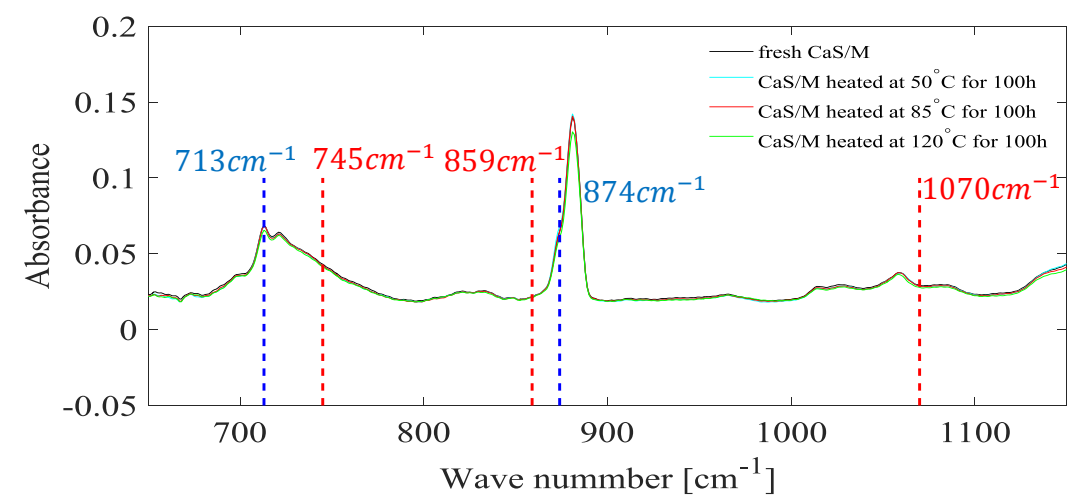

Figure 8 FTIR spectra of the fresh and thermal aged $\mathrm{CaS} / \mathrm{M}$ at different temperatures

\section{Shear stability of water contaminated CaS greases}

Cyriac et al. (33) showed that adding water to $\mathrm{CaS}$ grease increases the yield stress. However, they did not investigate if this would also happen after shearing the grease. It was shown in (18) that shear ageing in a grease worker resembles ageing in the Couette Ageing Machine and the change in yield stress would be similar if a similar 'input work density' $E$ is imposed to the grease. Since water was mixed into the grease using a grease worker, it was decided to also age the grease in this grease worker at ambient temperature $\left(25^{\circ} \mathrm{C}\right)$. The result is shown in Figure 9. Also plotted is the yield stress of the dry CaS greases which experienced the same ageing process as the wet grease. As expected (according to Figure 4, $50^{\circ} \mathrm{C}$ ), the yield stress for dry $\mathrm{CaS}$ greases remain stable during the ageing inside the grease worker. However, the yield stress for the wet CaS greases do change during ageing.

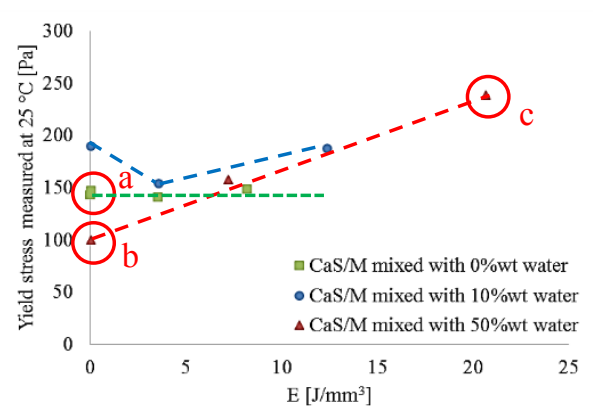

(a)

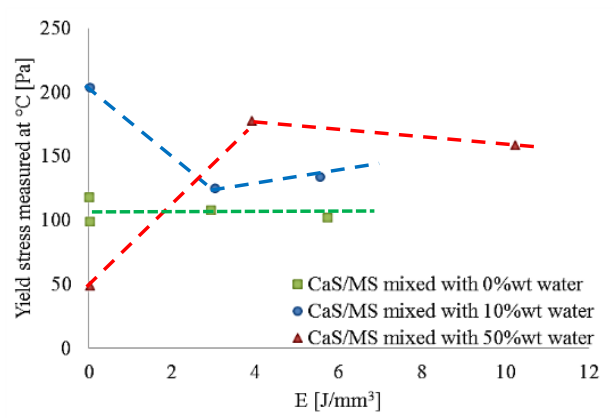

(b)

Figure 9 Grease worker ageing results for dry and wet CaS greases: (a) CaS/M; (b) CaS/MS (the samples selected for AFM evaluation are labelled as $\mathrm{a}, \mathrm{b}$ and $\mathrm{c}$ )

$$
\text { D-12 }
$$


At the starting point, i.e. 500 strokes $(E \approx 0)$, with $10 \%$ wt water, the yield stress is higher than in the absence of water for both $\mathrm{CaS} / \mathrm{M}$ and $\mathrm{CaS} / \mathrm{MS}$. This can be attributed to the generation of a limited amount of large water/CaS thickener micelles shown in Figure 10, where the water is trapped in the core surrounded by $\mathrm{CaS}$ thickener particles because the hydrophilic calcite aggregations in the CaS thickener will adhere to the water molecules and build a shell around the water droplet (8). These large micelles function as 'apparent thickeners', which increase the effective thickener content and strengthen the thickener matrix, resulting in a higher yield stress. However, when compared with the pure $\mathrm{CaS}$ thickener, these water/CaS thickener micelles have a reduced mechanical strength. With more applied shear, the large micellar structures are broken and the water effect is limited, resulting in smaller yield stress. After pro-longed ageing $\left(E>5.5 \mathrm{~J} / \mathrm{mm}^{3}\right)$, the released water is again distributed into smaller but more homogeneous water/CaS thickener micelles. In comparison with the CaS thickener particles, these small micelles are still larger and have higher capability to trap the base oil (34). This leads to a recovery of the yield stress.

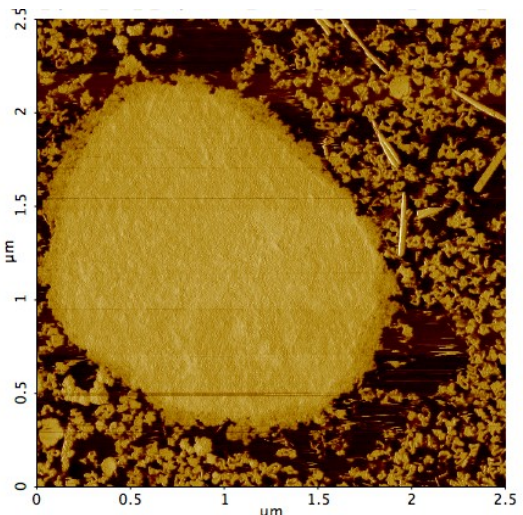

(a)

\section{$\mathrm{CaS}$ thickener particles}

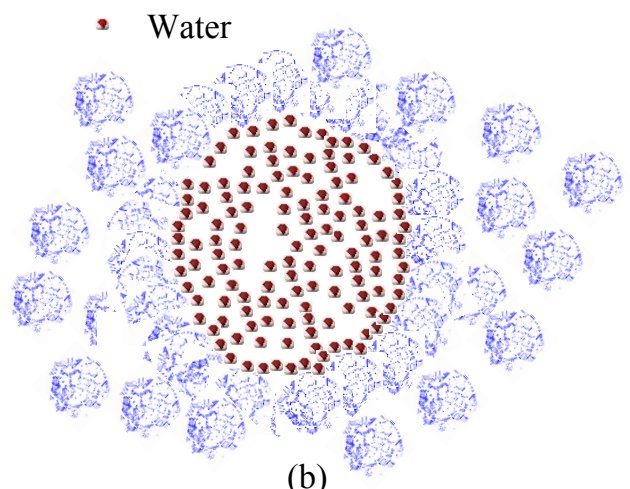

Figure 10 Micellar water/CaS thickener structure: (a) AFM phase image; (b) schematic drawing (base oil not shown)

However, for the CaS greases with $50 \%$ wt water, 500 strokes mixture $\left(E<0.03 \mathrm{~J} / \mathrm{mm}^{3}\right.$ shown in Figure 9) the yield stress is lower than in the absence of water. As suggested in (8), increasing water content not only results in more micelles but also in larger micelles. Although the micelles have a thin, hard shell formed by the CaS thickener, they consist mainly of low viscous water. Under shear, these large micelles are easy to deform and 
break. The larger they are, the weaker they are. During the rheological measurements, these weak micelles will result in shear banding/localization. During a rheological measurement using plate-plate configuration, the shear field is not uniform within the sample. At the high shear zone, the large fragile micelle filled with water will be broken, and this behaviour will dominate the mechanical response, effectively lowering the yield stress (35).

Similar to the $10 \%$ wt water/CaS grease mixture, with an increasing accumulated shear inside the grease worker, the large water/CaS thickener micelles shown in Figure 11-b are progressively broken. The water is released and distributed evenly into the smaller micelles during the pro-longed mixing. The stronger micellar structure shown in Figure 11-c thus results in a higher yield stress. For $\mathrm{CaS} / \mathrm{MS}$ a similar water/CaS thickener micellar structure was observed (not shown).

As shown in Figure 9, water contaminated CaS grease shows a dynamic ageing behaviour. But once the added water is completely emulsified into these small and homogeneous micelles, 50\%wt water/grease mixture will have a higher 'apparent thickener' fraction than the $10 \%$ wt water/grease mixture. As was shown in (36), a higher particle volume fraction in a colloidal gel will result in higher yield stress. This is confirmed in the current findings and the previous water/CaS grease mixing observations $(21,28,33)$. 


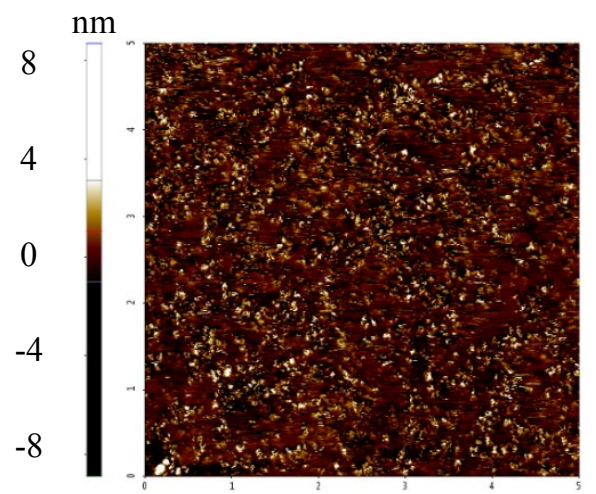

a-1
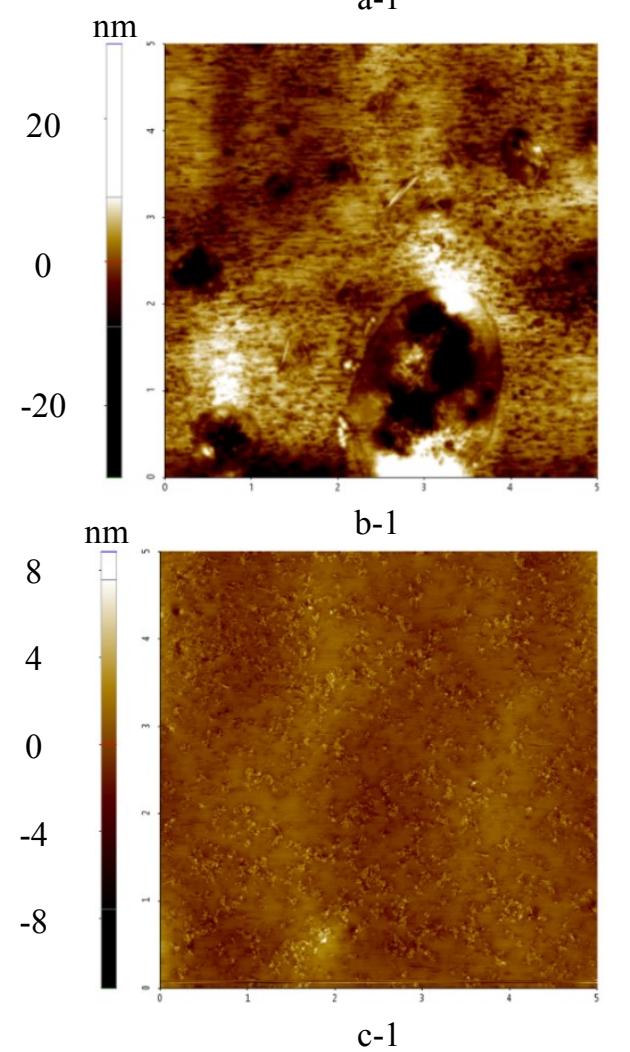
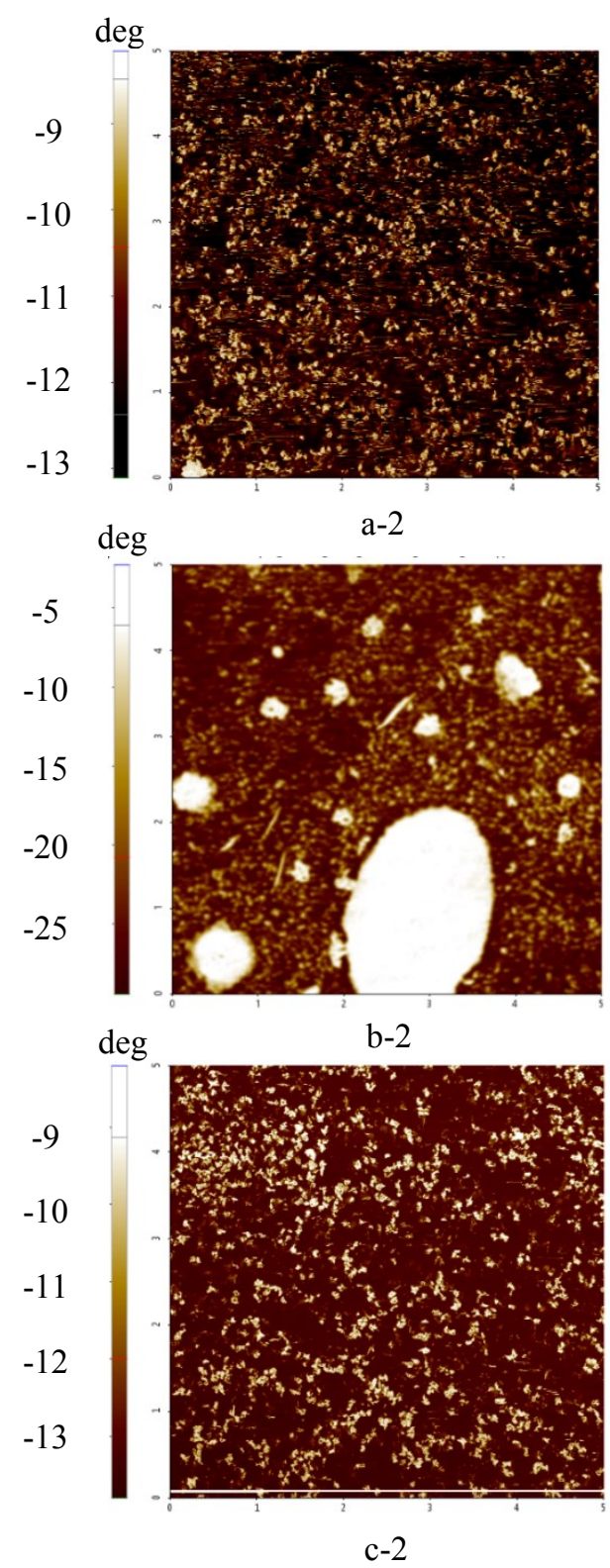

Figure 11 Micro-structure of (a) the fresh dry CaS/M grease; (b) 50\%wt water-grease mixture ( $E=0$ in Figure $9-\mathrm{a})$; (c) aged $50 \%$ wt water-grease mixture $\left(E=20.6 \mathrm{~J} / \mathrm{mm}^{3}\right.$ in Figure 9-a). The left column shows the height images and the right column shows the phase images; image size: $5 \times 5 \mu m$ 


\section{Conclusions}

In this work, the shear stability of dry and wet calcium sulphonate complex greases was studied using a housemade Couette Ageing Machine and grease worker. This type of grease has a particle-like thickener micro-structure, which is difficult to break down under shear. Unlike what was reported in $(2,17)$, no reduction of particle size was observed during shear ageing and the $\mathrm{CaS}$ greases remain unchanged at elevated temperature. Therefore, $\mathrm{CaS}$ greases do not show the ageing softening behaviour which was observed for the fibre-like structured greases, such as for lithium, lithium complex or the polyurea thickened greases, and the previous Ageing Master Curve concept is not applicable.

Water ingress in $\mathrm{CaS}$ grease forms large inverse micelles with a water core surrounded by $\mathrm{CaS}$ thickener particles. Although these big micelles are easy to break under shear, the released water does not stay as a separate phase but forms small and more homogeneous water/thickener micelles under continuous shear. This shows that CaS grease has an excellent water absorption capability and will prevent the formation of free water, which will protect the lubricated bearing from corrosion. In the meantime, this 'apparent thickener' increases the thickener volume fraction, which makes the water contaminated CaS grease stiffer.

\section{Acknowledgement}

The authors would like to thank SKF Research and Technology Development for technical and financial support and E.G. de Vries for his kind support in modifying the test rigs.

\section{References}

(1) Haiyan W. Manufacture and performance of Calcium sulphonate complex grease, in Chinese, Master thesis, Shandong University. 2007.

(2) Authier D, Herman A. Calcium sulphonate carbonate greases: a solution to water resistance. Eurogrease (3), S 2013:19-35.

(3) Liu D, Zhao G, Wang X. Tribological performance of lubricating greases based on calcium carbonate polymorphs under the boundary lubrication condition. Tribology Letters 2012;47(2):183-194.

(4) Mackwood W. Calcium sulphonate complex greases. Tribology \& lubrication technology Oct. 2016:28-40.

$$
\text { D-16 }
$$


(5) Kobylyanskii E, Kravchuk G, Makedonskii O, Ishchuk YL. Structure of ultrabasic sulphonate greases. Chem Technol Fuels Oils 2002;38(2):110-114.

(6) Ward B. Understanding Calcium Sulphonate Thickeners. 2006; Available at: http://www.machinerylubrication.com/Articles/Print/909. Accessed 11/6, 2014.

(7) Fish G. Calcium sulphonate greases. Performance and application overview. . Lubrisense white paper 2014;16.

(8) Bosman R, Lugt PM. The Microstructure of Calcium Sulphonate Complex Lubricating Grease and Its Change in the Presence of Water. Tribology Transactions 2018:1-8.

(9) Kumar A, Humphreys S, Mallory B. Overbased Calcium Sulphonate Greases For Extreme Environment. Greasetech India 2012;XIV(3):5-12.

(10) Papeykin O, Kobylyansky E, Zhelyezny L, Kravchenko O, Ishchuk Y. Resisting Corrosion. Lubes'n'Greases 2006;11:44-50.

(11) Giasson S, Espinat D, Palermo T. Study of microstructural transformation of overbased calcium sulphonates during friction. Lubrication Science 1993;5(2):91-111.

(12) Moore RJ, Cravath AM. Mechanical Breakdown of Soap- Base Greases. Industrial \& Engineering Chemistry 1951;43(12):2892-2897.

(13) Plint M, Alliston-Greiner A. A new grease viscometer: a study of the influence of shear on the properties of greases. NLGI spokesman 1992;56(2):7-15.

(14) Rezasoltani A, Khonsari MM. On the Correlation Between Mechanical Degradation of Lubricating Grease and Entropy. Tribology Letters 2014;56(2):197-204.

(15) Rezasoltani A, Khonsari M. An engineering model to estimate consistency reduction of lubricating grease subjected to mechanical degradation under shear. Tribology International 2016;103:465-474.

(16) Lugt PM. Grease Lubrication in Rolling Bearings. The Atrium, Southern Gate, Chichester, West Sussex, PO19 8SQ, United Kingdom: John Wiley and Sons; 2013.

(17) Jiang M, Guo X. Research Advancement of Overbased Calcium Sulphonate Complex Grease, in Chinese. Lubricating Oil 2013; 2:002.

(18) Zhou Y, Bosman R, Lugt PM. A master curve for the shear degradation of lubricating greases with a fibrous structure. Accepted for publication, Tribology Transactions 2018.

(19) Zhou Y, Bosman R, Lugt PM. A Model for shear degradation of lithium soap grease at ambient temperature. Tribology Transactions 2016 12/21:1-10.

(20) Dittes N, Marklund P, Pettersson A. Mixing grease with water. European Conference on Improvement in Bearing Technology: 23/02/2015-24/02/2015; 2015.

(21) Leckner, J., Water+Grease = fatal attraction? 25th ELGI Annual General Meeting Amsterdam, The Netherlands; 2013. 
(22) Mistry A. Performance of lubricating greases in the presence of water. NLGI Spokesman-Including NLGI Annual Meeting-National Lubricating Grease Institute: [Kansas City, Mo.] National Lubricating Grease Institute.; 2005.

(23) Dittes N, Pettersson A, Sjödahl M, Casselgren J, Lugt PM, Marklund P. Optical Attenuation Characterization of Water Contaminated Lubricating Grease. Tribology Transactions 2018 03/10:1-7.

(24) Duncanson M. Detecting and Controlling Water in Oil. 2005; Available at: https://www.machinerylubrication.com/Read/787/detecting-water-in-oil, 2018.

(25) Dietz TG. Minimizing water contamination extends equipment, lubricant life. Pulp and paper (USA) 1997.

(26) Cyriac F, Lugt PM, Bosman R, Venner CH. Impact of water on EHL film thickness of lubricating greases in rolling point contacts. Tribology letters 2016;61(3):23.

(27) Cyriac F, Lugt PM, Bosman R. Yield stress and low-temperature start-up torque of lubricating greases. Tribology letters 2016;63(1):6.

(28) Hudedagaddi CB, Raghav AG, Tortora AM, Veeregowda DH. Water molecules influence the lubricity of greases and fuel. Wear 2017;376:831-835.

(29) Eachus AC. The trouble with water. Tribology \& lubrication technology 2005;61(10):32.

(30) Braun M, Hannon W. Cavitation formation and modelling for fluid film bearings: a review. Proceedings of the Institution of Mechanical Engineers, Part J: Journal of Engineering Tribology 2010;224(9):839-863.

(31) Appleby M, Choy FK, Du L, Zhe J. Oil debris and viscosity monitoring using ultrasonic and capacitance/inductance measurements. Lubrication Science 2013;25(8):507524.

(32) Ray D, Vincent L, Coquillet B, Guirandenq P, Chene J, Aucouturier M. Hydrogen embrittlement of a stainless ball bearing steel. Wear 1980;65(1):103-111.

(33) Cyriac F, Lugt PM, Bosman R. Impact of water on the rheology of lubricating greases. Tribology Transactions 2016;59(4):679-689.

(34) Saatchi A, Shiller PJ, Eghtesadi SA, Liu T, Doll GL. A fundamental study of oil release mechanism in soap and non-soap thickened greases. Tribology International 2017;110:333-340.

(35) Divoux T, Fardin MA, Manneville S, Lerouge S. Shear banding of complex fluids. Annual Review of Fluid Mechanics 2016;48:81-103.

(36) Genovese DB. Shear rheology of hard- sphere, dispersed, and aggregated suspensions, and filler- matrix composites. Advances in colloid and interface science 2012;171-172:1-16. 


\section{List of Journal Publications}

- A model for shear degradation of lithium soap grease at ambient temperature (published 2016)

- A master curve for the shear degradation of lubricating greases with a fibrous structure (accepted 2018)

- An experimental study on film thickness in a rolling bearing for fresh and aged lubricating greases (submitted 2018)

- On the shear stability of dry and water contaminated calcium sulfonate complex lubricating greases (submitted 2018)

\section{Patent}

- Rolling bearing arrangement, device and method for determining a used and/or remaining period of a grease life-time, No. 102018201573.2 (in process)

\section{Conference Proceedings}

- A master-curve for the shear degradation of lubricating rolling bearing greases (STLE 2018)

- Grease film thickness in a ball bearing (STLE 2018) 